DANIEL DE ANDRADE LEMESZENSKI

TÉCNICA DE RECONSTRUÇÃO GEOMÉTRICA DA SUPERFÍCIE DO CORPO HUMANO BASEADA EM MÚLTIPLOS SENSORES DE PROFUNDIDADE PARA APLICAÇÃO EM TELECONFERÊNCIA IMERSIVA 
DANIEL DE ANDRADE LEMESZENSKI

\section{TÉCNICA DE RECONSTRUÇÃO GEOMÉTRICA DA SUPERFÍCIE DO CORPO HUMANO BASEADA EM MÚLTIPLOS SENSORES DE PROFUNDIDADE PARA APLICAÇÃO EM TELECONFERÊNCIA IMERSIVA}

Dissertação apresentada à Escola Politécnica da Universidade de São Paulo para obtenção do Título de Mestre em Ciências. 
DANIEL DE ANDRADE LEMESZENSKI

\section{TÉCNICA DE RECONSTRUÇÃO GEOMÉTRICA DA SUPERFÍCIE DO CORPO HUMANO BASEADA EM MÚLTIPLOS SENSORES DE PROFUNDIDADE PARA APLICAÇÃO EM TELECONFERÊNCIA IMERSIVA}

Dissertação apresentada à Escola Politécnica da Universidade de São Paulo para obtenção do Título de Mestre em Ciências.

Área de concentração:

Sistemas Digitais

Orientador:

Prof. Doutor Ricardo Nakamura 
Este exemplar foi revisado e corrigido em relação à versão original, sob responsabilidade única do autor e com a anuência de seu orientador.

São Paulo, de maio de 2013.

Assinatura do autor

Assinatura do orientador

FICHA CATALOGRÁFICA

Lemeszenski, Daniel de Andrade

Técnica de reconstrução geométrica da superfície do corpo humano baseada em múltiplos sensores de profundidade para aplicação em teleconferência imersiva / D.A. Lemeszenski. -versão corr. -- São Paulo, 2013.

$83 \mathrm{p}$.

Dissertação (Mestrado) - Escola Politécnica da Universidade de São Paulo. Departamento de Engenharia de Computação e Sistemas Digitais.

1.Reconstrução (Geometria e modelagem computacional) 2.Vídeo-avatar 3.Sensores ópticos 4.Técnicas de registro I. Universidade de São Paulo. Escola Politécnica. Departamento de Engenharia de Computação e Sistemas Digitais II.t. 
Dedico esse trabalho a minha esposa, aos meus pais e irmãos que sempre estiveram ao meu lado torcendo por min. 


\section{AGRADECIMENTOS}

Agradeço ao professor Ricardo Nakamura por ter me apresentado ao mundo acadêmico e ter me orientado durante esses anos com muita seriedade e profissionalismo.

Ao professor Romero Tori e a professora Fátima Nunes, pelas aulas dadas e demais oportunidades de aprendizado.

A todos meus colegas do Interlab, especialmente Daniel Makoto Tokunaga, Silvio Ricardo Rodrigues Sanches, Fernando Yoiti Obana, Cleber Gimenez Correa, Mayra Onishi e Mariza Ushijima Leone sempre prestativos colaboraram com este trabalho. 


\section{RESUMO}

O interesse no uso de técnicas de aquisição de dados 3D em vídeos interativos e sistemas de videoconferência imersiva aumentou significativamente nos últimos anos. A disponibilidade de sensores de profundidade baseados em luz estruturada no varejo apresenta uma série de novas oportunidades em sistemas de teleconferência, entretenimento e e-learning. No entanto, problemas de oclusão frequentemente ocorrem quando é utilizado um único sensor ou técnicas de reconstrução 2,5D. Outras técnicas de interação e aplicações de teleconferências podem exigir uma reconstrução mais completa do usuário. Uma possível solução para isso implica na utilização de múltiplos dispositivos simultaneamente, o que traz novos desafios relacionados ao processo de calibração de câmaras e a aferição do aumento da superfície capturada quando é adicionado um novo sensor. Neste trabalho é apresentada a proposta VMD (Video-avatar from Multiple Depth maps), uma arquitetura de sistema que trata essas questões supramencionadas. Com a finalidade de validar a viabilidade dessa proposta, três experimentos foram feitos resultando em uma análise qualitativa e quantitativa a fim de encontrar uma configuração adequada de múltiplos sensores de profundidade.

Palavras-Chave: Reconstrução (Geometria e modelagem computacional), Vídeo-avatar, Sensores ópticos, Técnicas de registro. 


\begin{abstract}
The interest in the use of 3D data acquisition techniques in video based interaction and immersive videoconferencing systems has noticeably increased in recent years. The availability of structured light 3D sensors as off-the-shelf hardware presents a series of new opportunities in teleconferences, entertainment and e-learning. However, occlusion issues often occur when it is used a single sensor or 2,5D reconstruction techniques. Other interaction techniques and teleconferencing applications may require a more complete reconstruction of the user. One possible solution to this involves the use of multiple devices simultaneously, which may bring new challenges related to the calibration process of cameras and measurement of the increase in covered area when it is added a new sensor.

In this work we present VMD (Video-avatar from Multiple Depth maps), a system architecture that addresses this two issues. In order to validate the feasibility of this proposal, three experiments were performed resulting in a qualitative and quantitative analysis with the purpose of finding a suitable setup with multiple depth sensors.

Keywords: Resconstruction (geometry and computational modeling), Video-avatar, Optical sensors, Registration techniques.
\end{abstract}




\section{LISTA DE FIGURAS}

2.1 Renderização de uma nuvem de pontos sem mesh em (a). Imagem ampliada em (b) . . . . . . . . . . . . . . . . . . . . . . . . 25

2.2 Frestas evidenciadas por um ponto de vista lateral . . . . . . . . . . . . 26

2.3 Conjunto de padrões de triângulos da técnica cubos marchantes (LORENSEN;

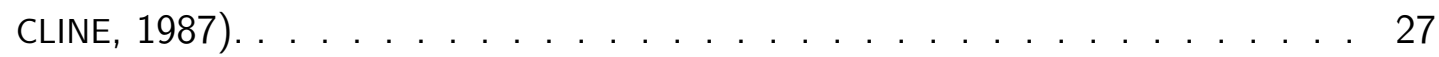

2.4 Malha de triângulos gerada pelo algoritmo de cubos marchantes. . . . . . . . 27

2.5 Etapas da reconstrução de Poisson em 2D(KAZHDAN; BOLITHO; HOPPE, 2006). 28

2.6 Orientação do sistema de coordenadas da nuvem de pontos gerada pelo Kinect. 29

2.7 Arranjo de equipamentos na técnica de luz estruturada convencional. . . . . . 29

2.8 Padrão projetado pelo LED do Kinect capturado por uma câmera IR. . . . . . 31

2.9 Exemplo de layout de arquivo do formato PCD . . . . . . . . . . . . . 32

3.1 Subsistemas da arquitetura do sistema AVMIX . . . . . . . . . . . . . . . . . 34

3.2 Infraestrutura de hardware do Coliseum (BAKER et al., 2005) . . . . . . . 36

3.3 Calibração manual com objeto de marcação da imagen obtida pela câmera RGB e pelo sensor de profundidade do Kinect (KREYLOS, 2011) . . . . . . . . . . . 38

3.4 Técnica com suporte rotativo $($ IIN; SUBBARAO, 2001) . . . . . . . . . . . . 39

4.1 Diagrama de componentes da arquitetura VMD . . . . . . . . . . . . 43

4.2 Nuvem de Pontos gerada pelo sensor sem tratamento do sistema de coordenadas $x y \ldots \ldots \ldots \ldots \ldots$. . . . . . . . . . . . . . . . . . . . . . . . . . . . . . . . . . . . 44

4.3 Nuvem de pontos projetada. . . . . . . . . . . . . . . . . . 45

4.4 Mapa de profundidade e imagem RGB correspondente ligeiramente desalinhados. 46

4.5 Textura RGB projetada na nuvem de pontos. . . . . . . . . . . . . . . . . 47

4.6 Segmentação nativa do SDK do Kinect. . . . . . . . . . . . . . . . . . . . . . 47 
4.7 Diagrama de sequência da variante do algoritmo de registro utilizado nesse trabalho.

4.8 Imagem da esquerda nuvem (a) obtida pelo Kinect 1, imagem central nuvem (b) obtida pelo Kinect 2 a $120 \mathrm{~cm}$ e imagem da direita nuvem (c) resultado da fusão das nuvens $(\mathrm{a})$ e $(\mathrm{b}) . \ldots \ldots$. . . . . . . . . . . . . . . . . 50

5.1 Arranjo de equipamentos com dois Kinects e um modelo. . . . . . . . . . . . 52

5.2 Diagrama representando a configuração de $90^{\circ}$ entre os dois Kinects. . . . . . . 53

5.3 Gráfico de barras com os valores de erro calculados. . . . . . . . . . . . . . 55

5.4 Imagens (a),(b),(c),(d),(f),(g),(h),(i),(j) e (k) correspondem aos mapas de profundidade capturados nos ângulos de $10^{\circ}, 15^{\circ}, 30^{\circ}, 45^{\circ}, 60^{\circ}, 75^{\circ}, 90^{\circ}, 120^{\circ}$, $150^{\circ}$ e $180^{\circ}$ respectivamente.

5.5 Padrão gerado pelo LED do Kinect capturado por uma câmera IR. A imagens (a) e (c) se referem às nuvens de pontos com apenas um Kinect ligado, (b) e (d) mostram o mesmo modelo com dois Kinects ativos posicionados a um ângulo de $30^{\circ}$. Imagens (c) e (d) são áreas aumentadas de (a) e (b) respectivamente. 56

6.1 Imagem capturada utilizando o sistema de 3D Vídeo de (KREYLOS, 2011). . . 58

6.2 Sensores posicionados com pontos de vista convergentes. . . . . . . . . . . . 60

6.3 Sensores posicionados com pontos de vista paralelos. . . . . . . . . . . . . . . . 60

6.4 A nuvem de cor verde foi capturada pelo primeiro sensor e a de cor vermelha pelo segundo. À esquerda são exibidas as duas nuvens desalinhadas antes do registro e à direita, as duas mesmas nuvens após o devido registro da segunda. 61

6.5 Nuvens de pontos com textura RGB completas sem aplicação de filtro. . . . . . 62

6.6 Nuvens de pontos completas da cena (sem remoção de fundo), à esquerda antes do registro por ICP e à direita com o registro indevido.

6.7 Gráfico com erro médio quadrático relacionado a execução do ICP para cada cenário que indica o nível de precisão do alinhamento entre nuvens.

6.8 Nuvens obtidas pelos dois sensores na posição paralela a uma distancia de $80 \mathrm{~cm}$. 66

6.9 Nuvens obtidas pelos dois sensores na posição convergente a uma distância de $80 \mathrm{~cm}$.

7.1 Setup experimento com base rotativa. 
7.2 Point Based Glueing. . . . . . . . . . . . . . . . . . . . . . . . . . . . . . 69

7.3 Visualização das dezessete nuvens de pontos desalinhadas capturadas no experimento. . . . . . . . . . . . . . . . . . . . 70

7.4 Modelo composto por 2 nuvens. . . . . . . . . . . . . . . . . . . . . 71

7.5 Modelo composto por 3 nuvens. . . . . . . . . . . . . . . . . . . . . . 72

7.6 Modelo composto por 4 nuvens. . . . . . . . . . . . . . . . . . . . . 73

7.7 Modelo composto por 5 nuvens. . . . . . . . . . . . . . . . . . . . . . . . . . 74

7.8 Ponto de vista superior do modelo com 17 nuvens. . . . . . . . . . . . . . . . . . 75 


\section{LISTA DE TABELAS}

3.1 Trabalhos relacionados e técnicas utilizadas. . . . . . . . . . . . . . . 40

5.1 Situação e posição de cada Kinect. . . . . . . . . . . . . . . . . . 52

5.2 Dados obtidos no experimento de medição de ruídos. . . . . . . . . . . . . . 54

6.1 Nas imagens à esquerda os dois sensores paralelos e à direita, convergentes. . . 64

6.2 Análise do registro das duas nuvens. . . . . . . . . . . . . . . . 65

7.1 Erro médio em metros entre a nuvem capturada na posição angular $x$ e as três nuvens subsequentes capturadas nas posições $x+22,5^{\circ}, x+45^{\circ}$ e $x+67,5^{\circ}$. Nas células vazias não foi alcançado o número mínimo de correspondências para ocorrer o alinhamento. . . . . . . . . . . . . . . . . . 76 


\section{LISTA DE ABREVIATURAS}

API Application Programming Interface.

AVMix Sistema de Vídeo-Avatar com Detecção de Colisão para Realidade Aumentada e Jogos.

AVTC Augmented Virtuality Tele-Conferencing.

CAVE Cave Automatic Virtual Environment.

GPU Graphics Processor Unit.

HMD Head-Mounted Display.

IBVH Image-Based Visual Hulls.

ICP Iterative Closest Point.

IR Infrared.

INTERLAB Laboratório de Tecnologias Interativas.

LAN Local Area Network

RA Realidade Aumentada.

RV Realidade Virtual.

SDK Software Development Kit.

SVGA Super Video Graphics Array.

VMD Video-avatar from Multiple Depth Map.

VRML Virtual Reality Modeling Language. 


\section{SUMÁRIO}

1 Introdução 16

1.1 Objetivos . . . . . . . . . . . . . . . . . . . . . . . . 17

1.2 Contribuições . . . . . . . . . . . . . . . . . . . . . . . . . . . . 17

1.3 Motivações . . . . . . . . . . . . . . . . . . . . . . . . . . . . . . . . . . . . . . 18

1.4 Justificativas . . . . . . . . . . . . . . . . . . . . . . . . . . . . . . 19

1.5 Organização do Texto . . . . . . . . . . . . . . . . . . . 20

2 Fundamentação $\quad 21$

2.1 Fundamentação Conceitual . . . . . . . . . . . . . . . . . . . . . . . . 21

2.1.1 Sistemas de Telecomunicação Imersiva . . . . . . . . . . . . . . . . . . 21

2.1.2 Nuvem de Pontos . . . . . . . . . . . . . . . . . . . . 22

2.1.3 Registro de Par de Nuvens de Pontos . . . . . . . . . . . . . . . . . . 22

2.1.4 Visualização de Nuvem de Pontos . . . . . . . . . . . . . . . . . . . . 25

2.2 Ferramental Tecnológico . . . . . . . . . . . . . . . . . . . . . . . . . . . 28

2.2.1 Captura de Profundidade por Sensores Ativos . . . . . . . . . . . . . . 28

2.2.2 Point Cloud Library . . . . . . . . . . . . . . . . . . . . . . . . . . 31

3 Trabalhos Relacionados 33

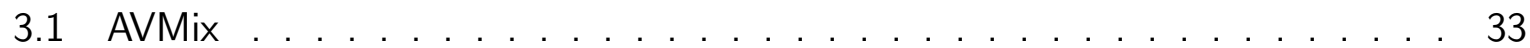

3.2 AVTC . . . . . . . . . . . . . . . . . . . . . . 34

3.3 Blue-C . . . . . . . . . . . . . . . . . . . . . . . . . 35

3.4 Coliseum . . . . . . . . . . . . . . . . . . . . . . . . 35

3.5 3D Video Avatar . . . . . . . . . . . . . . . . . . . . . . . . . . . . . . . . . . . . . . . 36 
3.6 Kinect Fusion . . . . . . . . . . . . . . . . . . . . . . . . . . . . . . . 36

3.7 Kinect 3D Video Capture . . . . . . . . . . . . . . . . . . . . . . . . . . . . . 37

3.8 KinectRGBDemo . . . . . . . . . . . . . . . . . . . . . . . . . . . 38

3.9 Técnicas de Reconstrução com Suporte Rotativo . . . . . . . . . . . . . . . . . 39

3.10 Comparação entre Técnicas . . . . . . . . . . . . . . . . . . . . . . . . . . 39

4 Proposta do Sistema Video-avatar from Multiple Depth Maps 42

4.1 Módulos Propostos . . . . . . . . . . . . . . . . . . . . . . . . . . . . . . 42

4.1.1 Aquisição de Dados de Profundidade da Superfície . . . . . . . . . . . . 44

4.1.2 Aquisição de Dados de Cor da Superfície . . . . . . . . . . . . . . . . . 45

4.1 .3 Remoção de Fundo . . . . . . . . . . . . . . . . . . . . . . . . 47

4.1 .4 Registro das Superfícies Parciais . . . . . . . . . . . . . . . . . . . . . 48

4.1 .5 Visualização . . . . . . . . . . . . . . . . . . . . . . . . 50

5 Experimento de Medição de Ruídos utilizando dois Kinects 51

5.1 Metodologia . . . . . . . . . . . . . . . . . . . . . . 51

5.2 Resultados . . . . . . . . . . . . . . . . . . . . . . . . 54

5.3 Análise dos Resultados . . . . . . . . . . . . . . . . . . . . . . 56

6 Experimento de Avaliação do ICP utilizando dois Kinects 58

6.1 Metodologia . . . . . . . . . . . . . . . . . . . . . . . . 59

6.2 Resultados . . . . . . . . . . . . . . . . . . . . . . 61

6.3 Análise dos Resultados . . . . . . . . . . . . . . . . . . . . . . . . . . 65

7 Experimento com Sensor Único e Base Rotativa $\quad 68$

7.1 Metodologia . . . . . . . . . . . . . . . . . . . 68

7.2 Resultados . . . . . . . . . . . . . . . . . . . . . . . . 70

7.3 Análise dos Resultados . . . . . . . . . . . . . . . . . . . . . . . . . . . . 75 
8 Conclusões $\quad 77$

8.1 Trabalhos Futuros . . . . . . . . . . . . . . . . . . . . . . 78

$\begin{array}{ll}\text { Referências Bibliográficas } & \mathbf{8 0}\end{array}$ 


\section{INTRODUÇÃO}

É cada vez mais frequente o uso de sistemas de educação a distância pelas instituições de ensino no intuito de aumentar o alcance e democratizar a educação. Aulas podem ser ministradas utilizando modernos sistemas de videoconferência com câmeras de alta resolução e microfones direcionais (TORI, 2010). Um grande desafio nesse canal de comunicação é propiciar uma boa experiência de imersão aos participantes, dado que existe uma camada tecnológica adicional entre o professor e os alunos remotos.

Um sistema de videoconferência convencional consiste na utilização de um meio tecnológico para que participantes localizados em diferentes locais se comuniquem por meio de fluxos de vídeo em tempo real, de forma que sintam-se presentes em um mesmo local. Para isso, o apresentador é filmado por uma ou mais câmeras de vídeo e, então, os fluxos de vídeo são transmitidos através de redes de alta velocidade para os demais participantes da conferência. O uso desse tipo de tecnologia, vídeo 2D convencional, restringe a percepção de profundidade dos participantes quando comparado com sistemas de videoconferência 3D.

Com o intuito de aumentar a imersão e a sensação de co-presença dos participantes dessa teleconferência, avanços tecnológicos recentes permitem evoluir uma videoconferência 2D em um sistema de teleconferência imersiva onde o apresentador é digitalizado e sua representação geométrica tridimensional, também conhecida como avatar natural (SISCOUTTO; TORI, 2004), é inserido em um ambiente virtual 3D.

Além de salas de aulas virtuais onde apenas é reconstruído o avatar realístico do apresentador que interage com os objetos virtuais, podem ser construídas outras aplicações, como por exemplo, laboratórios virtuais (SISCOUTTO; TORI, 2004) onde cada participante interage no ambiente virtual podendo visualizar e conversar com os outros através de fluxos de áudio e vídeo. 


\subsection{Objetivos}

O principal objetivo deste trabalho é apresentar uma técnica de reconstrução geométrica utilizando múltiplos sensores de profundidade, denominada VMD (Video-avatar from Multiple Depth Map), com montagem rápida dos equipamentos que capturam a forma geométrica e as cores da superfície externa de um ser humano em movimento e gera uma representação realística do usuário para aplicação em sistemas de teleconferência imersiva.

Os objetivos secundários alcançados com este trabalho são:

- Propor um modelo de estúdio de digitalização simplificado, sem necessidade de grandes estruturas rígidas para sustentar os equipamentos utilizados, de forma que esse arranjo seja facilmente instalado e desinstalado, diferentemente da técnica utilizada no sistema Blue-C (NAEF; STAADT; GROSS, 2004);

- Comprovar a viabilidade de um método automático de calibração das câmeras e sensores, sem a necessidade de marcadores e instrumentos de calibração. Existem técnicas, como por exemplo o sistema 3D Video Capture (KREYLOS, 2011), em que é necessário o uso de marcadores de calibração, com baixa tolerância a erros no posicionamento dos equipamentos e com processo de calibração manual de alta complexidade. A ideia desse trabalho é reduzir essas limitações, viabilizando o uso em maior escala.

- Reconstruir um modelo composto por múltiplas superfícies capturadas por diferentes pontos de vista do usuário em tempo real, diferentemente da técnica do Kinect Fusion (IZADI et al., 2011) que é incremental e não é a abordagem mais indicada para objetos deformáveis.

Essa combinação entre a representação geométrica dinâmica do usuário e um mundo virtual pode ser definida como integração de vídeo natural com o ambiente virtual 3D (SISCOUTTO, 2003).

\subsection{Contribuições}

A cada dia, com os adventos tecnológicos, são desenvolvidos novos sistemas de ensino a distância, novas aplicações interativas para entretenimento e novos sistemas de informática médica que possuem avatares realísticos dentre os demais objetos virtuais. Com a proposta apresentada neste trabalho é possível construir uma representação geométrica realística mais 
abrangente do ser humano alvo de forma mais simples quando comparada, por exemplo, com a técnica billboard (MöLLER; HAINES; HOFFMAN, 2008) que utiliza uma única webcam possibilitando uma interação mais rica dos usuários.

\subsection{Motivações}

Em alguns trabalhos anteriores de vídeo-avatar encontrados na literatura foi utilizada a técnica de billboarding, cujo avatar é representado por um plano onde é projetado o vídeo proveniente de uma câmera 2D fixa que captura imagens do apresentador em um estúdio. No entanto, há algumas limitações nessa abordagem, por exemplo, a situação onde um participante da conferência se move alterando seu ponto de vista dentro do ambiente virtual, ele notará que a representação do avatar é planar pois esse plano é rotacionado em relação ao seu eixo, sempre ficando perpendicular ao ponto de vista do usuário.

Outra técnica utilizada para evitar que o usuário perceba que a representação do avatar é um único plano é o switching planes (INSLEY; SANDIN; DEFANTI, 1997). Nessa abordagem o apresentador é filmado por diversas câmeras posicionadas em ângulos distintos, dessa forma, um usuário ao se mover pelo ambiente virtual visualizará o vídeo capturado pela câmera com ponto de vista mais próximo do seu ângulo. No entanto, quanto mais o usuário se aproxima do avatar, mais ele percebe que o mesmo é um modelo 2D.

O avatar não possui volume nessas duas técnicas pois se trata de uma representação planar. Com intuito de melhorar esse resultado foi utilizada uma técnica de estereoscopia para gerar uma representação do avatar não planar, nas seções 3.1 e 3.2 serão dados mais detalhes sobre as implicações dessa abordagem.

No trabalho denominado Blue-C (NAEF; STAADT; GROSS, 2004), foi utilizado um estúdio com dezenas de câmeras sustentadas por uma estrutura rígida para capturar imagens do usuário por diversos ângulos. Através da técnica de Visual Hull é gerado um modelo geométrico 3D do usuário. São utilizados servidores distribuídos para processar os fluxos de vídeos, gerar o modelo geométrico e renderizá-lo nas paredes de um ambiente imersivo de CAVE (Cave Automatic Virtual Environment).

Este trabalho se enquadra como uma proposta intermediária entre esses dois extremos, sendo que de um lado existem técnicas com infraestrutura simplificada, no entanto, o avatar obtido é pobre, representado de forma planar, e do outro lado, há plataformas como o Blue-C, onde um avatar tridimensional completo é gerado, porém é necessário um estúdio complexo que exige local e equipamentos dedicados. A proposta deste trabalho gera uma reconstrução 
tridimensional do modelo através de uma infraestrutura mais simples do que a utilizada no Blue- $C$ e de melhor qualidade do que as técnicas de billboarding.

\subsection{Justificativas}

O sistema AVMix desenvolvido para vídeo-avatar no Interlab (NAKAMURA, 2008) baseado na técnica de imageamento estéreo utilizava duas câmeras convencionais para reconstrução de uma superfície $2,5 \mathrm{D}$ do objeto de interesse. A etapa de calibração do par de câmeras era mais complexa em relação ao uso de sensores de profundidade pré-calibrados encontrados no mercado, pois exigia a utilização de objetos de calibração para obtenção dos parâmetros intrínsecos e extrínsecos de cada câmera.

Como resultado do uso de apenas um par de câmeras estéreo nesse sistema, uma reconstrução parcial do objeto de interesse era produzida, ocasionando um tratamento de colisão parcial no subsistema de interação.

A motivação deste trabalho é mitigar as restrições do módulo de mapa de profundidade do AVMix, através do desenvolvimento de um sistema composto por uma combinação de técnicas que seja capaz de produzir uma representação tridimensional mais completa, fundindo superfícies parciais do usuário obtidas por pontos de vista distintos.

Uma possível alternativa para alcançar esse objetivo envolve a utilização de múltiplos sensores de profundidade baseados na técnica de luz estruturada. A digitalização tridimensional de seres humanos utilizando dispositivos baseados nessa técnica envolve alguns desafios, dentre eles destacam-se:

- Redução de zonas de sombras. Devido às peculiaridades da forma do corpo humano, zonas de auto-oclusão podem ocorrer no modelo geométrico gerado quando, por exemplo, um membro superior obstruir parte do tronco (JANG; LEE, 2010);

- Seleção adequada do equipamento de captura. Como o objeto de interesse em questão é um ser humano em movimento, para gerar um vídeo tridimensional contínuo em tempo real é necessário um sensor com uma resolução e taxa de quadros por segundo compatível com esse objetivo;

- Seleção adequada da técnica de reconstrução. Técnicas de digitalização que utilizam projeção de padrões de luz visível sobre o alvo, podem gerar incômodo ao sistema visual dos seres humanos. 
A proposta apresentada nessa dissertação se tornou viável graças ao lançamento recente de sensores de profundidade de baixo custo, como é o caso dos sensores Microsoft Kinect, Asus Xtion e PrimeSense 3D, que fornecem as configurações mínimas para os objetivos desse trabalho sem incomodar a vista do apresentador como é o caso da luz estruturada com projeção de luz visível.

A utilização de um sensor de profundidade baseado na técnica de luz estruturada conta com pré-calibração de fábrica, o que simplifica o processo de instalação do sistema de aquisição de dados 3D para o usuário final.

\subsection{Organização do Texto}

No capítulo 2 são abordados conceitos teóricos e tecnológicos utilizados nos demais capítulos. No capítulo 3 são apresentados sistemas que utilizam técnicas relacionadas à proposta deste mestrado, que é apresentada no capítulo 4. Nos capítulos 5, 6 e 7 são apresentados os experimentos realizados e a análise dos resultados que comprovam a viabilidade dessa proposta. Para finalizar, são apresentadas as conclusões e as perspectivas de trabalhos futuros no capítulo 8. 


\section{FUNDAMENTAÇÃO}

Este capítulo é dividido em duas seções, sendo que a primeira se refere à fundamentação conceitual, onde são apresentados os conceitos teóricos que são utilizados neste trabalho e a segunda parte refere-se a fundamentação tecnológica, onde é dado um panorama da infraestrutura de software e hardware utilizada na proposta, que é apresentada no capítulo 4.

\subsection{Fundamentação Conceitual}

Neste capítulo serão apresentados os principais conceitos utilizados neste trabalho. Iniciando pelo tipo de aplicação alvo, depois é explicada a estrutura de dados utilizada para manipular as saídas geradas pelos sensores e por último, as etapas que constituem um sistema de Vídeoavatar com múltiplos sensores.

\subsubsection{Sistemas de Telecomunicação Imersiva}

A classe de aplicações denominada telecomunicação imersiva, segundo (PETIT et al., 2009), refere-se a sistemas que têm a capacidade de construir uma representação geométrica realística de um usuário real que é filmado em um local reservado e esse modelo geométrico é inserido em um mundo virtual compartilhado. Além dos avatares e demais componentes do cenário virtual, podem ser inseridos objetos virtuais sintéticos com os quais os avatares podem interagir.

Um avatar consiste na representação de um usuário real em um ambiente virtual (KIRNER et al., 2001), essa representação pode ser humanoide ou não. Neste trabalho, o avatar também será classificado em relação à completude do seu modelo geométrico, podendo ser planar, 2,5D, ou 3D.

Segundo (FOLLMER et al., 2011), utilizando um sensor Kinect é possível de se obter um modelo 2,5D do objeto de interesse, ou seja, nesse modelo existe informação de profundidade, diferentemente da captura 2D onde somente são fornecidas as coordenadas ( $x, y)$. No entanto, como não existe a informação completa da superfície do objeto, ainda não pode ser considerado 
como 3D.

$\mathrm{Na}$ área de sistemas imersivos, um vídeo avatar consiste em uma representação virtual do usuário obtida através de dispositivos de captura de vídeo em tempo-real (NAKAMURA, 2008). Dessa forma, sistemas de vídeo-avatar que possuem uma representação realística do usuário podem ser classificados como aplicações de Realidade Aumentada. No capítulo 3 serão listados alguns exemplos de sistemas de vídeo-avatar e técnicas de reconstrução geométrica.

\subsubsection{Nuvem de Pontos}

Para representar computacionalmente modelos geométricos tridimensionais referentes a superfícies externas de objetos reais é necessário um formato que facilite a manipulação. Um tipo de estrutura com essa característica é a nuvem de pontos. Uma nuvem de pontos é constituída por um conjunto de pontos em um sistema de coordenadas tridimensional. Cada ponto é definido pelas coordenadas $x$, y e z. Além disso, podem ser inseridas informações de cor e transparência (XYZRGBA) ou a informação do vetor normal do ponto em questão, em relação à sua vizinhança. Esses pontos são obtidos através de um sensor de profundidade (vide seção 2.2.1).

As nuvens de pontos são geradas geralmente através da projeção de mapas de profundidade. No mapa de profundidade, a coordenada z representa a distância (normalmente em metros) entre o ponto da superfície do objeto e um determinado ponto de vista (centro da lente da câmera do sensor). Detalhes são apresentados na seção 2.2.1.

\subsubsection{Registro de Par de Nuvens de Pontos}

O termo "registro"pode ser aplicado no sentido de alinhamento necessário entre dois modelos geométricos, com sistemas de coordenadas distintos, com objetivo de gerar uma cena consistente. Por exemplo, duas nuvens de pontos obtidas de ângulos distintos de um mesmo objeto real, após o registro, devem possuir um mesmo sistema de coordenada global. Dessa forma, o usuário tem a percepção de estar visualizando um único modelo geométrico.

Caso sejam utilizados dois sensores de profundidade do mesmo modelo (que gerem nuvens de pontos na mesma escala) para digitalizar o mesmo alvo, é necessário encontrar a função de transformação que rotaciona e translada uma das nuvens para geração do modelo integrado que as funde. Para calcular essa função de transformação existem três formas principais:

- Utilização de marcadores semelhantes a tabuleiros de xadrez que são filmados por todas 
as câmeras, sendo possível encontrar a função que altera o sistema de coordenadas do modelo geométrico gerado por uma câmera para um sistema global;

- Marcação manual de pontos correspondentes pelo usuário como por exemplo, a técnica de point base glueing apresentada em 7.1;

- Utilização de algoritmos de busca automática de superfícies parciais correspondentes entre os dois modelos de forma que não seja necessário utilizar marcadores de calibração como no primeiro item.

O método ICP (Iterative Closest Point) cujo algoritmo inicial foi criado por (BESL; McKay, 1992), se encaixa na terceira forma, e é a opção automática para encontrar a função de transformação que registra um par de nuvens de pontos desalinhadas em um modelo global consistente, ou seja, esse método estima a função que alinha as duas nuvens parciais gerando um modelo único composto pela união dos pontos das duas nuvens.

Uma premissa para que esse algoritmo iterativo convirja é que haja intersecção entre as superfícies dos dois modelos geométricos. Para cada par de nuvem de pontos a ser registrado, uma estrutura é considerada como modelo global e a outra como modelo de entrada. Uma função rígida de rotação e translação é estimada e aplicada no modelo de entrada iterativamente. A cada iteração é recalculada a distância euclidiana entre os pontos correspondentes de cada superfície até que esse valor fique inferior a um limiar pré-definido que ocasiona o fim da iteração.

Antes de apresentar o algoritmo do ICP, será explicado como foi calculada a distância entre as superfícies geométricas durante as iterações, o que será base para avaliação da convergência da função de registro na direção desejada. A distância entre um ponto $\vec{p}$ e um conjunto de pontos $A$ é dada pela equação $d(\vec{p}, A)=\min _{i \in\left\{1, \ldots, N_{a}\right\}} d\left(\vec{p}, \vec{a}_{j}\right)$, sendo o ponto mais próximo $\vec{a}_{j}$ de $A$ satisfaz a equação $d\left(\vec{p}, \vec{a}_{j}\right)=d(\vec{p}, A)$, ou seja, o ponto da superfície $A$ com a menor distância euclidiana em relação a $\vec{p}$ será escolhido para representar uma correspondência utilizada no algoritmo.

Após apresentados os cálculos utilizados para determinar a distância entre pontos correspondentes em duas nuvens de pontos distintas, é possível apresentar o algoritmo de ICP. Seguem os passos do fluxo base:

- Dados o conjunto de pontos $P$ com $N_{p}$ pontos $\{\vec{i}\}$ pertencentes à nuvem de entrada e o conjunto de pontos $X$ (com $N_{x}$ pontos) pertencentes à nuvem global. Os passos abaixo são executados até que a condição do item 4 seja alcançada. 
1. São calculados os pontos mais próximos: $Y_{k}=C\left(P_{k}, X\right)$ de acordo com a distância euclidiana;

2. É estimada a função de registro: $\left(\overrightarrow{q_{k}}, d_{k}\right)=Q\left(P_{o}, Y_{k}\right)$ responsável pela translação e rotação do modelo de entrada que minimiza a distância euclidiana entre os pontos correspondentes;

3. É aplicada a função de transformação na nuvem de entrada: $P_{k+1}=\overrightarrow{q_{k}}\left(P_{o}\right)$;

4. A iteração termina quando a variação no erro médio quadrático apresentar valor inferior a um limiar pré-definido $T>0$ que define a precisão desejada para o registro: $d_{k}-d_{k+1}<T$.

A função rígida de registro $\left(\overrightarrow{q_{k}}, d_{k}\right)=Q\left(P_{o}, Y_{k}\right)$ é definida por um vetor de translação e por uma matriz de rotação. Para estimar a função de rotação é utilizado um algoritmo baseado no vetor quaternário $q_{R}=\left[q_{0}, q_{1}, q_{2}, q_{3}\right]^{t}$ onde $q_{0}>0$ e $q_{0}^{2}+q_{1}^{2}+q_{2}^{2}+q_{3}^{2}=1$ (HORN, 1987). Com esse vetor é obtida a matriz de rotação $R$ conforme equação 2.1 .

$$
R=\left[\begin{array}{ccc}
q_{0}^{2}+q_{1}^{2}-q_{2}^{2}-q_{3}^{2} & 2\left(q_{1} q_{2}-q_{2} q_{3}\right) & 2\left(q_{1} q_{3}+q_{0} q_{2}\right) \\
2\left(q_{1} q_{2}+q_{0} q_{3}\right) & q_{0}^{2}+q_{2}^{2}-q_{1}^{2}-q_{3}^{2} & 2\left(q_{2} q_{3}-q_{0} q_{1}\right) \\
2\left(q_{1} q_{3}-q_{0} q_{2}\right) & 2\left(q_{2} q_{3}+q_{0} q_{1}\right) & q_{0}^{2}+q_{3}^{2}-q_{1}^{2}-q_{2}^{2}
\end{array}\right]
$$

Para encontrar a função completa de registro $\vec{q}=\vec{q} R \mid \vec{q} T$, composta pelo vetor quaternário, correspondente à rotação $\vec{q} R$, e o vetor de translação $\vec{q} T$ são executados os seguintes passos em cada iteração:

1. É calculada a matriz de covariância cruzada $\sum_{p x}$ (equação 2.2) para os pontos correspondentes $\vec{p}_{i}$ e $\vec{x}_{i}$ pertencentes aos conjuntos de pontos $P$ e $X$ respectivamente, onde $N_{p}=N_{x}$, com centros de massa $\mu_{p}$ e $\mu_{x}$;

$$
\sum_{p x}=\frac{1}{N_{p}} \sum_{i=1}^{N_{p}}\left[\left(\vec{p}_{i}-\overrightarrow{\mu_{p}}\right)\left(\vec{x}_{i}-\overrightarrow{\mu_{x}}\right)^{t}\right]
$$

2. Os componentes cíclicos da matriz assimétrica $A_{i j}=\left(\sum_{p x}-\sum_{p x}^{T}\right)_{i j}$ são utilizados para formar o vetor $\Delta=\left[\begin{array}{lll}A_{23} & A_{31} & A_{12}\end{array}\right]^{T}$ que, então, constituirá a matriz $4 \times 4$ simétrica $Q\left(\sum_{p x}\right)$. Na equação $2.3, \operatorname{tr}\left(\sum_{p x}\right)$ significa o traço da matriz $\sum_{p x}$ e $I_{3}$, a matriz identidade $3 \times 3$;

$$
Q\left(\sum_{p x}\right)=\left[\begin{array}{cc}
\operatorname{tr}\left(\sum_{p x}\right) & \Delta^{T} \\
\Delta & \sum_{p x}+\sum_{p x}^{T}-t r\left(\sum_{p x}\right) I_{3}
\end{array}\right]
$$


3. A função de rotação é encontrada calculando o auto-vetor $q_{R}=\left[q_{0}, q_{1}, q_{2}, q_{3}\right]^{t}$ (para $\left.Q\left(\sum_{p x}\right)\right)$ com maior auto-valor correspondente. Então, é calculado o vetor de translação $\vec{q}_{T}=\vec{\mu}_{x}-R\left(\vec{q}_{R}\right) \vec{\mu}_{p}$

\subsubsection{Visualização de Nuvem de Pontos}

Uma das aplicações para nuvens de pontos compostas é a impressão 3D que consiste em esculpir a forma do modelo geométrico em algum material sólido ou que se solidifique após uma reação química. Outra utilização comum é a visualização desse modelo através de monitores de vídeo.

Uma forma de visualizar nuvens de pontos que contenham informação referente a cor de cada vértice é a renderização de pontos desconectados (figura 2.1), sem utilizar malha de polígonos. Essa técnica consiste em varrer a matriz de pontos por linha e coluna e desenhar um ponto para cada vértice com a informação RGB correspondente.
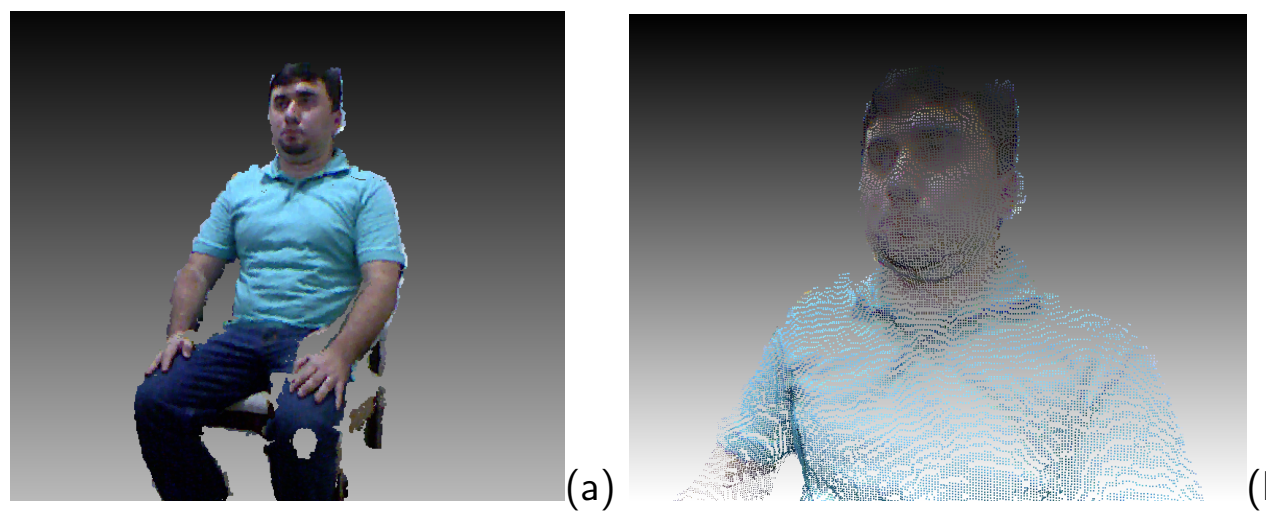

Figura 2.1: Renderização de uma nuvem de pontos sem mesh em (a). Imagem ampliada em (b).

Outra abordagem aplicável em tempo real é a técnica de microfacet billboarding (YAMAZAKI et al., 2002). Nessa técnica são renderizadas micro-facetas planas que sempre são posicionadas paralelamente ao plano onde se encontra a câmera ocasionando uma redução de frestas entre os pontos renderizados. Esses espaços são notados principalmente ao se observar o modelo por um ponto de vista lateral (vide figura 2.2). Uma extensão desta técnica denominada video-based microfacet billboard é apresentada em (TOKUNAGA et al., 2009), eliminando a necessidade de criar um modelo baseado em voxel ou visual hull e proporcionando um melhor desempenho. 


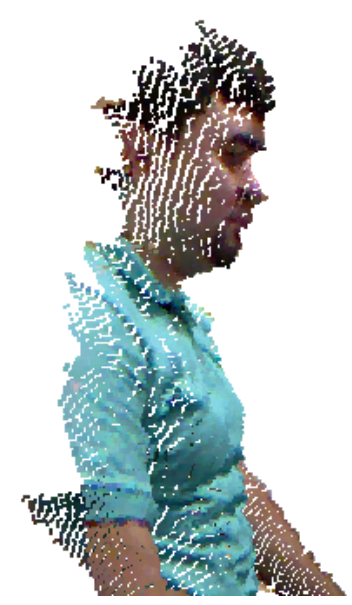

Figura 2.2: Frestas evidenciadas por um ponto de vista lateral

Partindo para a utilização de malhas de polígonos que exige um maior esforço computacional do que as técnicas de renderização de pontos desconectados anteriores, são encontrados vários algoritmos de reconstrução de superfície que tem uma nuvem de pontos como entrada e uma malha poligonal como saída. As técnicas de tecelagem com malha de triângulos são mais utilizadas pois a maior parte das GPUs (Graphics Processor Unit) e APIs (Application Programming Interface)são customizadas para manipular triângulos (MöLLER; HAINES; HOFFMAN, 2008). Como implementações dessa classe de técnicas destacam-se os algoritmos de cubos marchantes (LORENSEN; CLINE, 1987), de ball-pivoting e de Poisson (KAZHDAN; BOLITHO; HOPPE, 2006).

O algoritmo de cubos marchantes divide a nuvem de pontos em camadas (linhas) e para cada duas camadas adjacentes obtém oito vértices, quatro de cada camada, que constituirão um cubo lógico. O algoritmo encontra qual o padrão de triângulos será renderizado através da análise de como a superfície intersecta o cubo, comparando os valores de cada vértice do cubo com um conjunto de padrões de triângulos pré-estabelecidos (figura 2.3). 

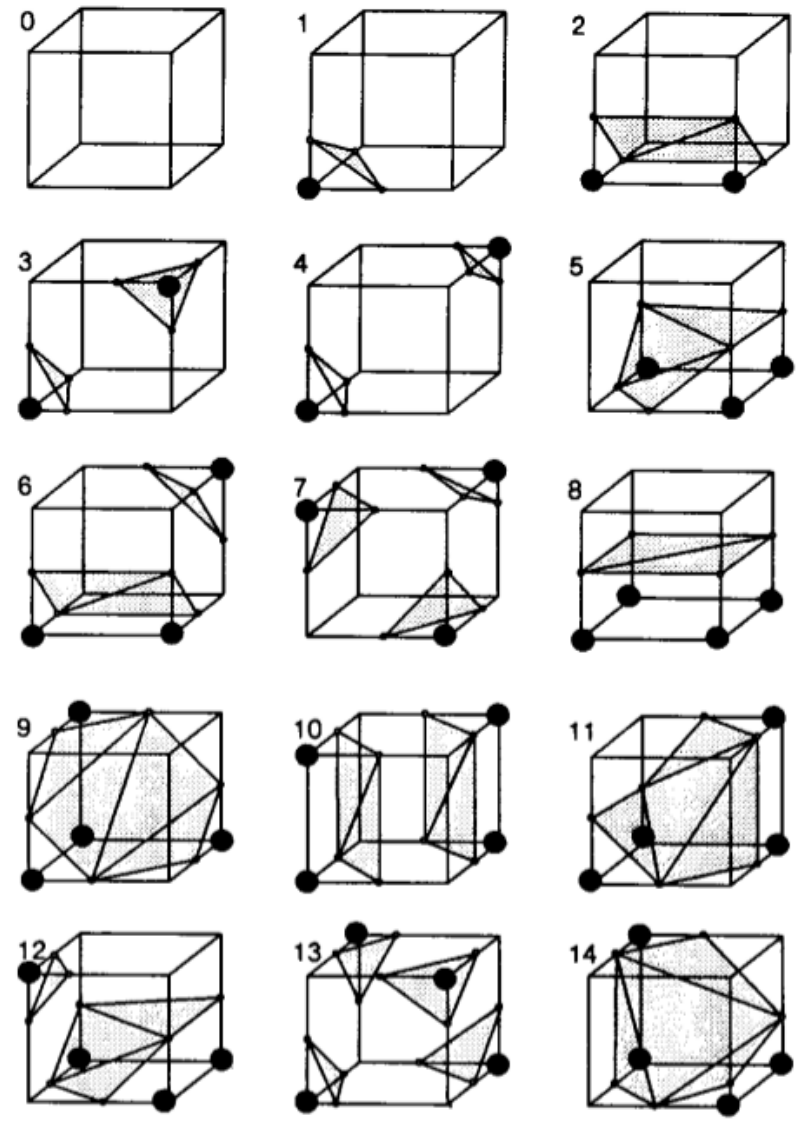

Figura 2.3: Conjunto de padrões de triângulos da técnica cubos marchantes (LORENSEN; CLINE, 1987).

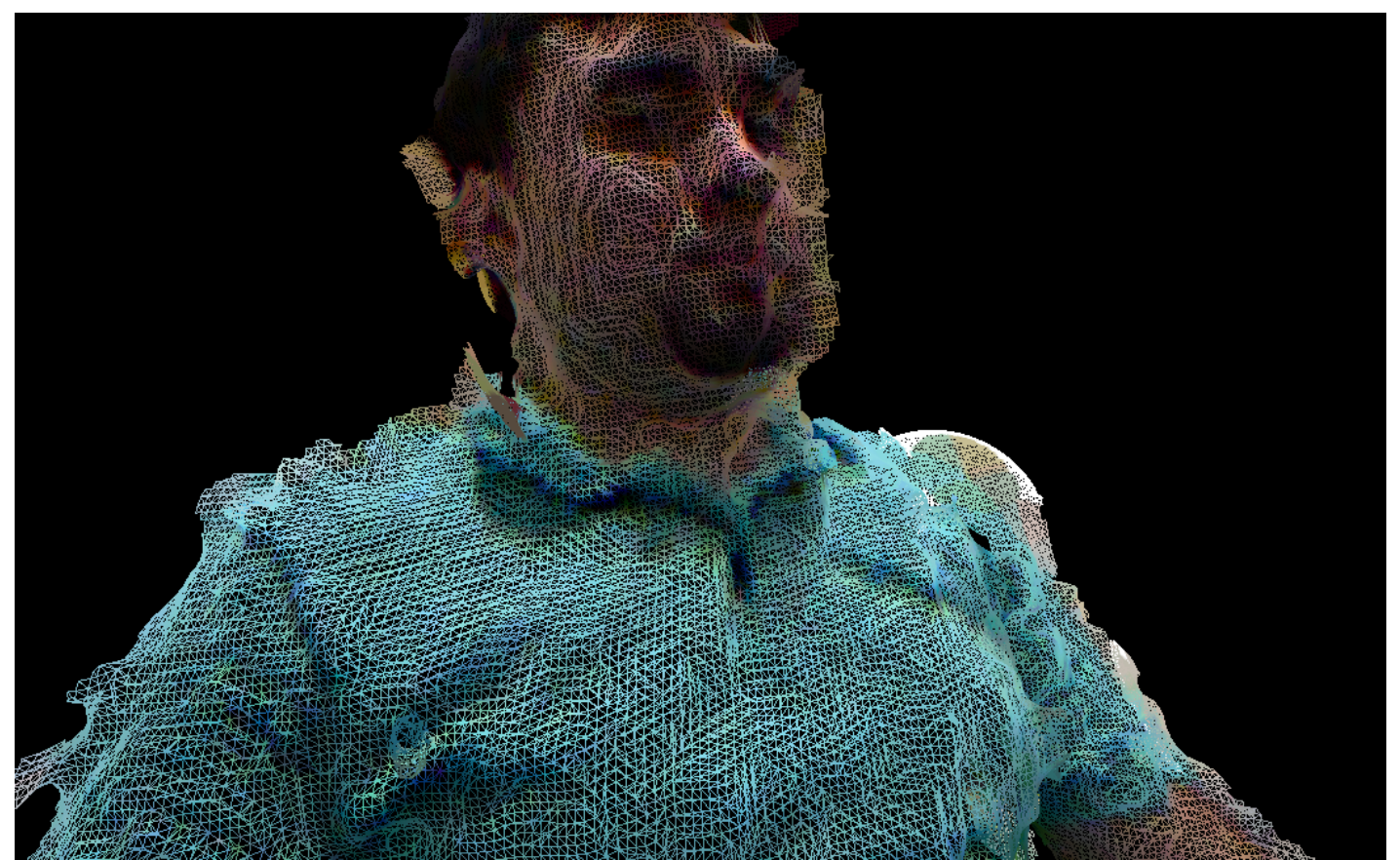

Figura 2.4: Malha de triângulos gerada pelo algoritmo de cubos marchantes. 
O algoritmo de ball-pivoting (BERNARDINI et al., 1999) começa seu processamento de um vértice raiz $p$ e gera um triângulo somente se a esfera com raio $R$ toca exclusivamente três pontos, então essa esfera se move em relação a uma aresta em busca de outro ponto para gerar outro triângulo vizinho e a tecelagem prossegue até que todas as arestas formadas sejam visitadas.

O algoritmo de Poisson (KAZHDAN; BOLITHO; HOPPE, 2006) para reconstrução de superfícies, é dentre as técnicas de malha poligonal, uma com grande resistência a ruídos em nuvens de pontos. Primeiramente, cada ponto é classificado através de uma função $\chi_{M}$ que indica se o ponto pertence à área interna do modelo (atribuindo o valor 1 ) ou à área externa (valor 0 ). Com isso, é reconstruído o modelo geométrico pelo cálculo da iso-superfície.

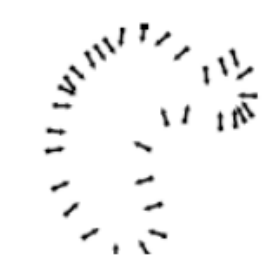

Pontos orientados

$\vec{V}$

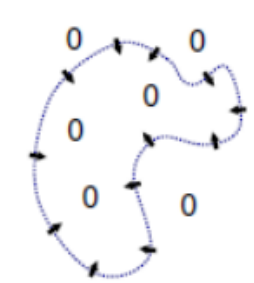

Gradiente indicador $\nabla \chi_{M}$

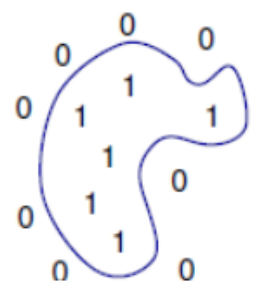

Função indicadora

$\chi_{M}$

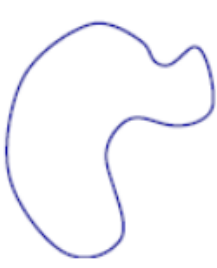

Superfície

$\partial M$

Figura 2.5: Etapas da reconstrução de Poisson em 2D(KAZHDAN; BOLITHO; HOPPE, 2006).

\subsection{Ferramental Tecnológico}

Nesta seção será detalhado o ferramental tecnológico utilizado nos experimentos dos capítulos 5,6 e 7, sendo composto pela parte de software e hardware.

\subsubsection{Captura de Profundidade por Sensores Ativos}

Sensores de profundidade são dispositivos que têm a capacidade de medir a distância entre os pontos da superfície do objeto alvo e o equipamento de captura. Dessa forma, é obtido um fluxo de dados com o mapa de profundidade (discussão em 2.1.2) relacionado à porção da superfície externa do objeto que está sendo digitalizado.

No caso de dispositivos como o sensor Kinect é gerado como saída um arranjo, onde para cada posição, são fornecidos os valores de $(x, y, Z)$ onde $(x, y)$ representam as coordenadas do respectivo pixel e $Z$ representa a distância entre o ponto e o sensor (figura 2.6) em uma dada unidade de medida. Essa estrutura de dados de saída gerada pelo sensor normalmente é 
conhecida como mapa de profundidade.

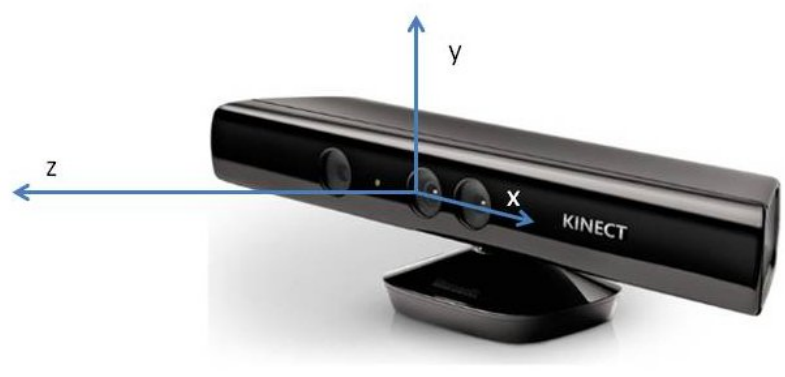

Figura 2.6: Orientação do sistema de coordenadas da nuvem de pontos gerada pelo Kinect.

Uma das técnicas de captura de profundidade se baseia em luz estruturada. Essa abordagem (WILL; PENNINGTON, 1971) consiste no uso de uma fonte emissora de um padrão de luz pré-definido sobre o objeto de interesse e, depois, são capturadas imagens do objeto iluminado por esse padrão. Dessa forma, o mapa de profundidade é calculado através da correspondência entre o padrão original e o padrão projetado sobre o modelo.

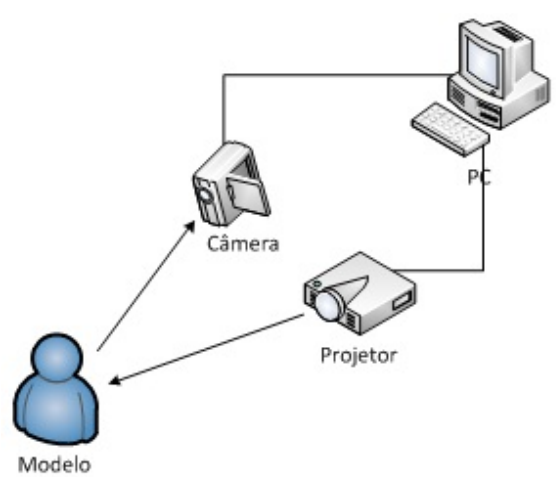

Figura 2.7: Arranjo de equipamentos na técnica de luz estruturada convencional.

Esse padrão é gerado por um equipamento emissor de luz, por exemplo, um projetor convencional (figura 2.7), ou um LED especializado como é feito no caso do Kinect. Cada padrão é constituído por uma sequência de códigos, dessa forma, cada ponto da superfície do objeto recebe um código que o identifica dentro do padrão. Assim, é obtido um mapeamento direto entre os códigos e as coordenadas $(\mathrm{x}, \mathrm{y})$ correspondentes de cada ponto do objeto.

As técnicas de luz estruturada podem ser classificadas de acordo com o tipo de padrão projetado em (SALVI; PAGES; BATLLE, 2004): 
- Multiplexação no tempo;

- Vizinhança Espacial;

- Codificação direta.

Na técnica de multiplexação no tempo, os códigos são representados através da projeção de uma sequência de padrões que se alternam ao longo do tempo, desta forma, os padrões utilizados podem ser mais simples do que em técnicas sem multiplexação. Aumentando a complexidade do padrão, existe a técnica de vizinhança espacial em que os códigos são representados por um único padrão fixo ao longo do tempo. Por último, na técnica de codificação direta é definido um código, baseado no nível de cinza ou na cor referente a cada pixel.

Para digitalizar superfícies deformáveis ou objetos que estão em movimento, algumas abordagens são menos apropriadas, como é o caso da maioria dos sistemas com os padrões multiplexados no tempo.

Um exemplo de sensor de profundidade baseado na técnica de luz estruturada é o Kinect (MICROSOFT, 2011). Esse sensor desenvolvido pela Microsoft é constituído pelos elementos:

- Uma câmera SVGA (Super Video Graphics Array);

- Uma câmera IR (Infrared);

- Um emissor de luz IR coerente;

- Um difusor que distorce a luz IR gerando um padrão de pontos de luz aleatório.

Esse dispositivo gera dois fluxos de dados como saída, um com a textura colorida e outro com o mapa de profundidade. O fluxo de cor é disponibilizado em dois formatos, RGB e YUV. Caso o primeiro modo seja escolhido, um valor de 32-bits no formato X8R8G8B8 para cada pixel será fornecido.

O emissor e a câmera IR são utilizados para obtenção do mapa de profundidade através da projeção de uma padrão respingado. Quando um feixe de luz coerente passa através do difusor, o mesmo é deformado gerando um padrão respingado (speckle pattern) sobre a a superfície alvo. Esse padrão é fixo ao longo do tempo e é invisível ao seres humanos sendo necessária uma câmera IR para registrá-lo (figura 2.8). 


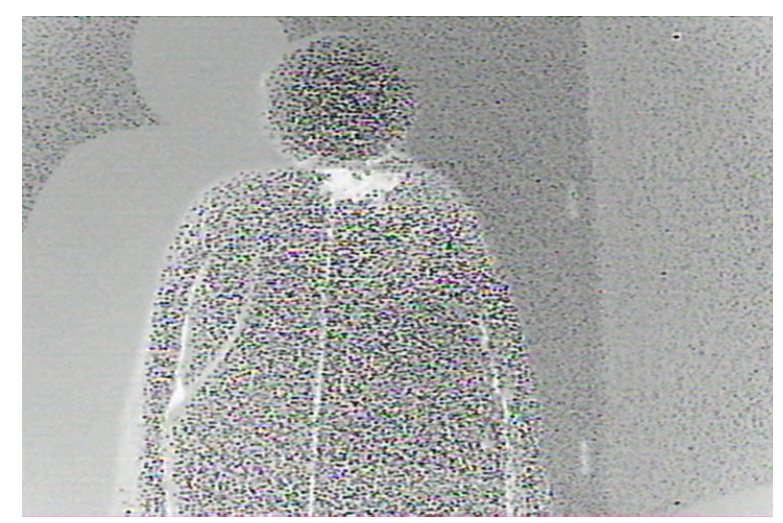

Figura 2.8: Padrão projetado pelo LED do Kinect capturado por uma câmera IR.

A câmera IR captura as imagens dos objetos refletindo o padrão de luz de acordo com as curvas da superfície. A distância entre cada ponto do objeto e o sensor (profundidade Z) é calculada por meio de uma função que encontra a correspondência entre o padrão inicial e o padrão deformado.

As principais APIs disponíveis para acessar os fluxos de dados gerados pelo Kinect são:

- Microsoft Kinect SDK: Interface disponibilizada pelo fabricante que além de acessar os fluxos de dados, disponibiliza um algoritmo de segmentação, classificação de articulações e rastreamento dos jogadores e pode ser utilizada nas linguagens $\mathrm{C} \#$ e $\mathrm{C}++$;

- OpenNI framework: API que pode ser utilizada para acessar Kinect, Asus Xtion e Primesense sensor. Também disponibiliza as mesmas funcionalidades do SDK da Microsoft e pode ser utilizada através da linguagem $\mathrm{C}++$. A biblioteca $\mathrm{PCL}$ descrita na seçao 2.2.2 utiliza esse framework para acessar o Kinect.

No SDK, para cada pixel no mapa de profundidade é fornecido um valor de 16-bits, onde os 13 bits mais significativos representam a distância entre o sensor e o objeto mais próximo dele em milímetros. Os outros três bits menos significativos representam o índice do usuário que foi classificado pela API fornecida pela Microsoft, pois essa biblioteca pode rastrear mais de um jogador simultaneamente.

\subsubsection{Point Cloud Library}

A Biblioteca PCL (Point Cloud Library) (RUSU; COUSINS, 2011) é resultado de um projeto de código aberto referente a processamento de nuvens de pontos. A biblioteca PCL possui diversos algoritmos, incluindo filtros, estimativa de features, reconstrução da superfície, registo, ajuste 
do modelo e segmentação que podem ser utilizados em projetos de reconstrução 3D utilizando as linguagens $\mathrm{C} / \mathrm{C}++$. Além disso, é definido um formato de arquivo que representa uma nuvem de pontos (figura 2.9). Este arquivo é composto por um cabeçalho com metadados definindo que informações são presentes para cada ponto, o tamanho e tipo de cada variável, as dimensões da nuvem de pontos e o formato do arquivo podendo ser ASCII ou binário.

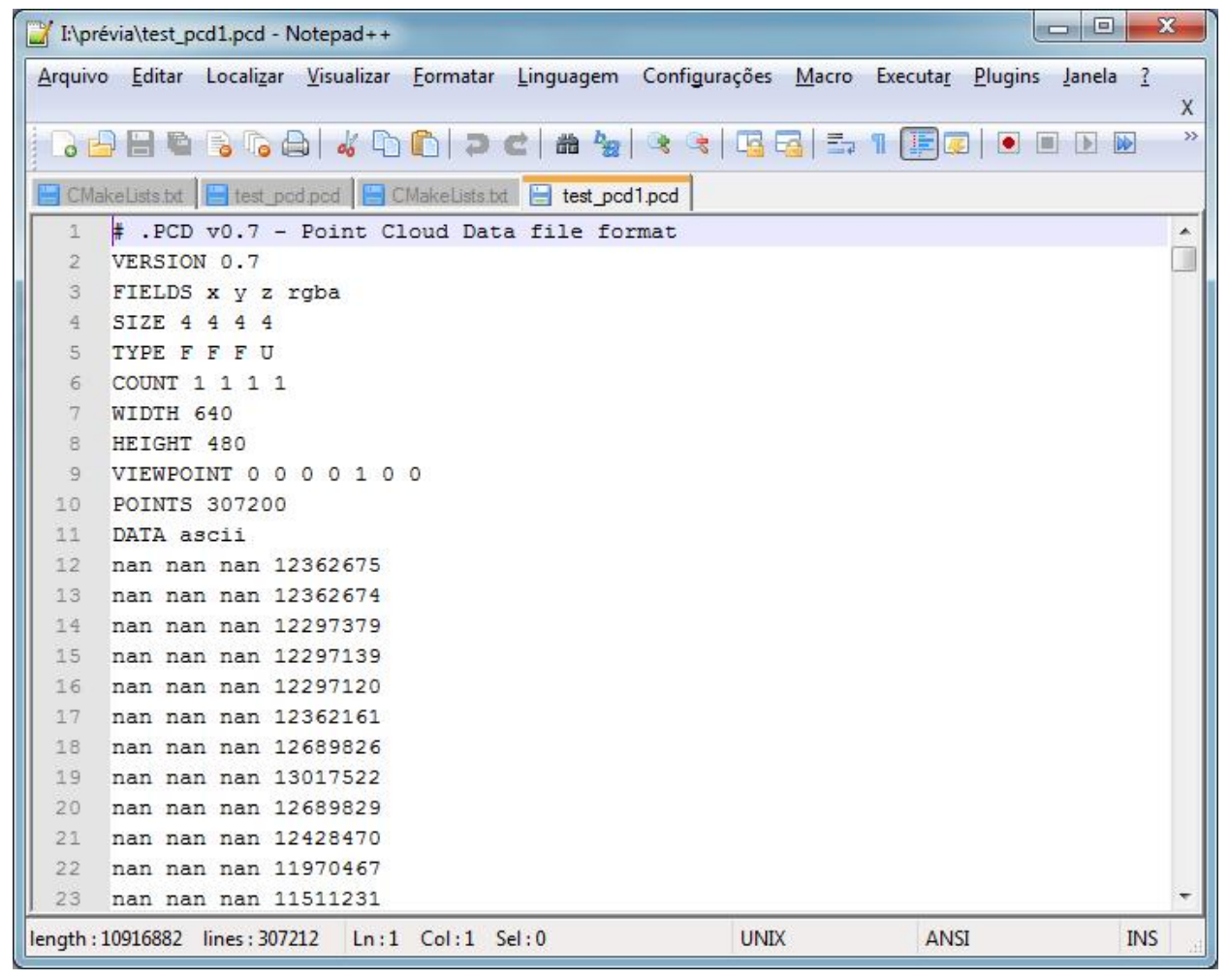

Figura 2.9: Exemplo de layout de arquivo do formato PCD.

Neste trabalho, foi utilizada a implementação do algoritmo de ICP fornecido por essa biblioteca na versão 1.7 através de sua compilação para Linux. 


\section{TRABALHOS RELACIONADOS}

Este capítulo apresenta sistemas de teleconferência imersiva e trabalhos com técnicas de reconstrução $2 \mathrm{D}, 2,5 \mathrm{D}$ e 3D que serviram de base para realização da proposta de sistema que será apresentada no próximo capítulo.

\subsection{AVMix}

O sistema AVMix (NAKAMURA, 2008) é uma aplicação de vídeo-avatar com interação 3D através da captura de imagens do usuário por câmeras de vídeo convencionais.

O sistema proposto foi dimensionado para ser executado em equipamentos domésticos como computadores pessoais e webcams, ou seja, sem a necessidade de hardware especial de alto custo e alta complexidade de configuração.

A arquitetura proposta na versão inicial é composta por cinco subsistemas (figura 3.1):

- Aquisição;

- Segmentação;

- Mapa de profundidade;

- Composição;

- Interação. 


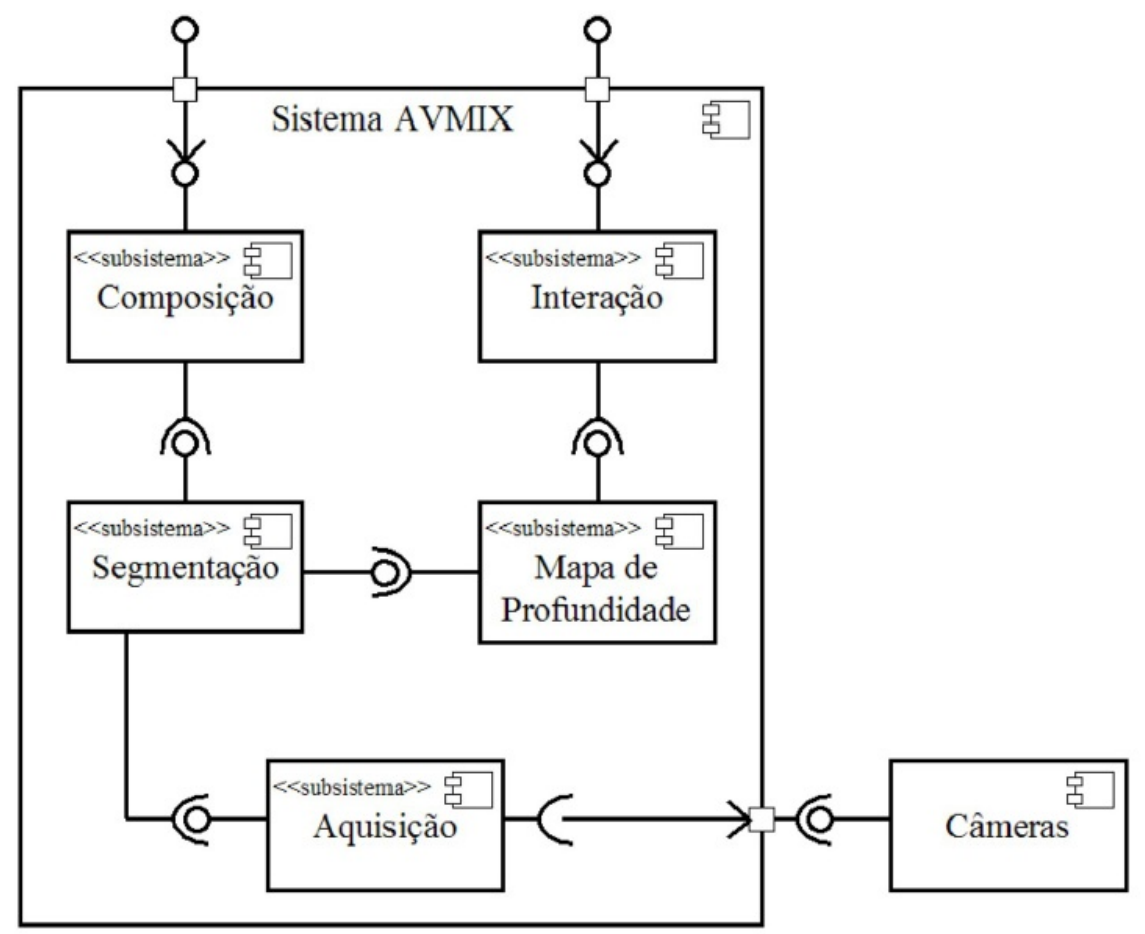

Figura 3.1: Subsistemas da arquitetura do sistema AVMIX.

O subsistema de aquisição é responsável por realizar a interface com o par de câmeras estéreo e obter os fluxos de vídeo. O módulo de segmentação é baseado na técnica de subtração de fundo estático e tem a finalidade de remover o fundo das imagens isolando o usuário do restante da cena.

O subsistema de mapa de profundidade calcula o mapa de profundidade através do par de imagens capturado, encontrando a correspondência entre elas e realizando triangulação. 0 subsistema de composição é responsável por renderizar a representação geométrica do usuário (avatar) no ambiente sintético. E por último, é apresentado o subsistema de interação responsável pelo tratamento de colisões.

\subsection{AVTC}

No sistema de teleconferência imersiva AVTC (Augmented Virtuality Tele-Conferencing) (SISCOUTTO; TORI, 2004) o apresentador é filmado por duas câmeras que geram um par estereoscópico de imagens. Essa digitalização é realizada em um estúdio com fundo azul devido o uso da técnica de chroma key para remoção do fundo.

Através do modulo de integração é possível inserir o vídeo estereoscópico no ambiente virtual 3D. Além disso, neste trabalho é apresentado um modelo de locomoção do apresentador 
definindo uma forma de comando do usuário em relação ao mundo virtual e uma proposta de sistema distribuído com um estúdio local e as salas remotas onde são detalhadas as interfaces e os protocolos envolvidos.

\subsection{Blue-C}

No trabalho desenvolvido por (GROSS et al., 2003) foi criado um ambiente de imersão do usuário constituído por três telas de projeção ativas e um sistema de captura de vídeo 3D.

É utilizada a técnica de Video-Based Visual Hull para reconstrução do modelo geométrico do usuário e splatting para renderização desse modelo.

Para obtenção das imagens do apresentador é utilizado um conjunto de quinze câmeras. Algumas filmam diretamente o alvo e outras estão posicionadas atrás das telas de projeção ativas de cristal líquido e as imagens são obtidas no momento em que as telas ficam translúcidas. Além disso, é aplicado um filtro de correção de cores nas imagens capturadas devido a variação do espectro de cor de cada uma das câmeras (REINHARD et al., 2001).

\subsection{Coliseum}

Coliseum é um sistema de teleimersão desenvolvido nos laboratórios da Hewlett-Packard (BAKER et al., 2005) para realização de vídeo-conferências com múltiplos participantes em tempo real. Para cada participante, uma representação geométrica realística é construída e inserida em um ambiente virtual. Novas perspectivas de cada usuário podem ser geradas através de um método baseado em IBVH (Image Based Visual Hull) que utiliza cinco câmeras VGA conectadas ao computador de cada participante.

As cinco câmeras são conectadas ao barramento Fire-Wire (IEEE 1394) de cada computador. Os participantes da videoconferência podem ser conectados através de uma LAN (Local Area Network) ou pela internet.

O ambiente virtual onde as representações dos usuários são inseridas foi desenvolvido com VRML (Virtual Reality Modeling Language). Foi realizada uma avaliação ponta-a-ponta das latências de cada dispositivo divida em: latência da câmera; latência de processamento; latência da rede e latência de renderização. Como resultado obteve-se uma taxa média de 16,3 quadros por segundo. 


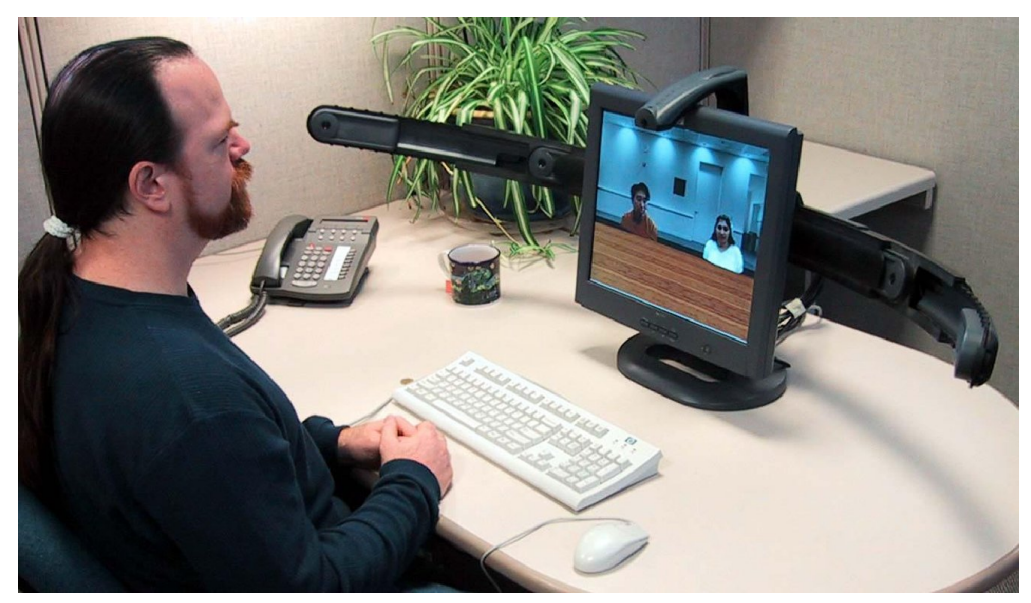

Figura 3.2: Infraestrutura de hardware do Coliseum (BAKER et al., 2005)

\subsection{D Video Avatar}

O sistema 3D Video Avatar (LEE et al., 2005) é uma aplicação de teleimersão onde o usuário é inserido em um estúdio cercado por telas de projeção. O processo responsável pela reconstrução do avatar tridimensional no ambiente virtual utiliza a técnica de IBVH, mesma técnica utilizada no Coliseum. O servidor onde esse processo é executado recebe os fluxos de vídeo de múltiplas câmeras e utiliza a GPU para realizar o processamento do algoritmo de reconstrução pela técnica de Visual Hull em tempo real.

Além disso, é utilizado um método de segmentação com câmera infravermelho para remoção do fundo e uma técnica de iluminação ativa onde apenas o corpo do participante é iluminado no intuito de obter a textura, sem abrir mão do ambiente imersivo de CAVE (Cave Automatic Virtual Environment).

\subsection{Kinect Fusion}

O projeto Kinect Fusion (IZADI et al., 2011) descreve um sistema capaz de reconstruir, de forma incremental, a geometria dos elementos encontrados em um ambiente interno, como por exemplo, um escritório. O usuário manipula o equipamento Kinect varrendo o ambiente e através dos dados capturados pela câmera de profundidade desse hardware, é renderizada gradualmente uma representação geométrica tridimensional do ambiente. Ao final da varredura manual da cena, uma representação tridimensional precisa e completa do ambiente é obtida.

O processo de geração da representação geométrica é composto pelas seguintes etapas:

1. Conversão do mapa de profundidade em nuvem de pontos tridimensionais: 
O vetor com a distância, para cada pixel, entre o objeto e o Kinect é convertido em uma nuvem de pontos 3D no sistema de coordenadas da câmera interna do Kinect.

2. Registro dos mapas de profundidade:

Nessa etapa é calculada a função de transformação necessária para alinhar o mapa de profundidade (nuvem de pontos) corrente com o mapa global que foi incrementado no último quadro, através da técnica de ICP (Iterative Closest Point) implementada na GPU.

3. Integração volumétrica:

Ao invés de fundir nuvens de pontos ou criar um mesh, é utilizada uma representação volumétrica da superfície baseada em árvore de voxels. Cada voxel é então atualizado iterativamente, ou seja, a cada nova medida é recalculada a distância média desse voxel.

4. Aplicação da técnica de Raycasting:

Dada a árvore de voxels obtida na etapa anterior, através da técnica de raycasting, são renderizados novos pontos de vista de superfícies implícitas. Através dessas novas superfícies é obtido um mapa de profundidade sintético que pode ser utilizado como base para a próxima iteração do ICP, melhorando a qualidade do modelo geométrico global de forma incremental.

\subsection{Kinect 3D Video Capture}

O sistema de captura de vídeo 3D (KREYLOS, 2011), utiliza o fluxo de dados de profundidade e o de textura gerados pelo Kinect para produzir um vídeo 2,5D em tempo real da cena que está sendo filmada. Além do modo de execução com apenas um Kinect, esse sistema suporta múltiplos Kinects.

Para gerar o vídeo 3D, os seguintes passos são necessários:

- Alinhamento da textura com mapa de profundidade. Como a câmera de profundidade e a câmera RGB do Kinect estão a alguns centímetros uma da outra, através de calibragem com marcador fiducial móvel é calculada a função de transformação para projetar a textura no mapa de profundidade. Nesta primeira calibragem, o marcador é identificado manualmente pelo usuário no mapa de profundidade e na imagem colorida (figura 3.3);

- No caso da utilização de múltiplos Kinects, é utilizado um marcador fiducial (tabuleiro de xadrez) fixo que é capturado por cada Kinect em seu ponto de vista. É então calculada 


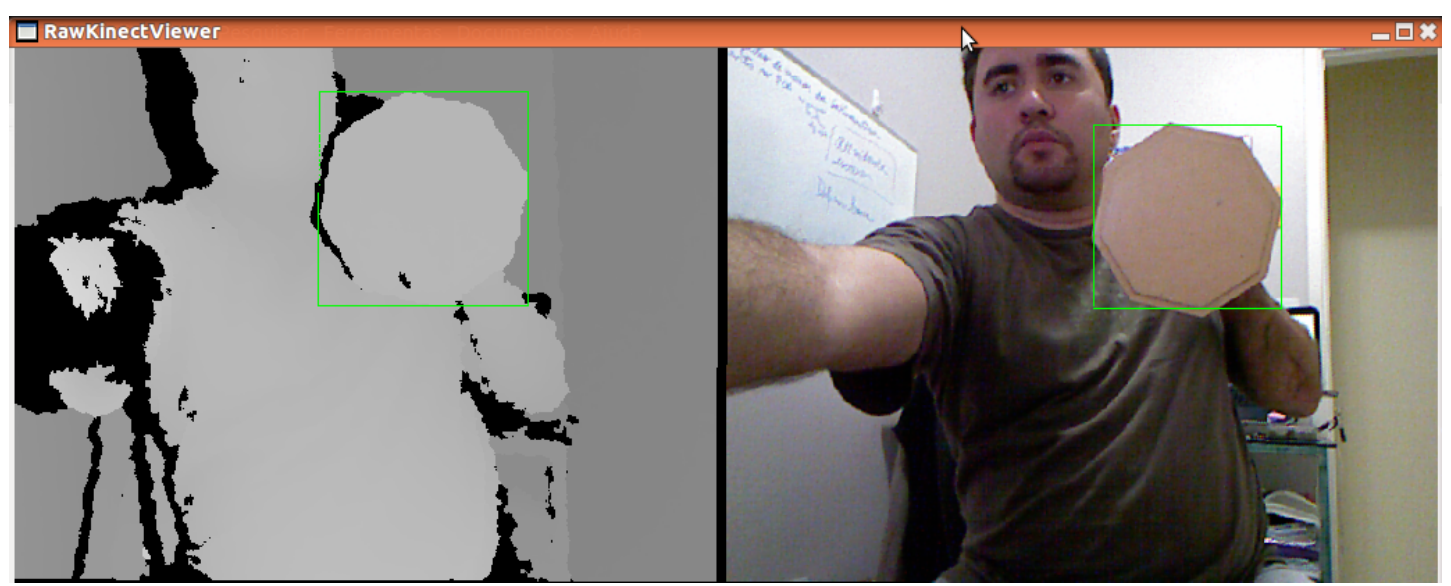

Figura 3.3: Calibração manual com objeto de marcação da imagen obtida pela câmera RGB e pelo sensor de profundidade do Kinect (KREYLOS, 2011).

uma função de transformação para cada Kinect que converte do sistema de coordenadas local para um sistema de coordenadas global.

\subsection{KinectRGBDemo}

No sistema KinectRGBDemo (BURRUS, 2011) foram desenvolvidas algumas funcionalidades com o equipamento Kinect, dentre elas, tendo em vista o objetivo deste trabalho, destacamse:

- Reconstrução tridimensional de cena varrendo o ambiente manualmente movendo o Kinect (semelhante ao KinectFusion).

- Reconstrução tridimensional de objetos integrando múltiplos Kinects em posições fixas.

Marcadores fiduciais foram utilizados para alinhar a imagem da textura colorida com o mapa de profundidade. Além disso, para integrar os dois Kinects foi utilizado um método híbrido, onde os dois modelos geométricos são alinhados manualmente pelo usuário, através de um ajuste visual onde o usuário rotaciona e translada cada nuvem até que ambas fiquem visualmente alinhadas.

Após essa calibração manual, há um refinamento do alinhamento das nuvens através de registro com ICP. 


\subsection{Técnicas de Reconstrução com Suporte Rotativo}

Outra forma de gerar uma reconstrução geométrica completa de um objeto rígido é utilizar um sensor de profundidade em posição fixa e um suporte rotativo onde é colocado o modelo real a ser digitalizado (figura 3.4).

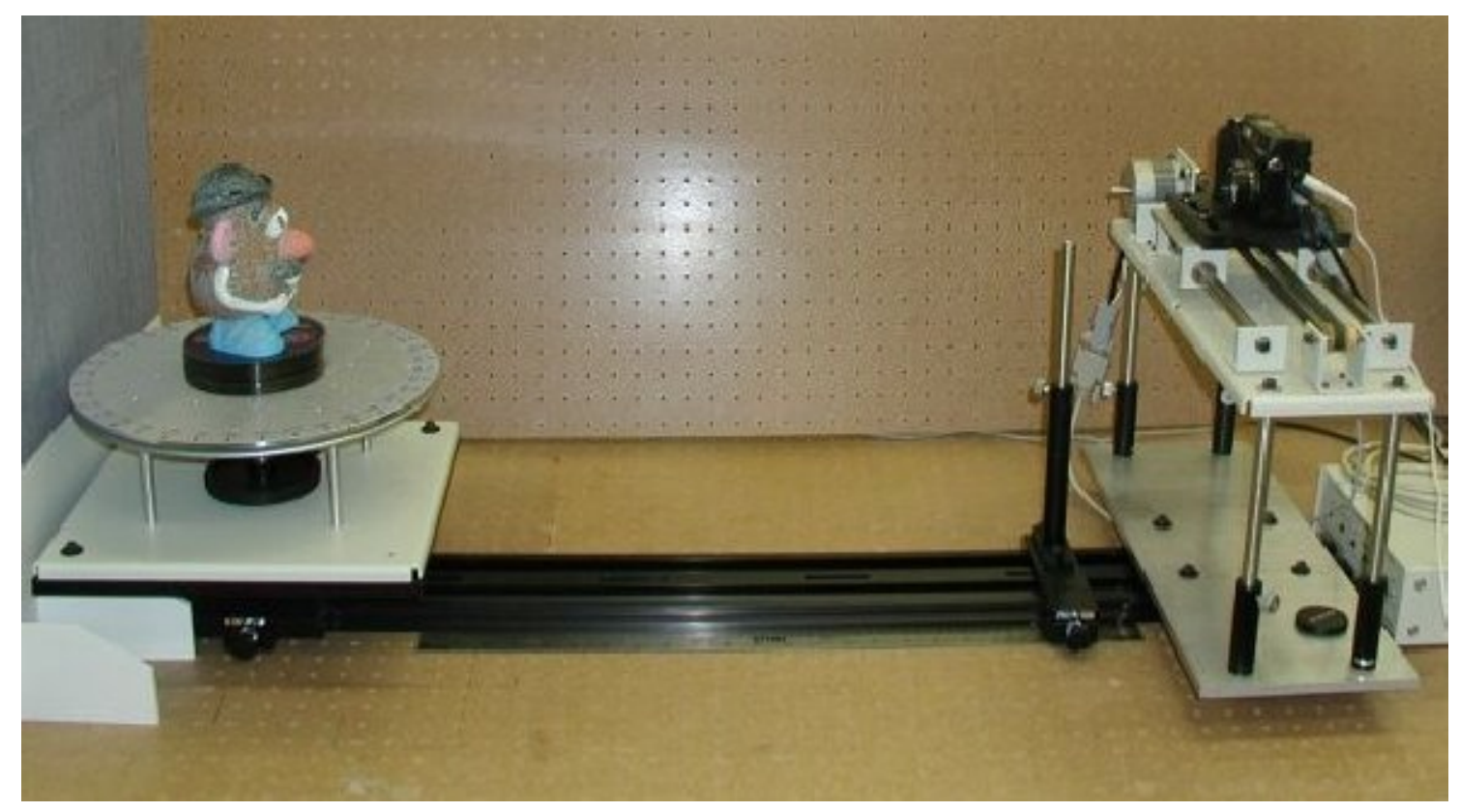

Figura 3.4: Técnica com suporte rotativo (LIN; SUBBARAO, 2001)

No trabalho de (LIN; SUBBARAO, 2001) é utilizado esse arranjo de equipamentos com suporte giratório. Uma função de rotação registra globalmente as nuvens de pontos capturadas em um conjunto de ângulos pré-definidos e então é gerada a representação geométrica completa do modelo.

Exite outro trabalho semelhante (LIU, 2005) onde foi utilizado um sensor de profundidade em posição fixa baseado na técnica de visão estéreo com três câmeras (digiclops) e um modelo em movimento diante do sensor. Nesse sistema, foi utilizado o algoritmo de ICP para registrar as informações adquiridas incrementalmente no modelo global.

\subsection{Comparação entre Técnicas}

Os sistemas apresentados neste capítulo serão comparados de acordo com a técnica de reconstrução geométrica utilizada para gerar o modelo da superfície. Além disso, serão listados os equipamentos utilizados e o setup desses dispositivos indicando se podem ser instalados e removidos de forma portátil ou se é necessário um estúdio com estruturas fixas. 
Tabela 3.1: Trabalhos relacionados e técnicas utilizadas.

\begin{tabular}{|c|c|c|c|c|c|c|c|}
\hline SISTEMA & TÉCNICA & INFRA & SETUP & $\begin{array}{l}\text { TEMPO } \\
\text { REAL }\end{array}$ & ALVO & CALIBRAÇÃO & SAÍDA \\
\hline AVMix & $\begin{array}{l}\text { stereo-vision } \\
\text { reconstruction }\end{array}$ & 2 webcams & portátil & sim & deformável & manual & $2,5 \mathrm{D}$ \\
\hline AVTC & estereoscopia & 2 câmeras & portátil & $\operatorname{sim}$ & deformável & manual & $2 \mathrm{D}$ \\
\hline Blue-C & visual hull & 15 câmeras & fixo & sim & deformável & manual & $3 \mathrm{D}$ \\
\hline Coliseum & visual hull & 5 webcams & fixo & $\operatorname{sim}$ & deformável & manual & $2,5 \mathrm{D}$ \\
\hline $\begin{array}{l}\text { 3D Video } \\
\text { Avatar }\end{array}$ & visual hull & $\begin{array}{l}\text { câmeras } \\
\text { RGB e IR }\end{array}$ & fixo & sim & deformável & manual & $3 \mathrm{D}$ \\
\hline $\begin{array}{l}\text { Kinect } \\
\text { Fusion }\end{array}$ & luz estruturada & 1 Kinect & portátil & $\begin{array}{l}\text { Incre- } \\
\text { mental }\end{array}$ & rígido & automática & $2,5 \mathrm{D}$ \\
\hline $\begin{array}{l}\text { 3D Video } \\
\text { Capture }\end{array}$ & luz estruturada & $\begin{array}{l}\text { Múltiplos } \\
\text { Kinects }\end{array}$ & portátil & $\operatorname{sim}$ & deformável & manual & $2,5 \mathrm{D}$ \\
\hline $\begin{array}{l}\text { Kinect RGB } \\
\text { Demo }\end{array}$ & luz estruturada & $\begin{array}{l}\text { Múltiplos } \\
\text { Kinects }\end{array}$ & portátil & sim & deformável & manual & $2,5 \mathrm{D}$ \\
\hline $\begin{array}{l}\text { Suporte Gi- } \\
\text { ratório }\end{array}$ & luz estruturada & $\begin{array}{l}\text { Range scan- } \\
\text { ner }\end{array}$ & fixo & $\begin{array}{l}\text { Incre- } \\
\text { mental }\end{array}$ & rígido & manual & $3 \mathrm{D}$ \\
\hline $\begin{array}{l}\text { Digiclops e } \\
\text { suporte ro- } \\
\text { tatório }\end{array}$ & $\begin{array}{l}\text { stereo-vision } \\
\text { reconstruction }\end{array}$ & 3 câmeras & fixo & $\begin{array}{l}\text { Incre- } \\
\text { mental }\end{array}$ & rígido & manual & $3 \mathrm{D}$ \\
\hline
\end{tabular}

A classificação em relação ao tipo de processamento da imagem sendo divido em tempo real ou incremental. Nesse segundo caso, os objetos da cena são reconstruídos incrementalmente à medida que a varredura os alcança. Quando o sistema é classificado como tendo calibração manual significa que foi necessário o uso de marcadores de calibração para determinar as posições das câmeras.

Através da análise da tabela 3.1 é possível agrupar os sistemas em três macro grupos de acordo com as principais características de cada abordagem.

1. O primeiro grupo é composto por sistemas onde é necessário o uso de um estúdio com estruturas rígidas para sustentar equipamentos como projetores e câmeras. Para realizar a reconstrução completa do modelo é necessário um setup complexo em um local reservado como estúdio de captura que mantém as câmeras em posições fixas para não se perder a calibração realizada. Enquadram-se nessa classificação Blue-C e 3D 
Video-avatar que geram como saída um modelo completo 3D;

2. No segundo grupo são apresentados sistemas que geram o modelo incrementalmente como é o caso do Kinect Fusion e das técnicas que utilizam base rotatória. Nessa abordagem não é possível obter o modelo completo da cena em um único passo;

3. No terceiro e último grupo, é gerada uma superfície $2,5 \mathrm{D}$ do objeto através de um par de câmeras estéreo ou sensores baseados na técnica de luz estruturada. Enquadram-se nesse grupo os sistemas AVTC, AVMix, Kinect RGB Demo e 3D Video-capture onde a saída é um modelo 2,5D em tempo real com setup de fácil instalação.

Este trabalho propõe uma solução intermediária que possibilita a geração de um modelo 3D (ou pelo menos um modelo 2,5D mais abrangente) semelhante às soluções do primeiro grupo, no entanto, com um setup simplificado conforme as técnicas do terceiro grupo. Para atingir esse objetivo, é necessário o uso de um mecanismo automático de registro de modelos parciais que não exija calibração manual e suporte pequenas variações no posicionamento dos equipamentos.

O Kinect Fusion possui esse mecanismo de registro automático, no entanto, não é indicada sua aplicação em sistemas de videoconferência imersiva, pois como só é utilizado um sensor, a cena é formada de forma incremental. 


\section{PROPOSTA DO SISTEMA VIDEO-AVATAR FROM MULTIPLE DEPTH MAPS}

Após a revisão das técnicas apresentadas no capítulo anterior e uma breve comparação das vantagens e desvantagens de cada uma, uma proposta de arquitetura de sistema para reconstrução geométrica da superfície do corpo humano em tempo real utilizando múltiplos sensores de profundidade denominado VMD (Video-avatar from Multiple Depth maps) é apresentada.

Na primeira seção deste capítulo é exibida uma visão geral da arquitetura de software e nos demais capítulos são detalhados cada componente.

\subsection{Módulos Propostos}

O objetivo desta arquitetura é suportar uma solução ponta a ponta de reconstrução geométrica da superfície do ser humano, começando pelos módulos de captura até a visualização da nuvem de pontos global.

Na seção 4.1.1 é apresentado o subsistema de captura de fluxo RGB e fluxo de mapa de profundidade. Na próxima seção, o módulo de remoção de fundo é detalhado. Após essa segmentação, o alinhamento das nuvens de pontos parciais é explicado na seção 4.1.4. Na última seção desse capítulo, é explanado o módulo de visualização que é responsável por renderizar o modelo geométrico final a ser visualizado pelos usuários.

Na figura 4.1, o diagrama de componentes da arquitetura proposta do sistema VMD é apresentado. 


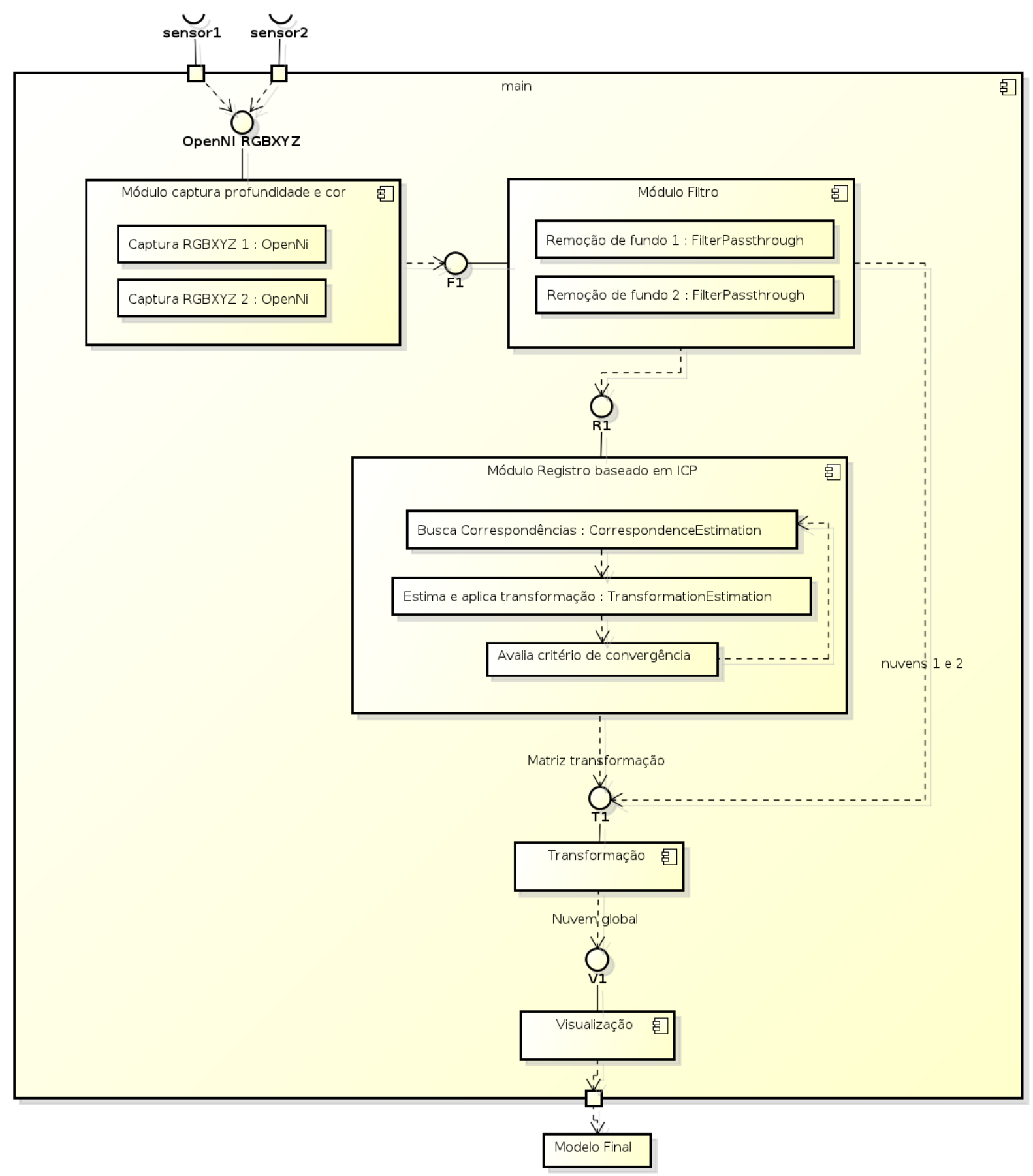

Figura 4.1: Diagrama de componentes da arquitetura VMD

Nota-se que no diagrama (figura 4.1) é apresentado apenas um par de sensores como entrada gerando um modelo 2,5D. No entanto, caso seja desejado gerar um modelo mais abrangente podendo alcançar a representação 3D, é possível utilizar mais de dois sensores, considerando que, se um enésimo novo sensor for inserido, a matriz de transformação correspondente $T_{N}$ é calculada registrando a nuvem de entrada do sensor $n$ com a nuvem composta 
pela união das $n-1$ nuvens alinhadas anteriores.

Nas demais seções deste capítulo é explicado o funcionamento de cada componente e detalhes das interfaces entre os módulos com os dados de entrada e saída de cada etapa.

\subsubsection{Aquisição de Dados de Profundidade da Superfície}

Nesta etapa que compreende o início do fluxo do sistema VMD, são capturados os dados de profundidade da superfície a ser digitalizada. É necessária a utilização de um ou conjunto de dispositivos para geração do mapa de profundidade da superfície a ser reconstruída. Nos experimentos deste trabalho foi utilizado o sensor Microsoft Kinect, conforme explicado na seção 2.2.1.

As coordenadas $(x, y, Z)$ são obtidas diretamente desse dispositivo, onde $(x, y)$ são as coordenadas horizontal e vertical do ponto com unidade de acordo com a resolução do sensor, por exemplo $640 \times 480$. O valor de Z corresponde a distância entre um ponto pertencente à superfície do objeto e o plano onde está situado o centro da lente da câmera do sensor. Esse valor normalmente é medido em metros ou milímetros. Devido à unidade utilizada no eixo $Z$ ser diferente da unidade utilizada nos eixos $x$ e y, há uma distorção no mapa de profundidade gerado (figura 4.2).

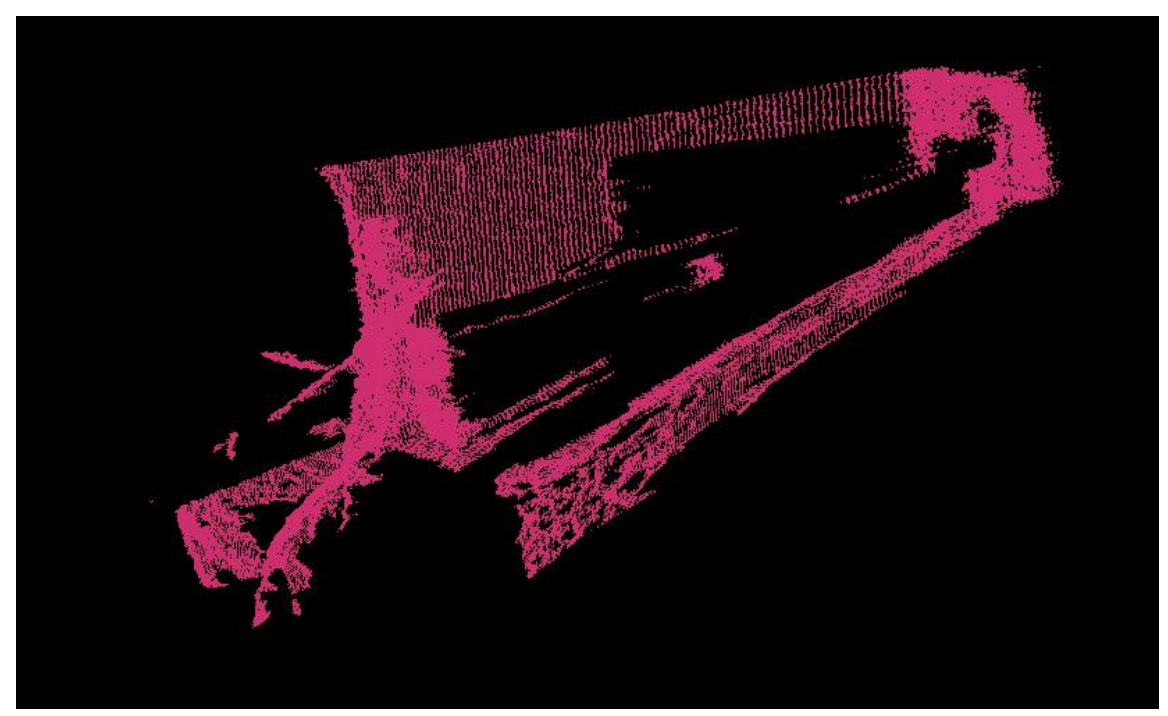

Figura 4.2: Nuvem de Pontos gerada pelo sensor sem tratamento do sistema de coordenadas $x y$.

Para calcular a nuvem de pontos projetada é necessário transformar as coordenadas $(\mathrm{x}, \mathrm{y})$ para (u,v) em milímetros, utilizando $u=f * x / z$ e $v=f * y / z$, sendo $f$ é o valor da distância 
focal da câmera IR do sensor. Nessa proposta, essa distância focal padrão do dispositivo é fornecida pela biblioteca OpenNI ou KinectSDK e é invariável. No entanto, caso se necessite de uma maior precisão considerando pequenas variações na câmera de cada dispositivo, uma possível forma é realizar um processo de calibração utilizando marcadores e a função de calibração de câmera do OpenCV.

Na figura 4.3 é exibida uma nuvem de pontos com as coordenadas $(x, y)$ transformadas em $(u, v)$.

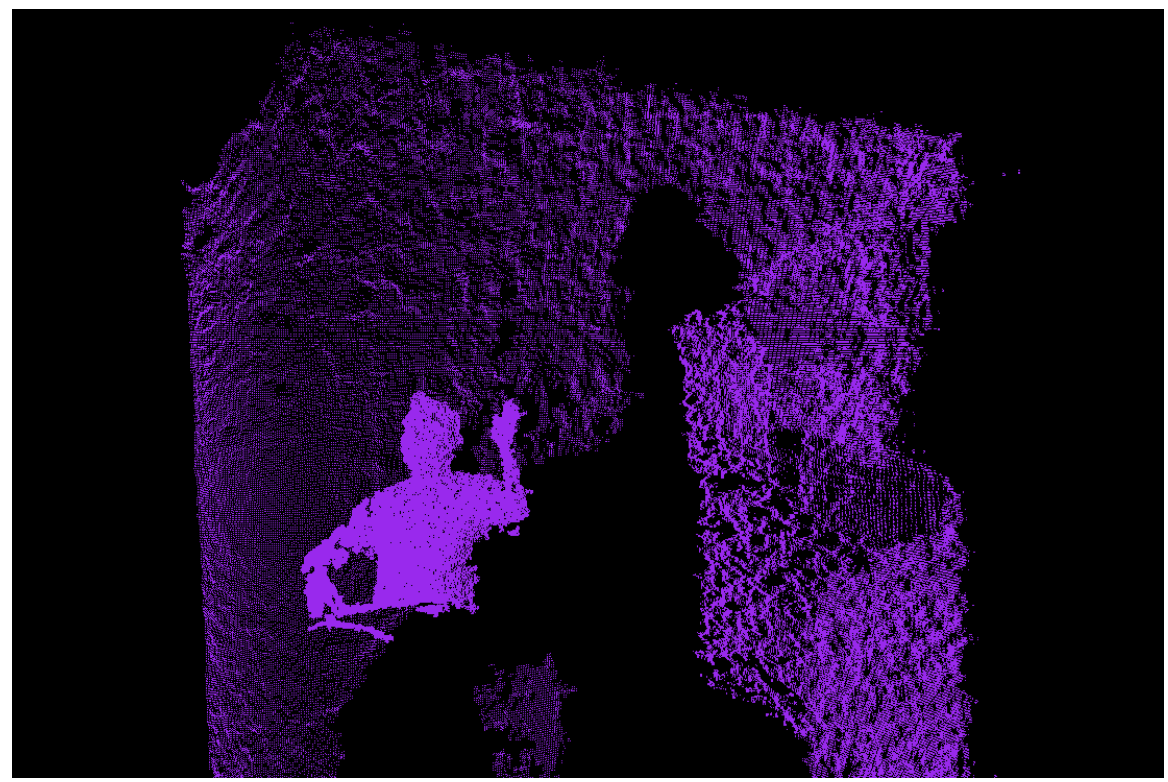

Figura 4.3: Nuvem de pontos projetada.

\subsubsection{Aquisição de Dados de Cor da Superfície}

Além do fluxo com o mapa de profundidade, o sensor Kinect também gera um fluxo RGB da cena.

Como esse dispositivo possui uma câmera responsável pelo fluxo RGB e outra câmera responsável pelo mapa de profundidade e ambas são separadas por uma distância de $2,5 \mathrm{~cm}$, a imagem RGB gerada é desalinhada em relação ao mapa de profundidade. 

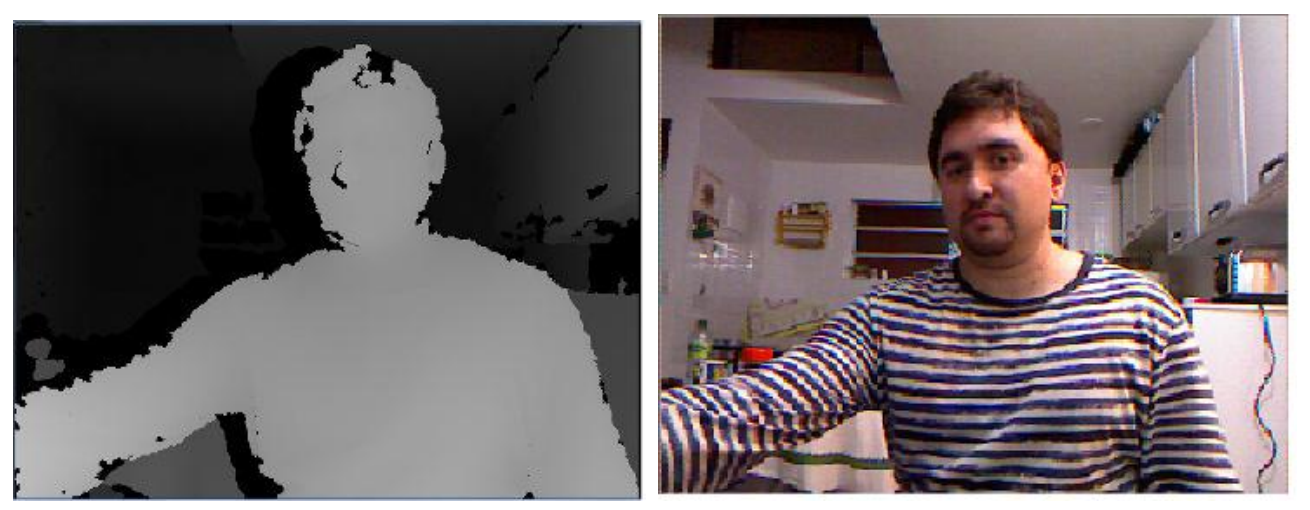

Figura 4.4: Mapa de profundidade e imagem RGB correspondente ligeiramente desalinhados.

Nessa proposta foi utilizado o modelo de câmera de orifício (GONZALEZ; WOODS, 2000) que descreve a correspondência entre as coordenadas do espaço do mapa de profundidade tridimensional $(X, Y, Z)$ e pontos da imagem RGB bidimensional $(u, v)$. Essa correspondência se dá por uma função $R^{3} \rightarrow R^{2}$.

Essa função (equação 4.1) pode ser descrita através da multiplicação das características intrínsecas $\left(f_{x}, f_{y}, c_{x}\right.$ e $\left.c_{y}\right)$ e extrínsecas $\left(r_{11}, \ldots, r_{33}\right)$ e $\left(t_{1}, t_{2}\right.$ e $\left.t_{3}\right)$ da câmera de acordo com (TSAl, 1987). A biblioteca OpenCV (OpenCV, 2012) possui um método para estimar esses parâmetros utilizando um marcador de calibração semelhante a um tabuleiro de xadrez.

$$
\left[\begin{array}{l}
u \\
v \\
1
\end{array}\right]=\left[\begin{array}{ccc}
f_{x} & 0 & c_{x} \\
0 & f_{y} & c_{y} \\
0 & 0 & 1
\end{array}\right] *\left[\begin{array}{llll}
r_{11} & r_{12} & r_{13} & t 1 \\
r_{21} & r_{22} & r_{23} & t 2 \\
r_{31} & r_{32} & r_{33} & t 3
\end{array}\right] *\left[\begin{array}{c}
X \\
Y \\
Z
\end{array}\right]
$$

Uma possível técnica de visualização de nuvens de pontos com informação RGB é exibida na figura 4.5 e é explicada na seção 4.1.5. Para cada ponto $\overrightarrow{p_{i}}$ foi obtida a respectiva cor através da projeção da imagem RGB correspondente. 


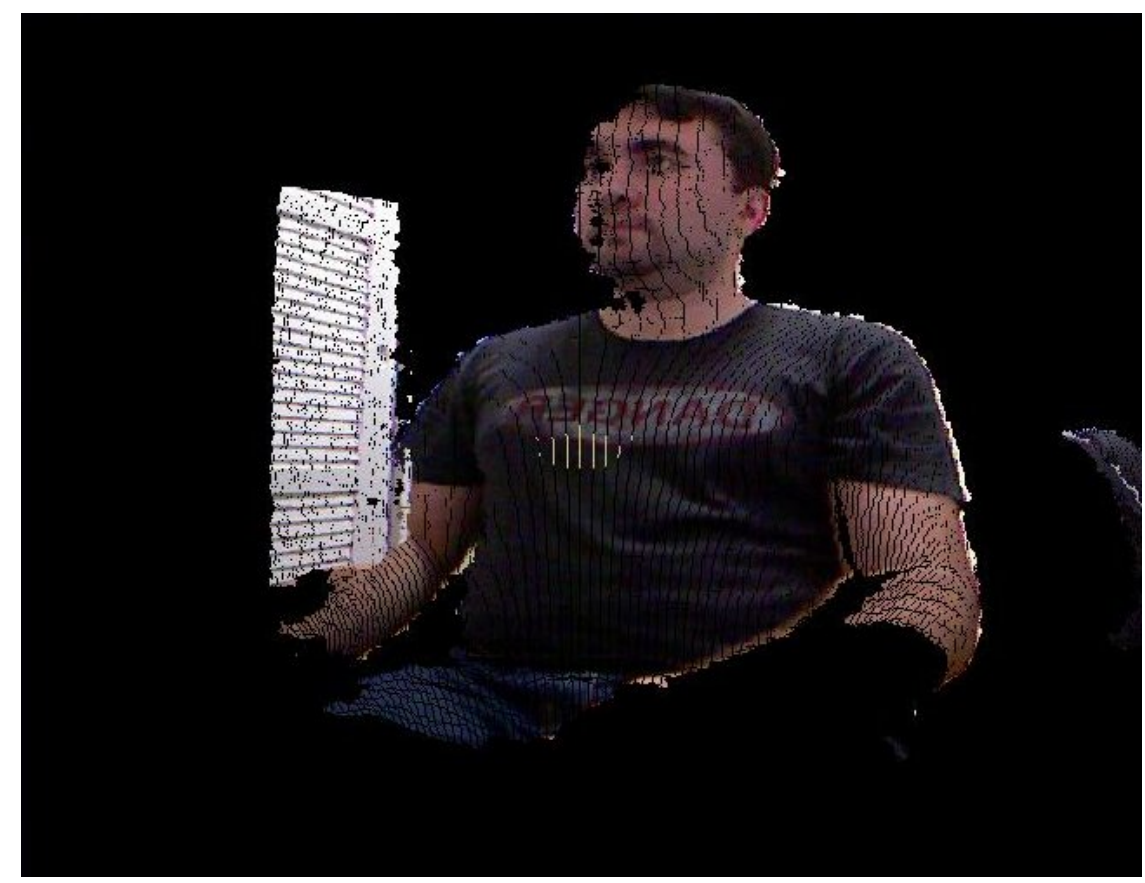

Figura 4.5: Textura RGB projetada na nuvem de pontos.

\subsubsection{Remoção de Fundo}

No caso específico do SDK da Microsoft, no fluxo de mapa de profundidade é fornecido, para cada coordenada $(\mathrm{x}, \mathrm{y})$, um atributo de classificação que indica se o ponto pertence a um determinado jogador ou a alguma parte do cenário. Esse indicador pode ser utilizado para remoção do fundo.

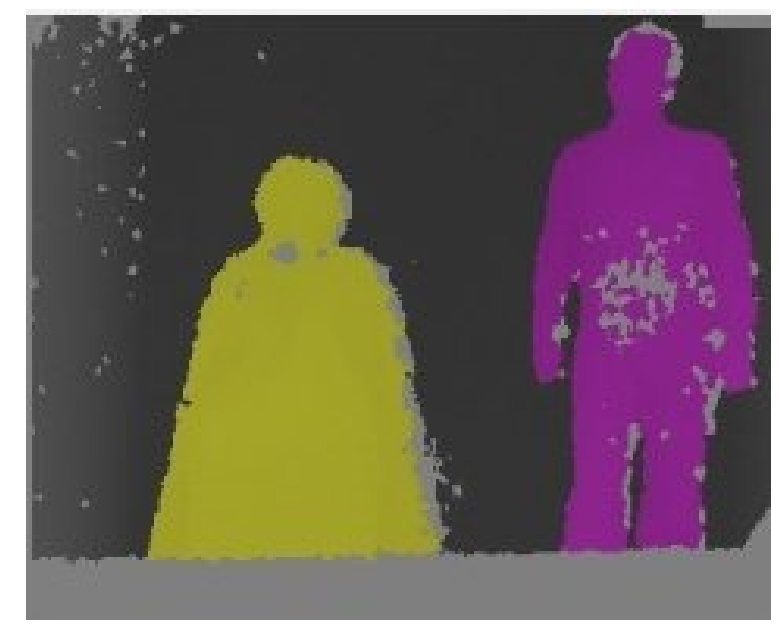

Figura 4.6: Segmentação nativa do SDK do Kinect.

Como foi utilizada a biblioteca OpenNI (em substituição ao SDK da Microsoft) na proposta 
final deste trabalho, o uso do algoritmo de remoção de fundo baseado em limiar de distância foi escolhido para classificar quais pontos pertencem ao usuário e remover aqueles pertencentes ao fundo devido à simplicidade e desempenho inerentes a esse método que atendem ao primeiro objetivo secundário apresentado em 1.1.

Também conhecido como filtro passa-faixa, esse algoritmo remove os pontos que não estão no intervalo de 0,5 a 2,0 metros de distância do sensor em relação ao eixo $z$ e entre -0,9 e 0,9 metros em relação ao eixo $x$, o que acarreta na remoção de fundo no caso de ambientes pequenos ou com mobília próxima ao usuário.

\subsubsection{Registro das Superfícies Parciais}

Para gerar um modelo geométrico único integrando múltiplas nuvens de pontos desalinhadas obtidas por sensores posicionados em diferentes posições é necessário realizar o registro.

Recapitulando a seção de fundamentação de registro 2.1.3, para registrar um par de nuvens de pontos desalinhadas existem três formas: duas delas sendo classificadas como calibração manual, dado que o usuário precisa identificar pontos correspondentes nos modelos desalinhados, e a outra terceira forma, que consiste no processo automático de registro, ou seja, o próprio sistema encontra as correspondências sem a intervenção manual do usuário através de algoritmos de varredura e busca.

O método ICP (Iterative Closest Point) cujo algoritmo inicial foi criado por (BESL; McKay, 1992), atende ao segundo objetivo secundário apresentado no capitulo 1.1, referente a simplicidade na etapa de calibração das câmeras. As técnicas de registro utilizadas nos demais trabalhos relacionados não o atendem, visto que é necessária, em algum momento, a etapa de calibração manual.

O algoritmo de Iterative Closest Point e variações do mesmo, no sentido de torná-lo mais performático, são opções automáticas para encontrar a função de transformação que registra um par de nuvens de pontos desalinhadas em um modelo global consistente. Devido a essa característica de não necessitar de atividade manual do usuário e de marcadores específicos, esse algortimo (detalhado na seção 2.1.3) foi escolhido para ser utilizado no VMD.

Essa técnica compara duas nuvens de pontos capturadas por ângulos distintos de um mesmo objeto de interesse (com sobreposição) e determina a matriz de transformação que rotaciona e translada a segunda nuvem fazendo com que ela se alinhe com a primeira.

Na figura 4.7 é apresentado o diagrama de sequência do algoritmo de registro utilizado que 
descreve os passos envolvidos no subsistema de alinhamento das superfícies parciais. Detalhes de implementação das funções correspondencias() e calculaTransformação() são apresentadas em 2.1.3.

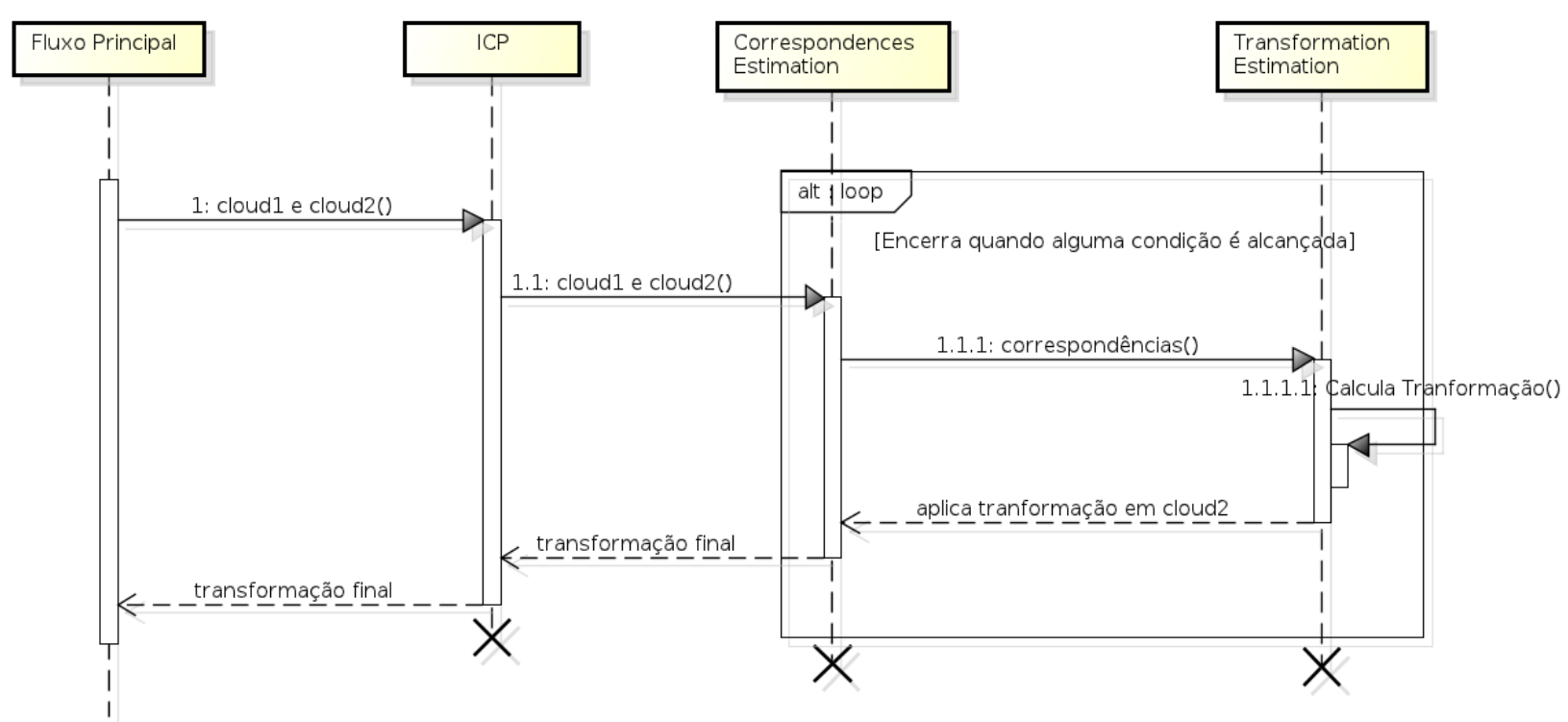

Figura 4.7: Diagrama de sequência da variante do algoritmo de registro utilizado nesse trabalho.

Como se pode notar no diagrama (figura 4.7), para cada iteração, é estimado um conjunto de pares de pontos correspondentes entre as duas nuvens, encontrados através da menor distância euclidiana. Então, a transformação (matriz de rotação e translação) que alinha as duas nuvens é estimada, dado o conjunto de pontos correspondentes e a transformação anterior.

Para avaliação se a convergência foi alcançada, são definidos os seguintes valores pelo usuário:

- Número máximo de iterações;

- Máxima distância euclidiana aceita entre um par de pontos correspondentes;

- Diferença mínima entre duas transformações consecutivas (a partir desse valor é considerado que a convergência foi alcançada);

- Valor mínimo da soma dos quadrados da distância euclidiana entre pixels correspondentes (a partir desse valor é considerado que a convergência foi alcançada). 


\subsubsection{Visualização}

O módulo de visualização é responsável pela última etapa do fluxo do sistema VMD e corresponde a renderização do modelo geométrico gerado.

Nos experimentos deste trabalho foi utilizada a renderização de pontos com informação de cor RGB sem malha poligonal. Devido a baixa complexidade desse algoritmo, seu desempenho é melhor em relação às técnicas de malha de polígonos. A desvantagem dessa técnica é que ao visualizar o modelo de um ponto de vista mais próximo ou lateral é possível de perceber que os pontos estão desconectados.
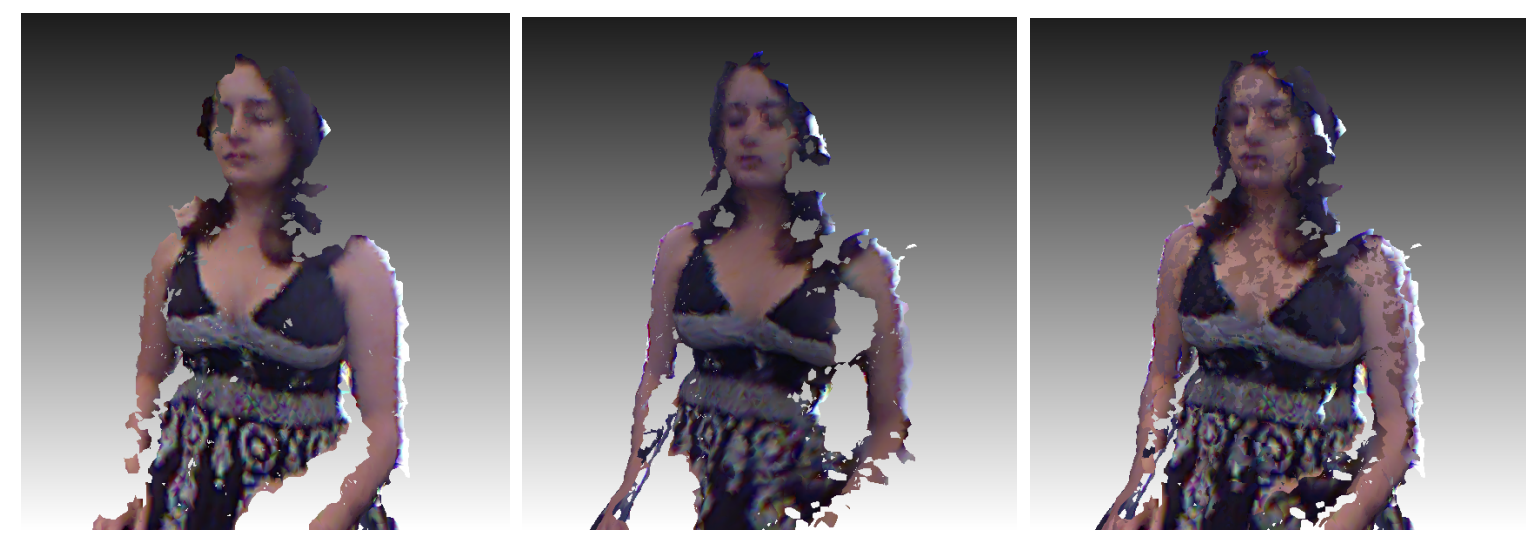

Figura 4.8: Imagem da esquerda nuvem (a) obtida pelo Kinect 1, imagem central nuvem (b) obtida pelo Kinect 2 a $120 \mathrm{~cm}$ e imagem da direita nuvem (c) resultado da fusão das nuvens (a) e (b).

Nota-se na imagem (c) (figura 4.8) pequenas variações de cor distribuídas pela imagem. Isso se deve a diferença no espectro de cores das câmeras RGB dos Kinects 1 e 2. No Blue-C (NAEF; STAADT; GROSS, 2004) esse comportamento foi tratado através da aplicação de filtro de correção de cor (REINHARD et al., 2001). 


\section{EXPERIMENTO DE MEDIÇÃO DE RUÍDOS UTILIZANDO DOIS KINECTS}

Devido à técnica de reconstrução geométrica utilizada pelo sensor Kinect ser baseada em projeção de luz difusa, nas regiões do objeto alvo em que os padrões IR projetados por dois Kinects se sobrepõem ocorrem interferências. Esses ruídos são constatados nos mapas de profundidade gerados por cada equipamento.

\subsection{Metodologia}

Esse experimento inicial tem como intuito medir o nível de interferência ocasionado pela adição de um segundo Kinect na mesma cena.

Para este experimento, foram utilizados dois Kinects e um computador pessoal com processador dual-core e 4GB de RAM. O primeiro ponto relevante constatado foi que cada Kinect consome aproximadamente $60 \%$ da banda do barramento USB, desta forma, foi necessário o uso de uma placa controladora USB complementar para receber os fluxos de dados provenientes dos dois sensores em um único computador.

Foi desenvolvida uma aplicação com o SDK da Microsoft (MICROSOFT, 2011) para capturar o fluxo de profundidade do Kinect e renderizá-lo em níveis de cinza. Além disso, foi utilizada uma câmera capaz de capturar luz infravermelha para visualizar o padrão emitido pelo emissor IR do Kinect. O próximo passo foi definir as posições dos sensores e preparar um modelo próximo da forma humana (figura 5.1).

O primeiro Kinect foi mantido em uma posição fixa voltada para o modelo. Um segundo sensor foi inserido no ambiente no intuito de projetar seu padrão sobrepondo a área do primeiro sensor. A posição do segundo equipamento foi alterada em cada cenário e uma foto do mapa de profundidade foi capturada através do primeiro sensor em cada posição. 

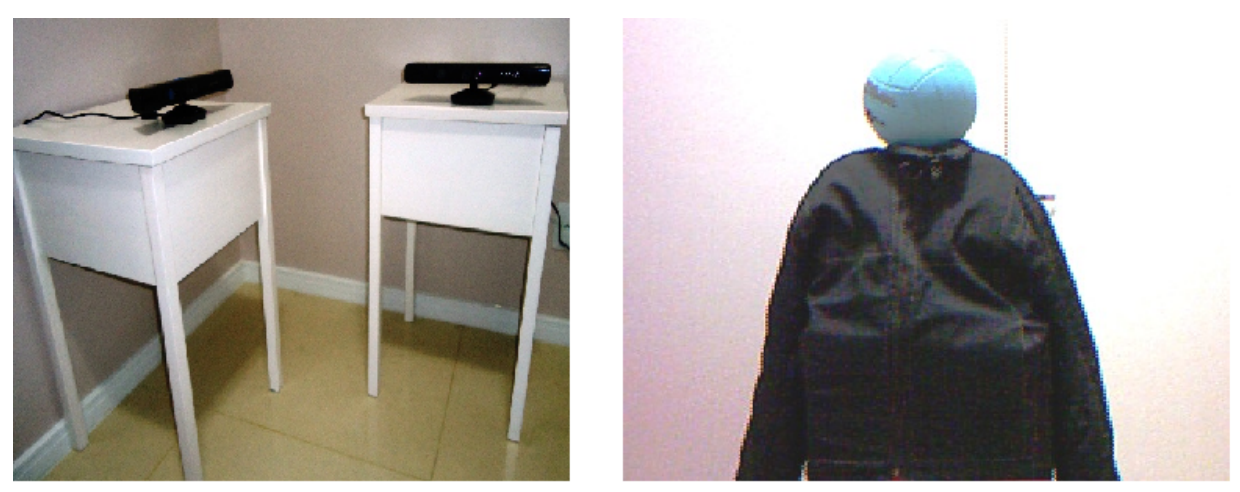

Figura 5.1: Arranjo de equipamentos com dois Kinects e um modelo.

O segundo sensor Kinect foi colocado em dez posições, no mesmo plano do primeiro (paralelo ao solo), sempre voltado para o mesmo objeto alvo, formando os ângulos de $10^{\circ}$, $15^{\circ}, 30^{\circ}, 45^{\circ}, 60^{\circ}, 75^{\circ}, 90^{\circ}, 120^{\circ}, 150^{\circ}$ e $180^{\circ}$ em relação ao primeiro sensor.

Tabela 5.1: Situação e posição de cada Kinect.

\begin{tabular}{cc}
\hline \hline IMAGE & POSIÇÃO E SITUAÇÃO DOS SENSORES \\
\hline Image 1 & Primeiro Kinect ligado, segundo desligado \\
Image 2 & Ambos sensores ligados posicionados a $10^{\circ}$ \\
Image 3 & Ambos sensores ligados posicionados a $15^{\circ}$ \\
Image 4 & Ambos sensores ligados posicionados a $30^{\circ}$ \\
Image 5 & Ambos sensores ligados posicionados a $45^{\circ}$ \\
Image 6 & Ambos sensores ligados posicionados a $60^{\circ}$ \\
Image 7 & Ambos sensores ligados posicionados a $75^{\circ}$ \\
Image 8 & Ambos sensores ligados posicionados a $90^{\circ}$ \\
Image 9 & Ambos sensores ligados posicionados a $120^{\circ}$ \\
Image 10 & Ambos sensores ligados posicionados a $150^{\circ}$ \\
Image 11 & Ambos sensores ligados posicionados a $180^{\circ}$ \\
\hline
\end{tabular}

A imagem 1 (mapa de profundidade sem interferência, pois o segundo sensor estava desligado) foi comparada com as dez outras imagens com interferência. Como o padrão de luz é constante ao longo do tempo, o manequim estático pode ser utilizado no lugar de um modelo em movimento.

Outro ponto relevante referente à preparação do ambiente é a distância entre os dois sensores e o modelo. Neste experimento, foi escolhida a distância de 1,20 metros que corresponde a um ponto médio da faixa operacional do Kinect. 


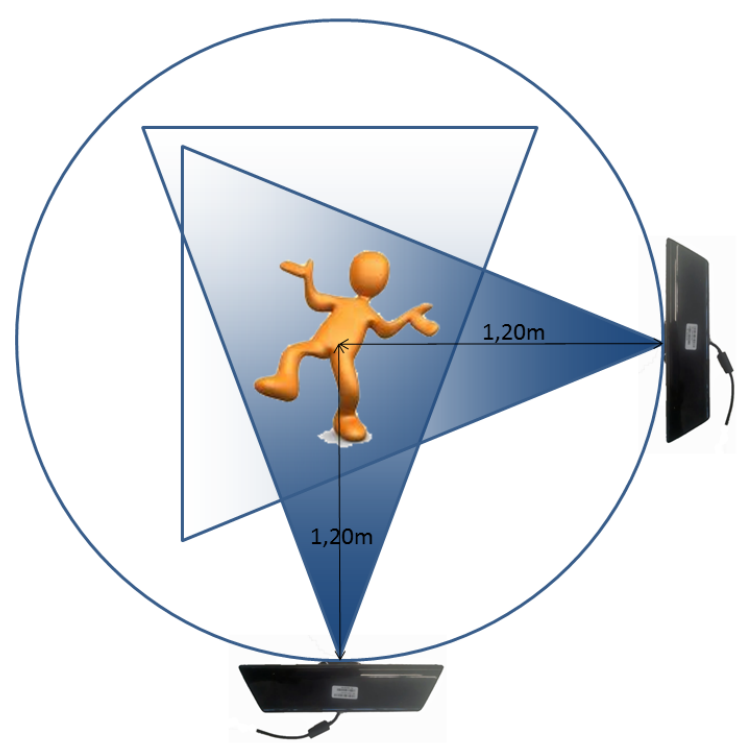

Figura 5.2: Diagrama representando a configuração de $90^{\circ}$ entre os dois Kinects.

Para medição do nível de interferência dos dispositivos baseados na técnica de luz estruturada foram utilizados algoritmos de cálculo de erro entre um par de imagens que consistem em percorrer cada pixel de uma imagem e comparar com seu respectivo pixel na outra imagem utilizando alguma função de comparação.

Existem vários algoritmos de cálculo de erro entre duas imagens semelhantes, para este trabalho, foram escolhidos PBMP (Percentage of Bad Matching Pixels) equação 5.1 (SCHARSTEIN; SZELISKI, 2002) e MAE (Mean Absolute Error) equação 5.2 (WANG et al., 2004) para comparar as imagens obtidas nesse experimento.

PBMP: Percentage of Bad Matching Pixels

$$
P=\frac{1}{N} \sum_{(x, y)}\left(\left|d_{C}(x, y)-d_{T}(x, y)\right|>\delta_{d}\right)
$$

$N$ é o número total de pixels $(N=x \times y), d_{C}(x, y)$ é o valor do nível de cinza (valor entre 0 e 255) para coordenada $(x, y)$ da imagem computada, $d_{T}(x, y)$ é o valor do nível de cinza da imagem de referência (ground truth), $\delta_{d}$ é uma tolerância de erro de disparidade. Nos experimentos, foi utilizado $\delta_{d}=4.0$ (4 de 255 níveis de cinza), este valor foi empiricamente escolhido comparando alguns pares de imagens capturadas apenas com o primeiro Kinect ligado em diferentes instantes. 
MAE: Mean Absolute Error

$$
M=\frac{\sum_{(x, y)}\left|d_{C}(x, y)-d_{T}(x, y)\right|}{N}
$$

Para apresentar o erro médio absoluto em porcentagem, o resultado foi multiplicado por $100 / 255$.

\subsection{Resultados}

Nesta seção são apresentados os resultados do experimento, uma análise quantitativa sobre os números extraídos, uma análise qualitativa sobre as imagens capturadas e por último, as implicações dos resultados.

A imagem 1 referente ao mapa de profundidade obtido pelo primeiro Kinect com o segundo desligado, foi comparada com as demais imagens (imagem 2 até imagem 11) referente ao mapa de profundidade obtido pelo primeiro sensor com o segundo equipamento também ativo. Foi desenvolvida uma aplicação que realizou a comparação entre duas imagens calculando MAE e PBMP.

Tabela 5.2: Dados obtidos no experimento de medição de ruídos.

\begin{tabular}{ccc}
\hline Ângulo & PBMP & MAE \\
\hline $10^{\circ}$ & $2,27 \%$ & $0,69 \%$ \\
$15^{\circ}$ & $2,10 \%$ & $0,69 \%$ \\
$30^{\circ}$ & $1,70 \%$ & $0,46 \%$ \\
$45^{\circ}$ & $1,53 \%$ & $0,43 \%$ \\
$60^{\circ}$ & $1,55 \%$ & $0,43 \%$ \\
$75^{\circ}$ & $1,98 \%$ & $0,48 \%$ \\
$90^{\circ}$ & $3,09 \%$ & $0,64 \%$ \\
$120^{\circ}$ & $3,60 \%$ & $1,79 \%$ \\
$150^{\circ}$ & $0,97 \%$ & $0,95 \%$ \\
$180^{\circ}$ & $0,62 \%$ & $0,21 \%$ \\
\hline
\end{tabular}

O gráfico 5.3 apresenta os números gerados por essa aplicação. 


\section{Medição de ruído}

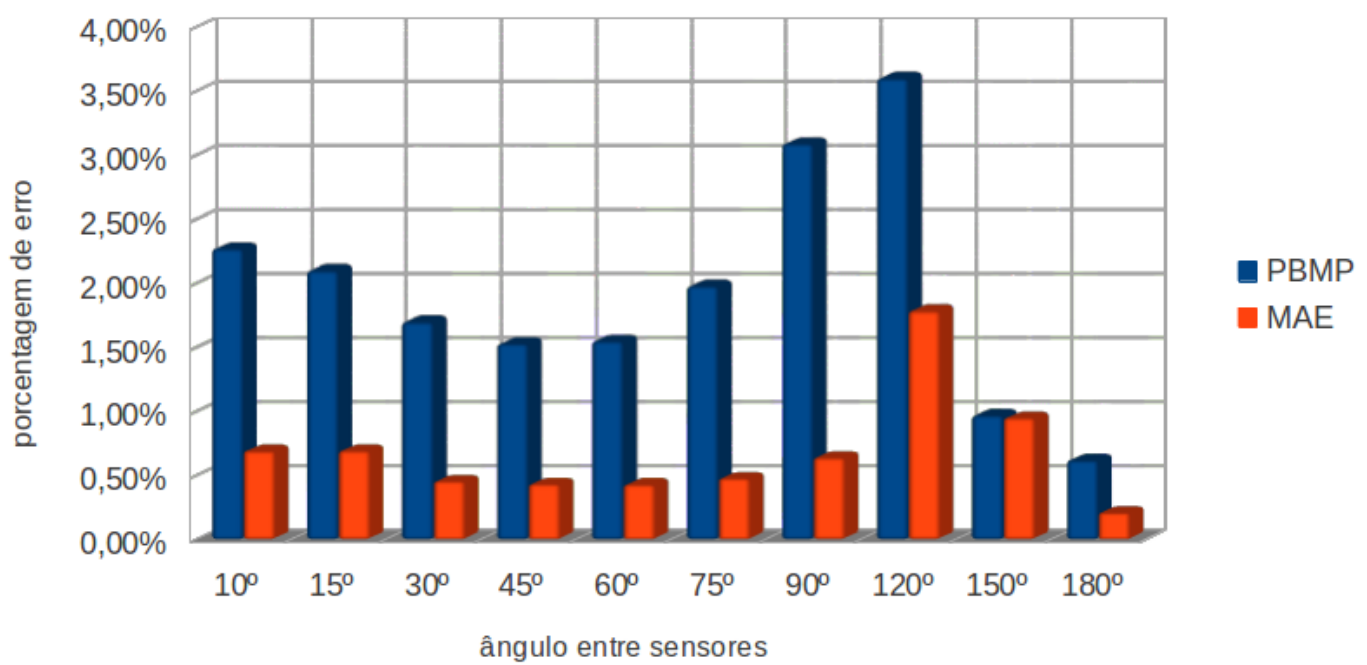

Figura 5.3: Gráfico de barras com os valores de erro calculados.

De acorco com a tabela 5.2, nas configurações com o ângulo menor que $75^{\circ}$, o valor de PBMP é menor que 2.5\%. Quando o ângulo é aumentado, um valor máximo de erro de 3.6\% é observado, na configuração com $120^{\circ}$. Para entender o motivo desses valores, foi realizada uma análise qualitativa das imagens em busca das zonas de sombra.

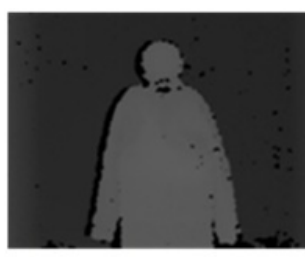

(a)

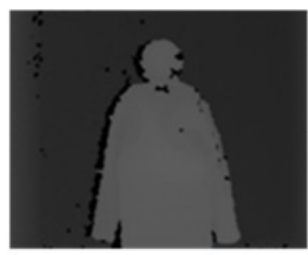

(g)

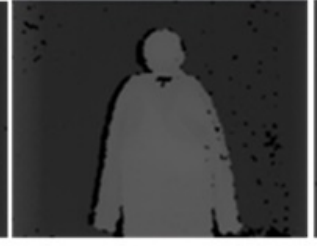

(b)

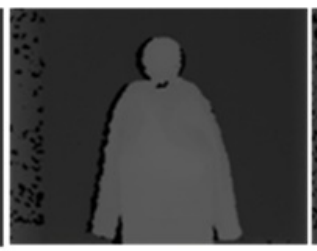

(h)

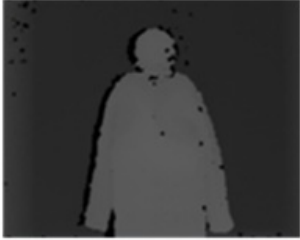

(c)

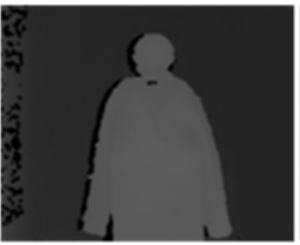

(i)

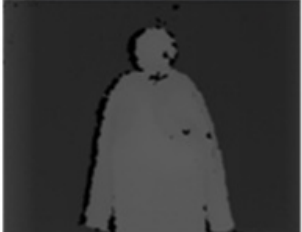

(d)

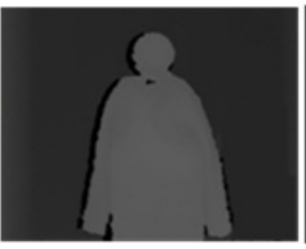

(j)

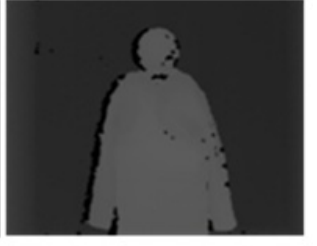

(f)

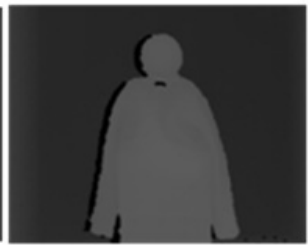

$(\mathrm{k})$

Figura 5.4: Imagens (a),(b),(c),(d),(f),(g),(h),(i),(j) e (k) correspondem aos mapas de profundidade capturados nos ângulos de $10^{\circ}, 15^{\circ}, 30^{\circ}, 45^{\circ}, 60^{\circ}, 75^{\circ}, 90^{\circ}, 120^{\circ}, 150^{\circ}$ e $180^{\circ}$ respectivamente.

As zonas de oclusão nos mapas de profundidade são renderizados em preto. Para todas situações, o valor do MAE é menor do que $1,785 \%$ com o valor máximo no ângulo de $120^{\circ}$ como mencionado anteriormente. Nas imagens (g),(h) e (i), é possível perceber uma faixa de 
oclusão na parte esquerda da imagem, esta faixa ocorre devido ao padrão de luz do segundo Kinect, que é refletido na parede, gerando um maior valor de erro. Se a análise se prender apenas ao modelo, não existem muitos pontos de oclusão nesses três mapas de profundidade. Além disso, é possível notar que nas configurações com $10^{\circ}, 15^{\circ}$ e $75^{\circ}$ há mais zonas de sombra no modelo do que em outras configurações.

Outro ponto relevante é quando o segundo Kinect é posicionado a $150^{\circ}$ e $180^{\circ}$. Nessas configurações não se nota muito ruído, devido ao padrão projetado do segundo Kinect não refletir em uma área visível ao primeiro sensor.

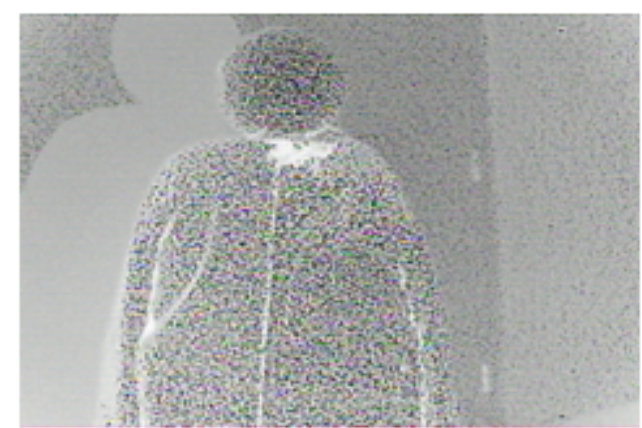

(a)

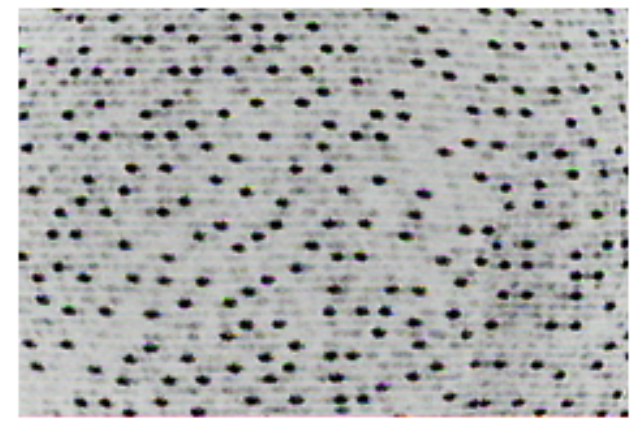

(c)

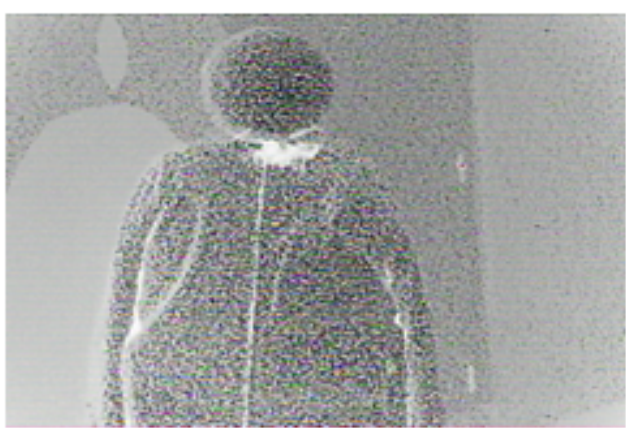

(b)

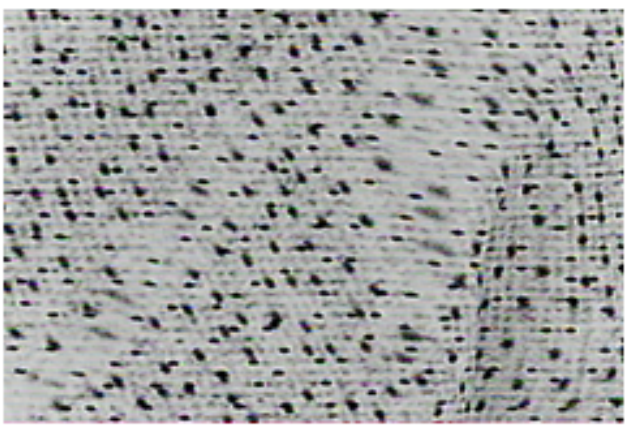

(d)

Figura 5.5: Padrão gerado pelo LED do Kinect capturado por uma câmera IR. A imagens (a) e (c) se referem às nuvens de pontos com apenas um Kinect ligado, (b) e (d) mostram o mesmo modelo com dois Kinects ativos posicionados a um ângulo de $30^{\circ}$. Imagens (c) e (d) são áreas aumentadas de $(\mathrm{a})$ e (b) respectivamente.

Através dessas imagens, pôde ser constatado que quando ambos Kinects estão ligados o padrão de luz projetado é mais denso. Na imagem (d) capturada com os dois Kinects, o padrão é duas vezes mais denso do que (c).

\subsection{Análise dos Resultados}

O valor máximo da interferência gerada pela inserção do segundo Kinect foi de 3,6\% utilizando o método de PBMP. Além disso, não foi constatada variação significante de ruído alterando 
o ângulo do segundo Kinect.

Conforme exibido na figura 5.5, o padrão de luz projetado é duas vezes mais denso do que na configuração com apenas um sensor ativo. No entanto, essa alteração da densidade não reflete em deformações no mapa de profundidade, exceto no que se refere aos pequenos ruídos inseridos.

Analisando as zonas de oclusão inseridas no mapa de profundidade, técnicas de preenchimento de orifícios podem ser utilizadas em uma tentativa de corrigi-las.

Os resultados desse experimento motivaram a criação da proposta VMD, visto que não foi constatada grande interferência (LEMESZENSKI; NAKAMURA, 2011). 


\section{EXPERIMENTO DE AVALIAÇÃO DO ICP UTILIZANDO DOIS KINECTS}

Um modelo geométrico da superfície de uma pessoa gerado através dos dados de profundidade capturados por um único sensor possui notáveis zonas de sombras mesmo quando visto frontalmente, devido às oclusões ocasionadas por sobreposições de partes do corpo ou pela limitação do ângulo da câmera do equipamento. Com o uso de múltiplos sensores também é possível reduzir essas zonas de auto-oclusão além de ampliar a superfície coberta.

Para ter uma estimativa qualitativa do ganho obtido com a adição do segundo sensor, preliminarmente foi realizado um experimento utilizando apenas um sensor na técnica de $3 D$ Video Capture (KREYLOS, 2011). O resultado pode ser visto na figura 6.1.

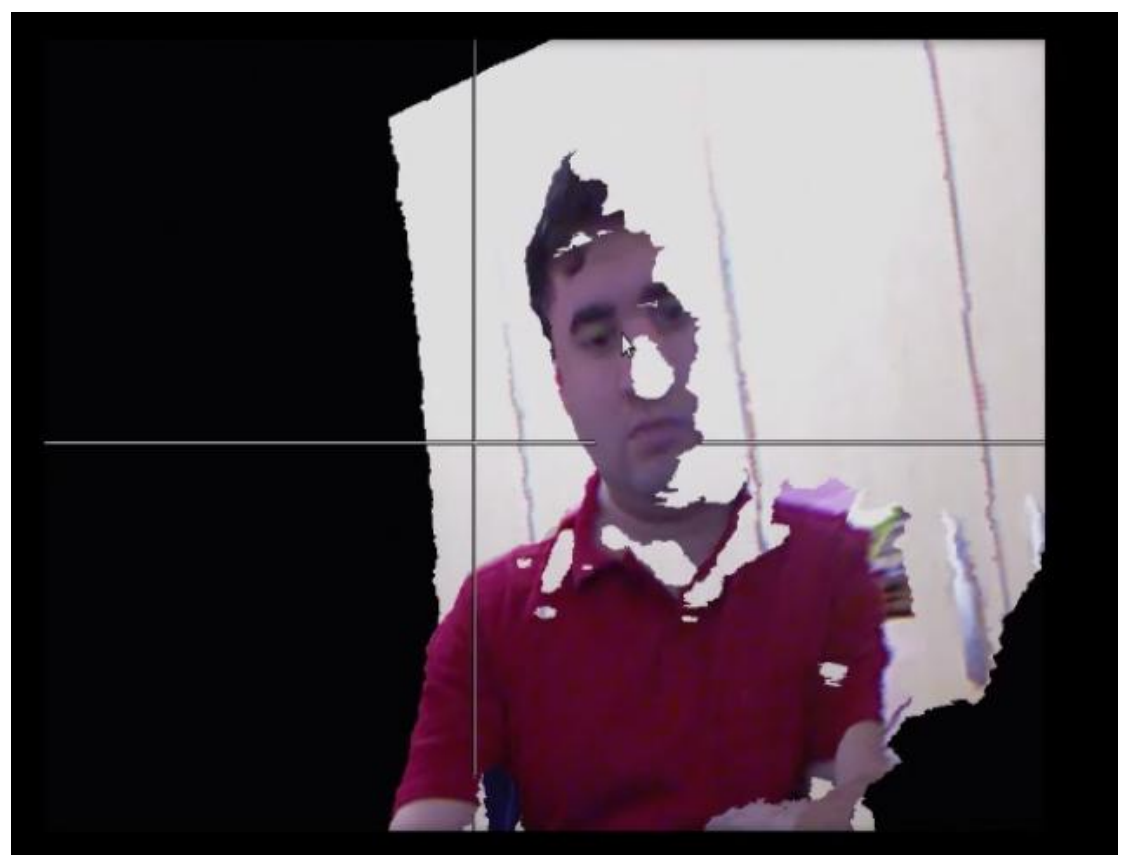

Figura 6.1: Imagem capturada utilizando o sistema de 3D Vídeo de (KREYLOS, 2011).

Pode-se notar diversas zonas de sombra na face frontal do modelo, o que compromete significativamente a qualidade da percepção do usuário final que assiste a videoconferência 
imersiva.

\subsection{Metodologia}

Nesta seção são apresentados os cenários elaborados para averiguar a viabilidade da proposta arquitetural do VMD. Na próxima seção serão apresentados os resultados obtidos através do protótipo utilizado.

Foram considerados dois grupos de parâmetros nos experimentos com os dois sensores:

- O primeiro grupo está relacionado à posição dos sensores, compreendendo a distância entre eles e o alvo, e a posição angular de cada sensor em relação a seu centro na direção do eixo $y$;

- O segundo grupo se refere aos parâmetros de calibração do ICP, este algoritmo pode ser parametrizável de acordo com os parâmetros: número máximo de iterações; máxima distância de correspondência (soma das distâncias euclidianas) e valor da distância de decremento por iteração.

Os dois sensores foram posicionados a distância de 40,60, 80, 100, 120, 140 e $160 \mathrm{~cm}$ entre eles e a uma distância de $150 \mathrm{~cm}$ do centro do objeto alvo, além disso, em dois pontos de vista diferentes, primeiramente de forma paralela e depois convergente conforme ilustrado nas figuras 6.2 e 6.3. Em cada posição foi capturado um quadro com a nuvem de pontos de cada sensor. 


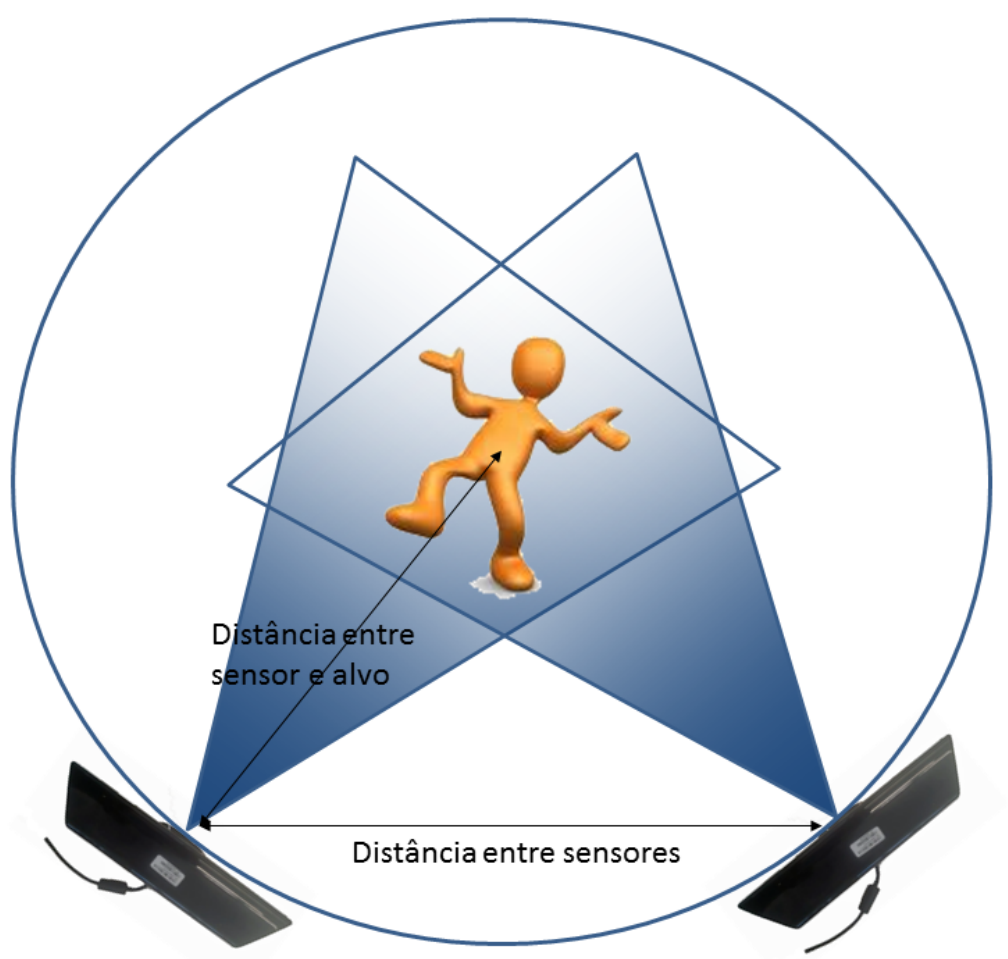

Figura 6.2: Sensores posicionados com pontos de vista convergentes.

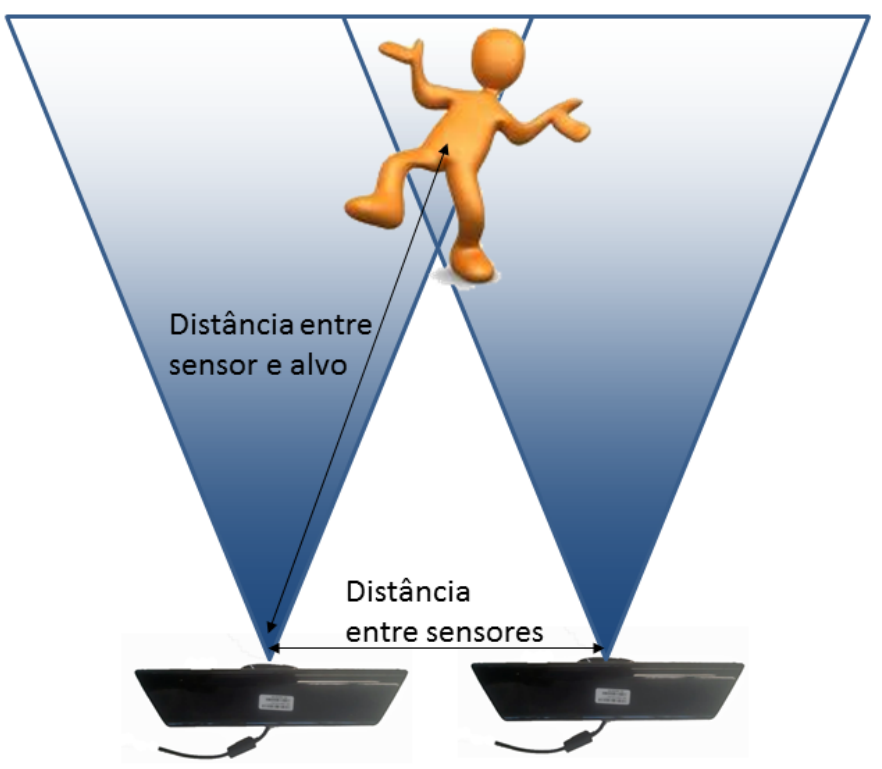

Figura 6.3: Sensores posicionados com pontos de vista paralelos.

Outro detalhe importante é a forma geométrica do alvo, para que a técnica ICP gere um registro mais preciso é importante que existam cantos ou arestas sobressalentes no modelo. Nos testes realizados neste experimento foi utilizado uma cadeira, pois a mesma atende a essas 
necessidades.

\subsection{Resultados}

O subsistema de registro baseado na técnica de ICP recebe como entrada duas nuvens de pontos e tem como saída a matriz de transformação que rotaciona e translada a segunda nuvem no intuito de registrá-la com a primeira. Na figura 6.4 é exibida uma imagem exemplo capturada em um dos cenários do experimento em questão demonstrando as duas nuvens de entrada e a nuvem fundida como saída do processo de registro.

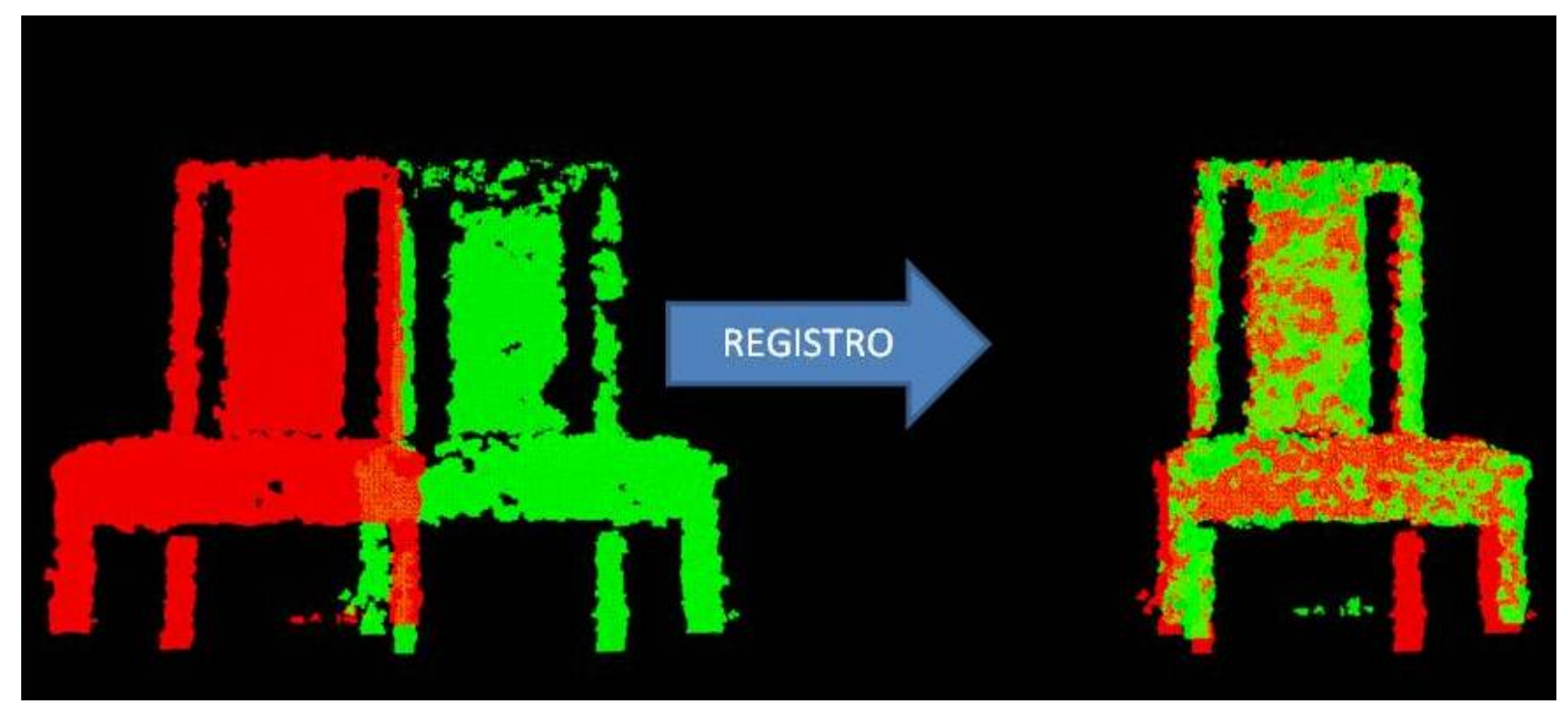

Figura 6.4: A nuvem de cor verde foi capturada pelo primeiro sensor e a de cor vermelha pelo segundo. À esquerda são exibidas as duas nuvens desalinhadas antes do registro e à direita, as duas mesmas nuvens após o devido registro da segunda.

Inicialmente nesse experimento, não foram aplicados filtros a essas nuvens de pontos. Dessa forma, esses mapas de profundidade possuíam pontos de toda a cena incluindo os entornos como paredes e piso além do objeto de interesse (figuras 6.5 e 6.6). 


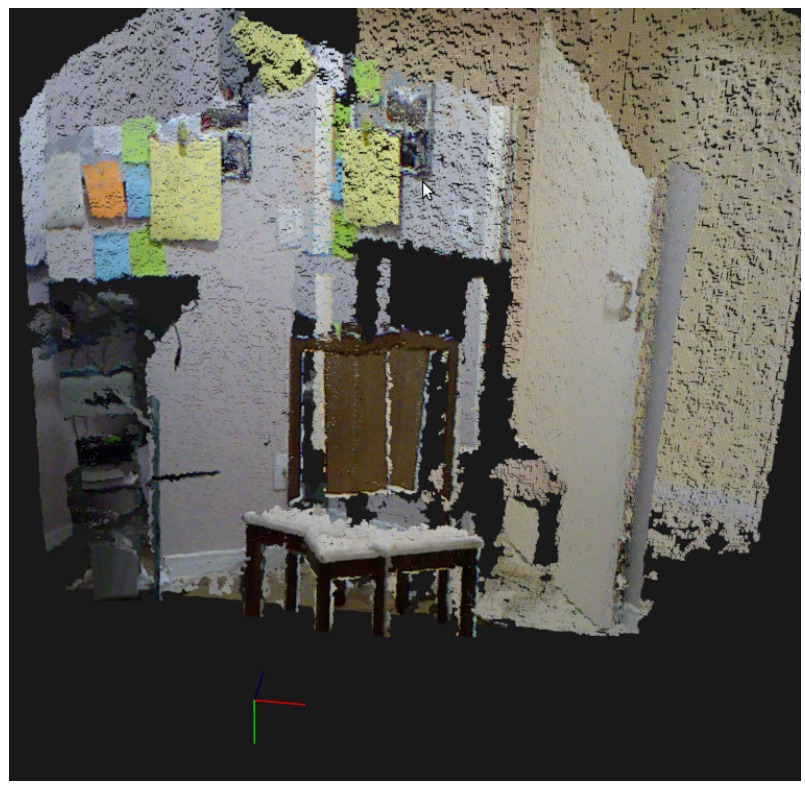

Figura 6.5: Nuvens de pontos com textura RGB completas sem aplicação de filtro.

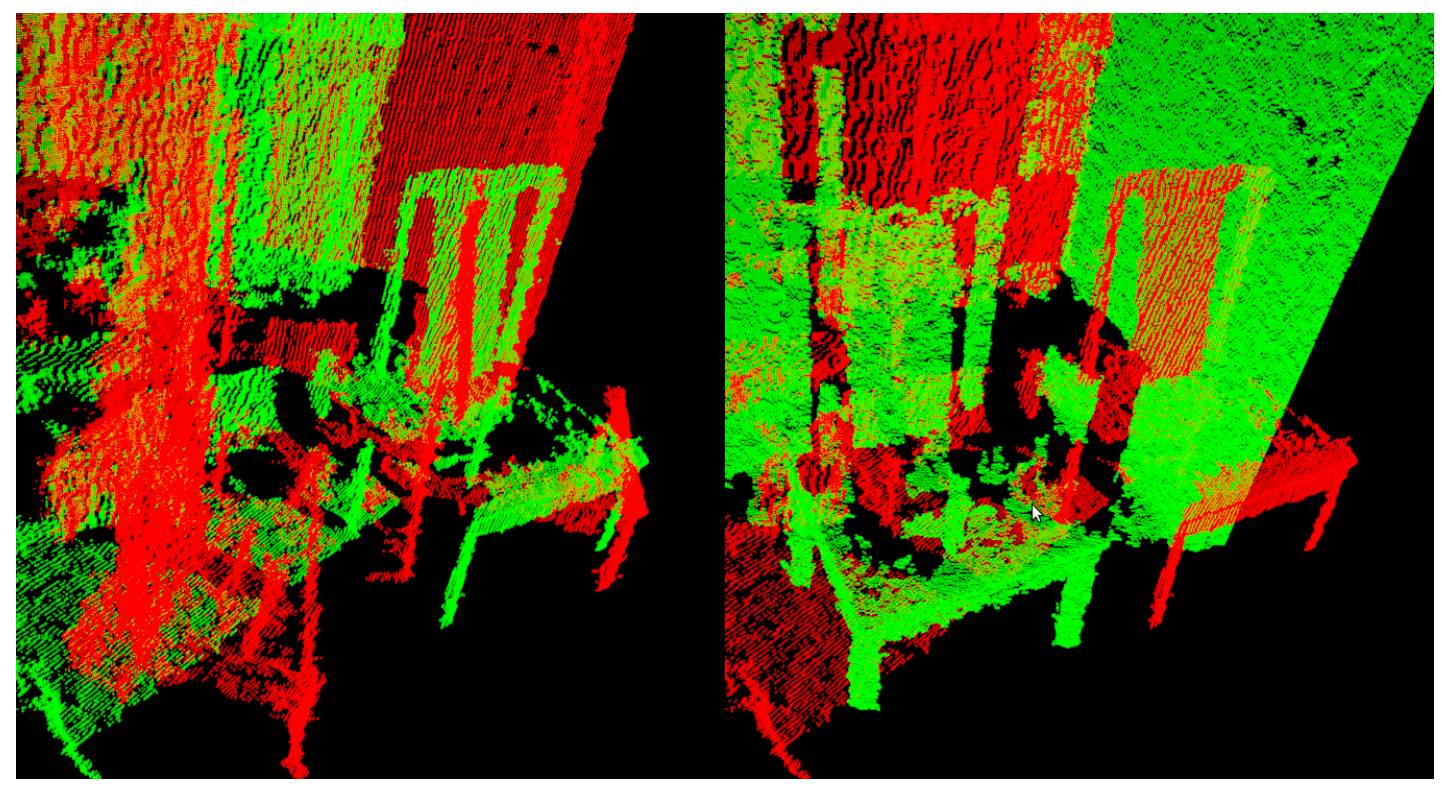

Figura 6.6: Nuvens de pontos completas da cena (sem remoção de fundo), à esquerda antes do registro por ICP e à direita com o registro indevido.

Como se pode averiguar na figura 6.6 na imagem à direita, não houve o alinhamento esperado após aplicar a matriz de rotação e translação computada pelo ICP e os conjuntos de pontos referente a cadeira na duas nuvens ficaram desalinhados. Esses pontos deveriam se sobrepor na imagem à direita. Os Kinects estavam posicionados a $60 \mathrm{~cm}$ nessa figura, mas além dessa distância entre os dois sensores, houve tentativas a 80 e $100 \mathrm{~cm}$ com pontos de 
vista convergentes e paralelos, todas sem sucesso.

Ao aplicar o filtro de distância para remoção do fundo nas mesmas condições dos cenários acima, o registro passou a funcionar corretamente. Foi definido o filtro que remove os pontos fora do intervalo de distância entre 1 e 2 metros do sensor em relação ao eixo y e z.

Os experimentos descritos na seção 6.1 foram executados com a finalidade de capturar as nuvens de pontos em cada posição. Na tabela 6.1 são exibidas as nuvens de pontos capturadas antes e depois do registro com ICP nas posições supra citadas.

Na tabela 6.1, em cada imagem, a cena à esquerda se refere às duas nuvens desalinhadas antes de aplicar o ICP e, à direta, a cena com as duas nuvens após o registro. As imagens (a) e (b) referem-se às nuvens capturadas com os sensores posicionados a uma distância de $40 \mathrm{~cm}$ entre eles, (c) e (d) de 60cm, (e) e (f) de $80 \mathrm{~cm},(\mathrm{~g})$ e (h) de $100 \mathrm{~cm},(\mathrm{i})$ e (j) de $120 \mathrm{~cm},(\mathrm{j})$ e $(\mathrm{k})$ de $140 \mathrm{~cm}$, e por último $(\mathrm{m})$ e $(\mathrm{n})$ de $160 \mathrm{~cm}$.

Para cada posição a após execução do registro baseado em ICP foram observados os valores do erro médio quadrático (EMQ), do número de iterações executadas até alcançar a convergência e do valor da distância máxima entre pontos correspondentes encontrado para alcançar a convergência. Na tabela 6.2 são apresentados os dados numéricos obtidos por meio do registro com ICP realizado nas nuvens de pontos referentes as imagens apresentadas na tabela 6.1 . 
Tabela 6.1: Nas imagens à esquerda os dois sensores paralelos e à direita, convergentes.

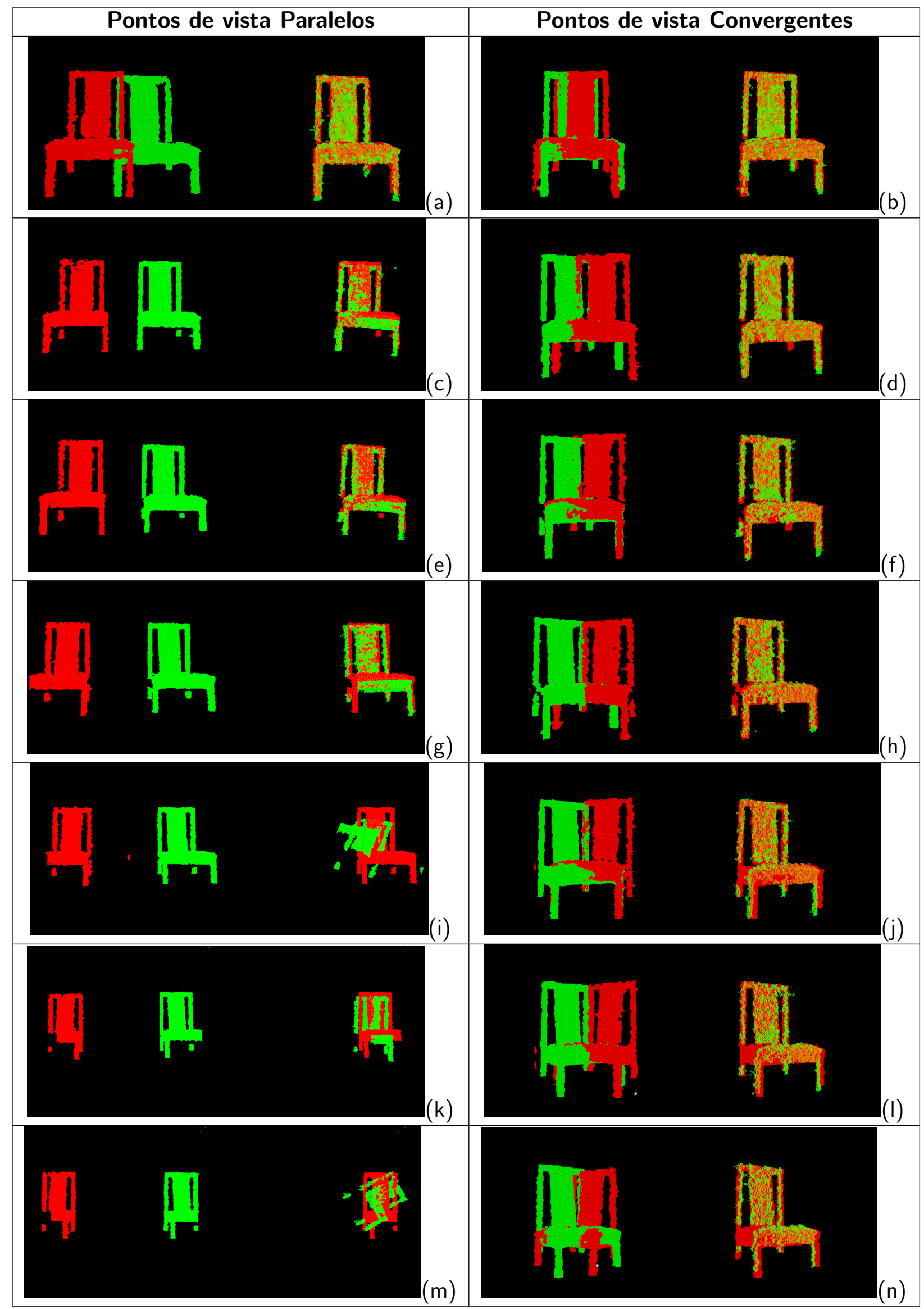


Tabela 6.2: Análise do registro das duas nuvens.

\begin{tabular}{|c|c|c|c|c|c|c|}
\hline & \multicolumn{2}{|c|}{ SENSORES CONVERGENTES } & \multicolumn{3}{c|}{ SENSORES PARALELOS } \\
\hline Distância & EMQ & Iterações & Máx. Distância & EMQ & Iterações & Máx. Distância \\
\hline $40 \mathrm{~cm}\left(15^{\circ}\right)$ & 0,000047 & 47 & 0,1 & 0,000045 & 71 & 0,1 \\
\hline $60 \mathrm{~cm}\left(23^{\circ}\right)$ & 0,000041 & 69 & 0,1 & 0,000307 & 52 & 0,3 \\
\hline $80 \mathrm{~cm}\left(31^{\circ}\right)$ & 0,000054 & 61 & 0,1 & 0,000775 & 57 & 0,4 \\
\hline $100 \mathrm{~cm}\left(39^{\circ}\right)$ & 0,000092 & 68 & 0,1 & 0,000664 & 41 & 0,6 \\
\hline $120 \mathrm{~cm}\left(47^{\circ}\right)$ & 0,000185 & 47 & 0,1 & 0,001159 & 24 & 0,9 \\
\hline $140 \mathrm{~cm}\left(56^{\circ}\right)$ & 0,000250 & 61 & 0,1 & 0,002233 & 33 & 0,9 \\
\hline $160 \mathrm{~cm}\left(64^{\circ}\right)$ & 0,000990 & 65 & 0,3 & 0,002444 & 95 & 1,1 \\
\hline
\end{tabular}

Em todos os cenários desse experimento o algoritmo convergiu no número de iterações descristas na tabela 6.2 e a condição de parada foi o alcance do valor mínimo da diferença entre transformações de iterações consecutivas. No gráfico da figura $6.7 \mathrm{com}$ os valores do erro médio quadrático (EMQ), que é a métrica utilizada nessa técnica para medir a precisão do alinhamento entre as duas nuvens.

\section{Erro Médio Quadrático}

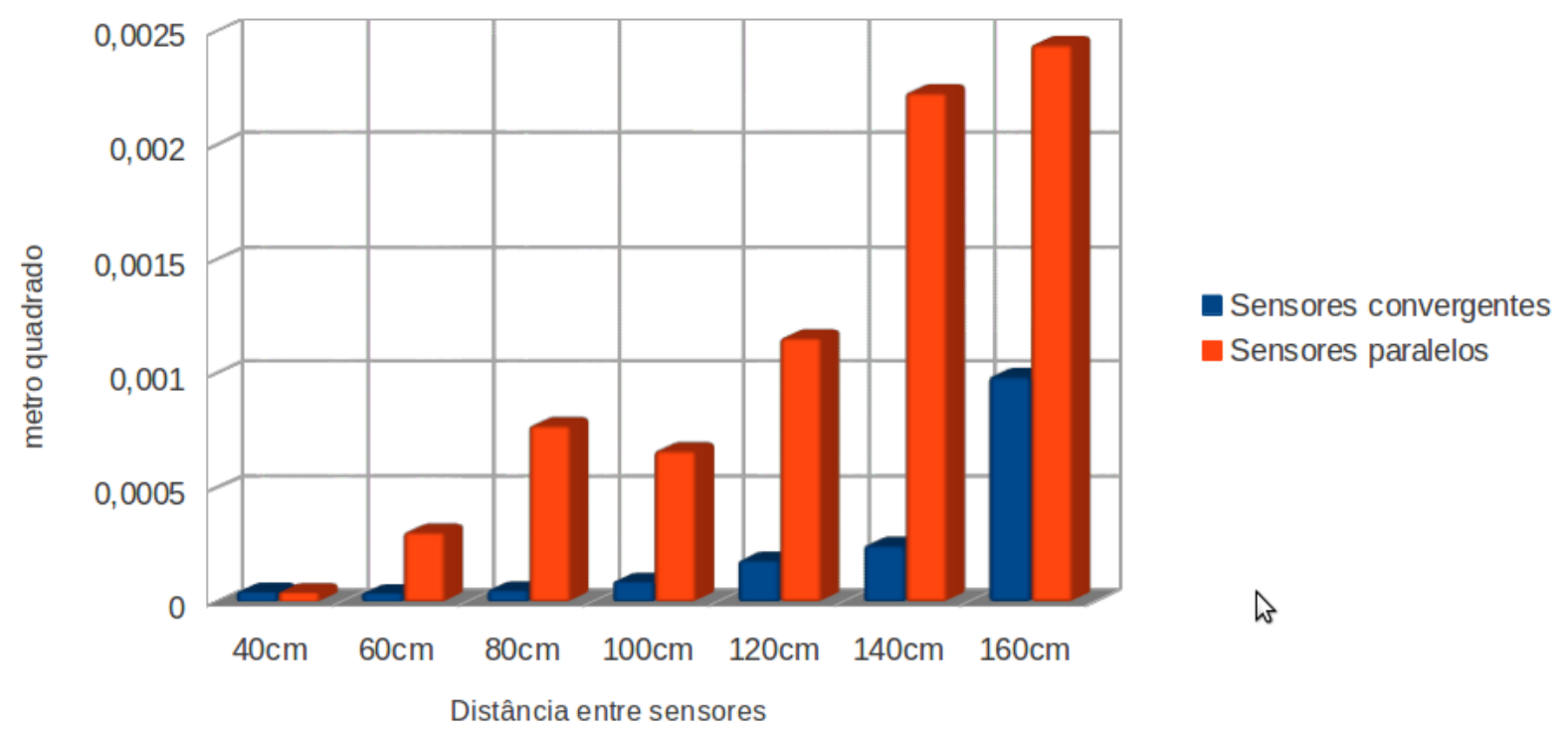

Figura 6.7: Gráfico com erro médio quadrático relacionado a execução do ICP para cada cenário que indica o nível de precisão do alinhamento entre nuvens.

\subsection{Análise dos Resultados}

Como se pode notar nas figuras da tabela 6.1 , em todos os cenários onde os dois sensores foram posicionados com pontos de vista convergentes houve o alinhamento esperado após o 
critério de convergência ser alcançado com EMQ menor que 0,001. Realizando uma análise das imagens (b), (d), (f), (h), (j), (I) e (n) não se nota desalinhamentos perceptíveis a olho nu. A maior distância atingida foi de $160 \mathrm{~cm}$ entre os dois sensores, ambos a $150 \mathrm{~cm}$ do alvo, o que representa um ângulo de $64^{\circ}$.

No entanto, nas imagens (g), (i), (k) e (m) com pontos de vista paralelos com distância entre sensores maior do que $100 \mathrm{~cm}$, apesar do algoritmo convergir, o EMQ foi maior que 0,001 e analisando qualitativamente, nota-se que não ocorreu o alinhamento adequado.

Comparando os valores do EMQ entre os pontos de vista paralelos e convergentes, em geral, observa-se que o registro das nuvens de pontos obtidas através dos pontos de vista convergentes possui um alinhamento significavelmente mais preciso do que na configuração com os sensores em paralelo, com valor pico da diferença na distância entre sensores de $80 \mathrm{~cm}$ conforme figuras 6.8 e 6.9 , onde o erro médio quadrático da posição convergente é quatorze vezes inferior a posição paralela.

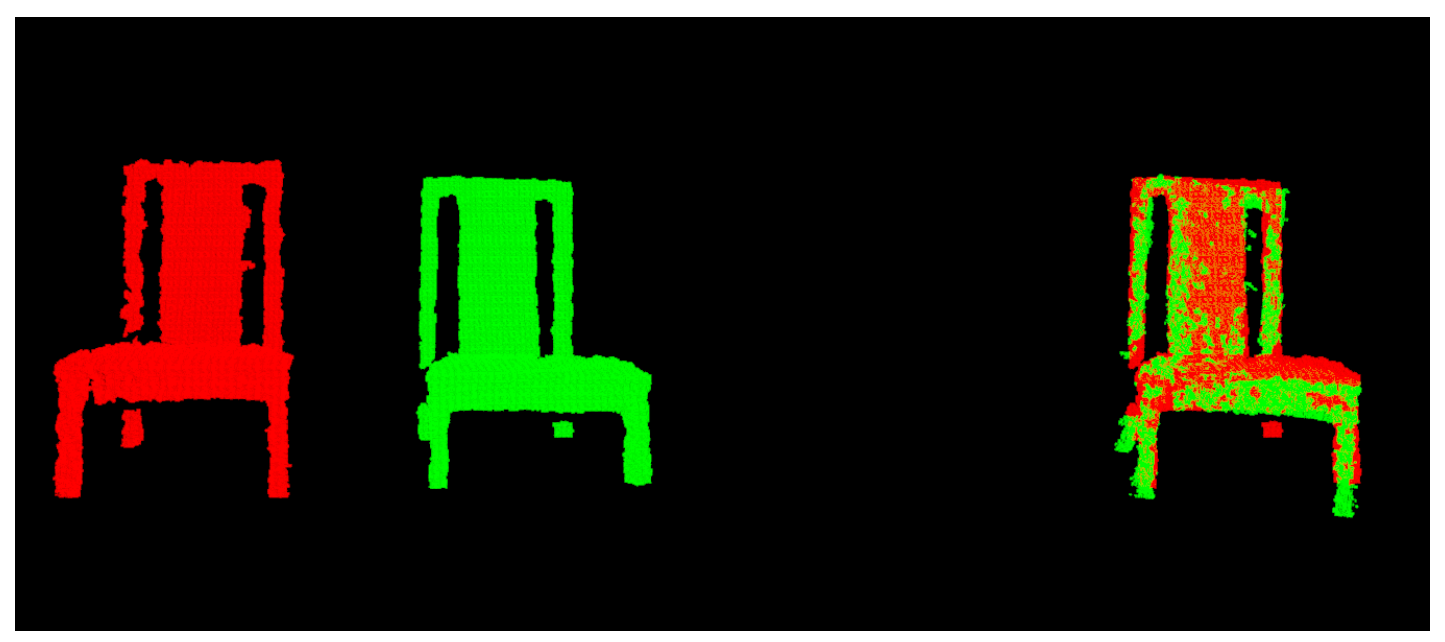

Figura 6.8: Nuvens obtidas pelos dois sensores na posição paralela a uma distancia de $80 \mathrm{~cm}$. 


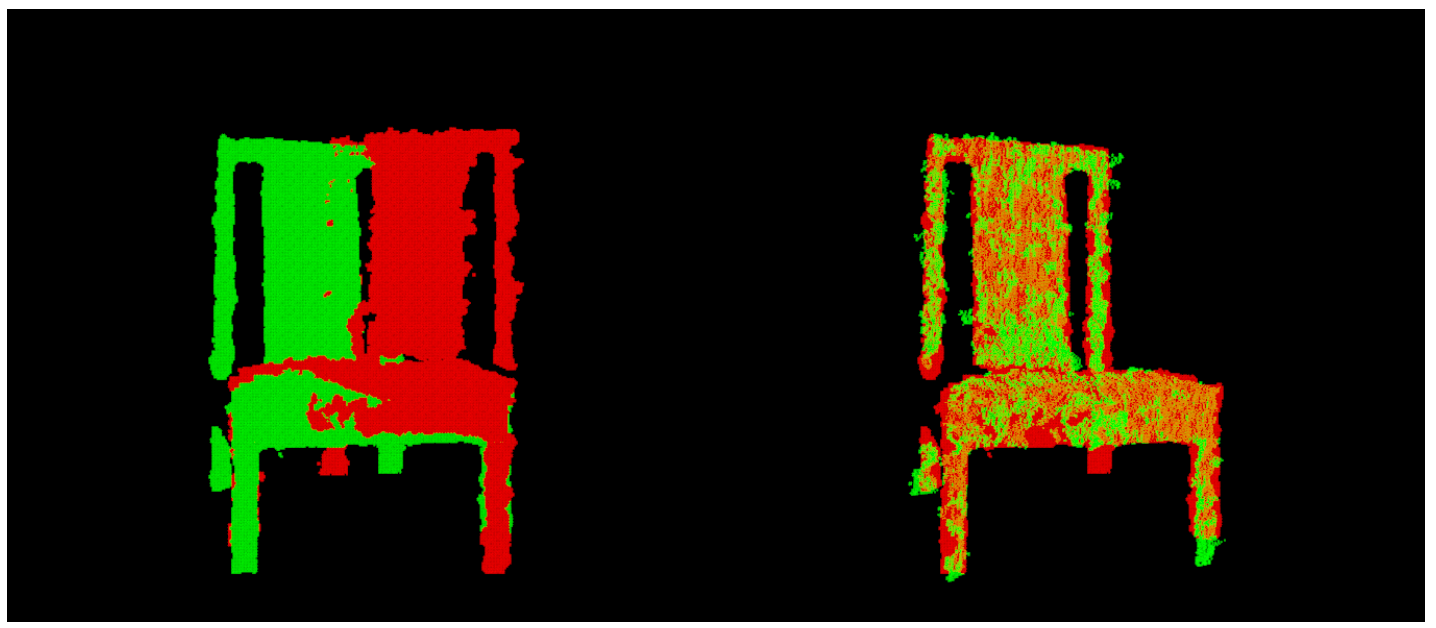

Figura 6.9: Nuvens obtidas pelos dois sensores na posição convergente a uma distância de $80 \mathrm{~cm}$.

Analisando as imagens 6.8 e 6.9 no detalhe é possível notar que na posição paralela dos sensores (figura 6.8) há um pequeno desalinhamento que deixa a perna direita da cadeira da nuvem verde em uma posição mais baixa em relação à nuvem vermelha. No entanto, na figura 6.9 com os dois sensores em posição convergente, o alinhamento é mais preciso e o mesmo desalinhamento encontrado na posição paralela não é notado. 


\section{EXPERIMENTO COM SENSOR ÚNICO E BASE ROTATIVA}

Somente com os dados e a análise apresentados no experimento do capítulo 6 não é possível de se estimar qual é a menor quantidade de sensores necessária para gerar um modelo 3D completo do usuário. O objetivo do experimento deste capítulo é realizar uma estimativa qualitativa a fim de se obter essa resposta.

\subsection{Metodologia}

Para realização do experimento foi utilizado um setup semelhante ao apresentado em (LIN; SUBBARAO, 2001). A figura 7.1 demonstra a posição do sensor e do alvo que foram colocados a uma distância de $1,20 \mathrm{~m}$.

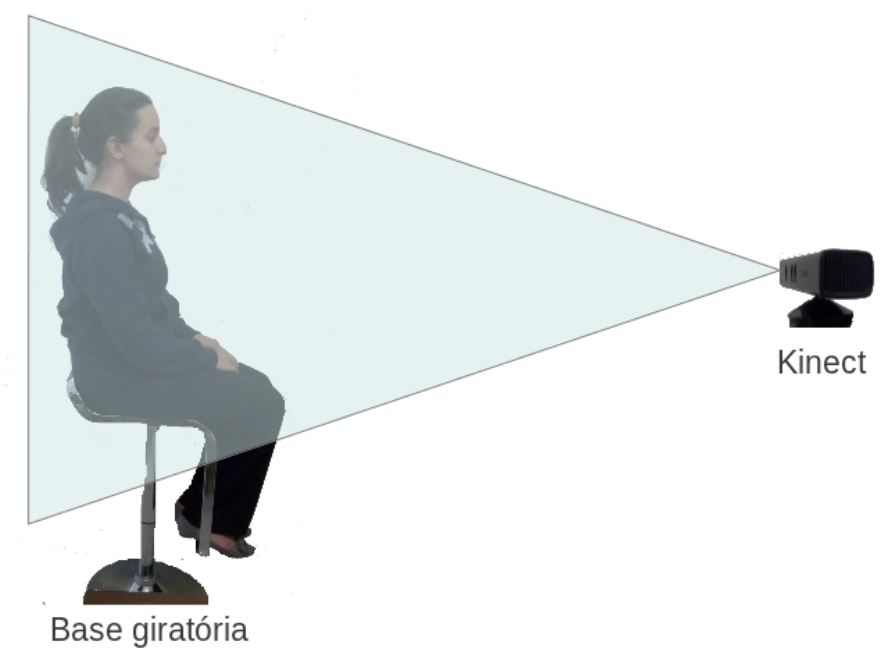

Figura 7.1: Setup experimento com base rotativa.

Foi desenvolvida um aplicação que gera dez nuvens de pontos por segundo e armazena em arquivo com extensão ply. O banco foi rotacionado lentamente enquanto o sensor capturava 


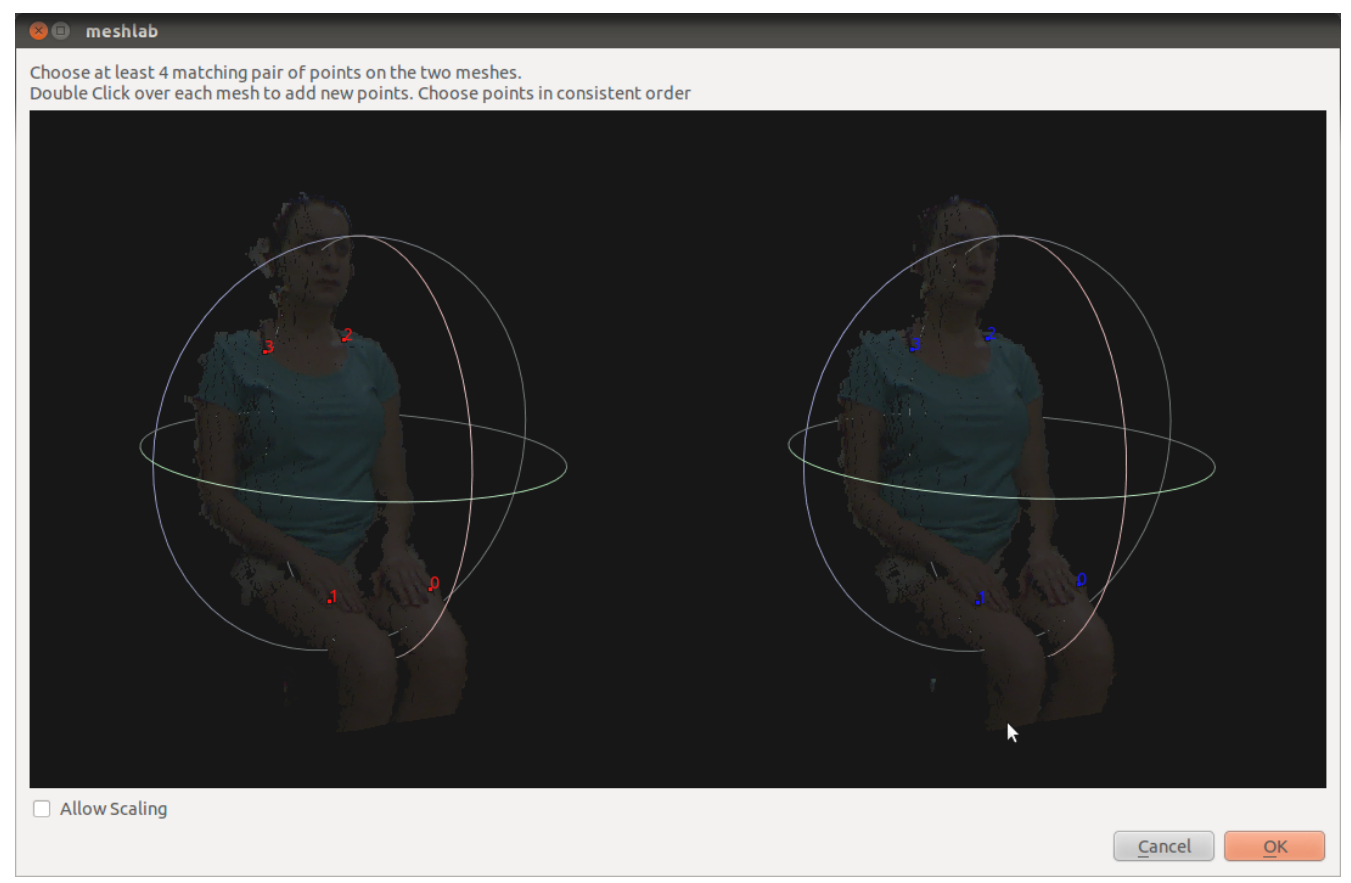

Figura 7.2: Point Based Glueing.

as nuvens de pontos em cada posição angular.

Após os arquivos serem gerados, os mesmos foram carregados no Meshlab (MeshLab, 2012) e o processo de alinhamento foi realizado nessa ferramenta.

Para realização do registro de par de nuvens foi utilizada a ferramenta de alinhamento point based g/ueing que consiste em marcar manualmente pelo menos quatro pontos correspondentes nas duas nuvens de pontos (figura 7.2). Através desses pontos correspondentes é encontrada a função de transformação que alinha o par de nuvens. Os centros de massas das duas nuvens são utilizados para encontrar a matriz de translação e o vetor quaternário para determinar a matriz de rotação. O ICP também utiliza esses dois métodos em seu algoritmo para determinar a matriz de roto-translação iterativamente (seção 2.1.3).

Nesse experimento, após todos modelos estarem alinhados manualmente através da identificação de quatro pontos correspondentes, é executado o algoritmo de ICP sobre todos os possíveis pares de nuvens com o propósito de refinar o alinhamento manual e gerar um relatório do erro médio (distância média entre pontos correspondentes). 


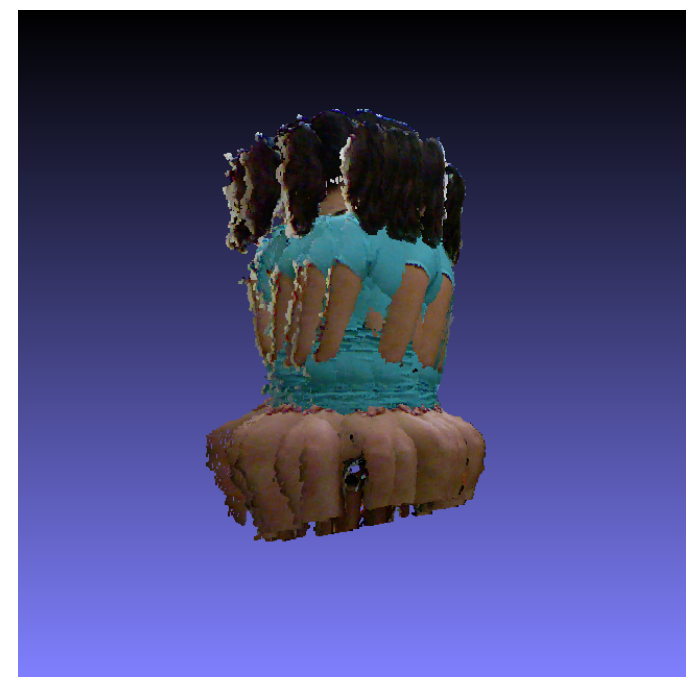

Figura 7.3: Visualização das dezessete nuvens de pontos desalinhadas capturadas no experimento.

\subsection{Resultados}

Os modelos apresentados nesta seção são compostos por um subconjunto das nuvens de pontos obtidas nas diferentes posições angulares (figura 7.3) após o devido registro. A tabela 7.1 apresenta as posições angulares das dezessete nuvens capturadas com intervalo de $22,5^{\circ}$, totalizando $360^{\circ}$. Além disso, foi realizado o alinhamento com ICP entre cada nuvem $x_{i}$ e as três nuvens subsequentes $\left(x_{i+1}, x_{i+2}\right.$ e $\left.x_{i+3}\right)$, obtendo o erro médio correspondente para cada par.

Nas figuras 7.4, 7.5, 7.6 e 7.7 são exibidos os modelos gerados por duas, três, quatro e cinco nuvens respectivamente. Dessa forma, é possível identificar qualitativamente o ganho ocasionado ao se adicionar mais nuvens ao modelo. 


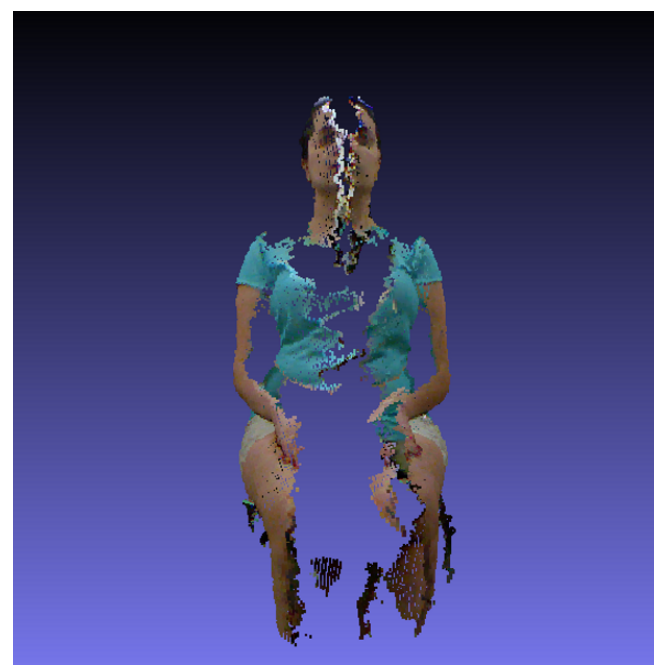

(a)
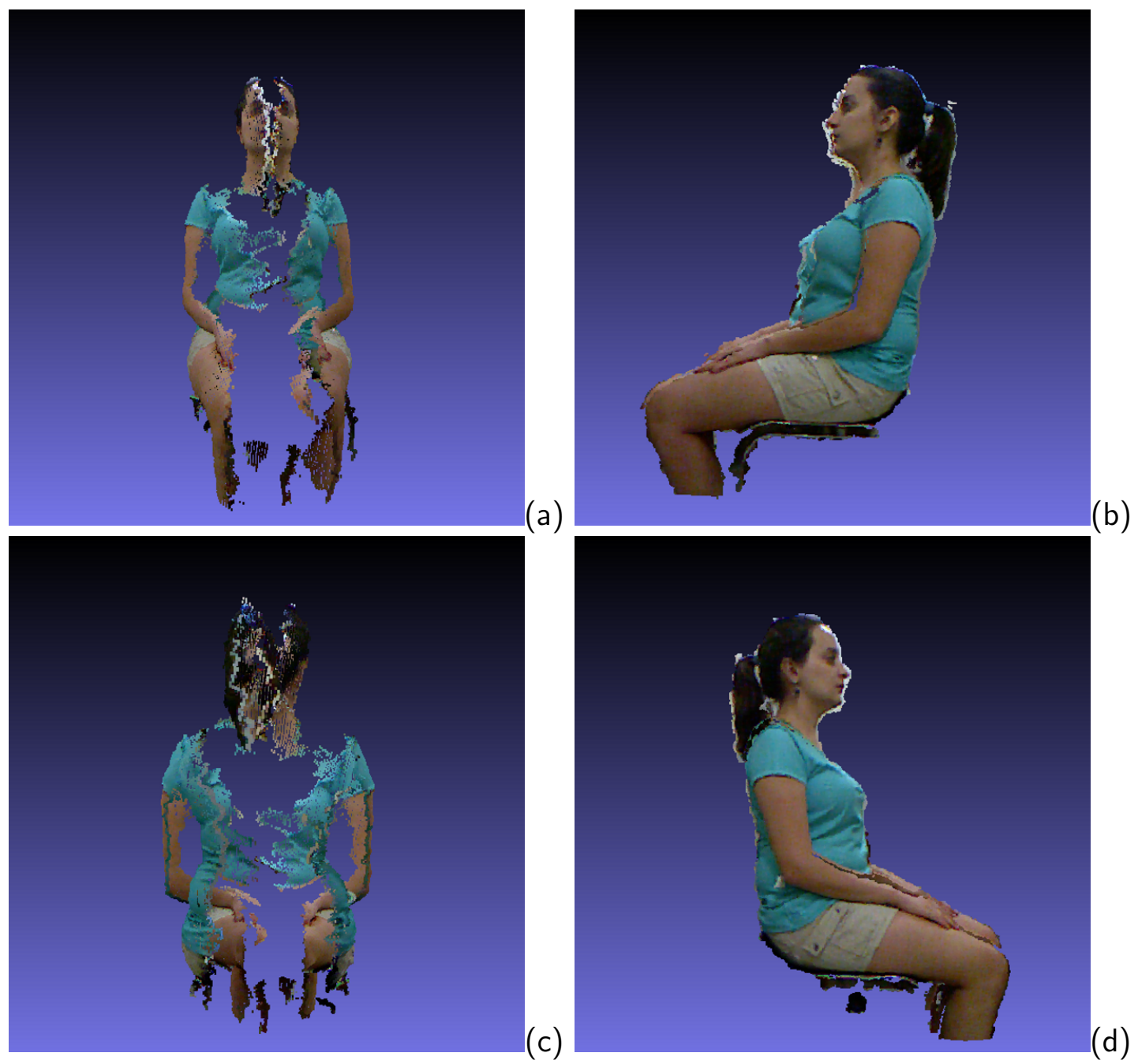

Figura 7.4: Modelo composto por 2 nuvens.

Nas imagens (a) e (c) da figura 7.4 é possível notar uma área não reconstruída na região frontal e dorsal do modelo. Nas imagens laterais (b) e (d) não são constatadas zonas de sombra. 


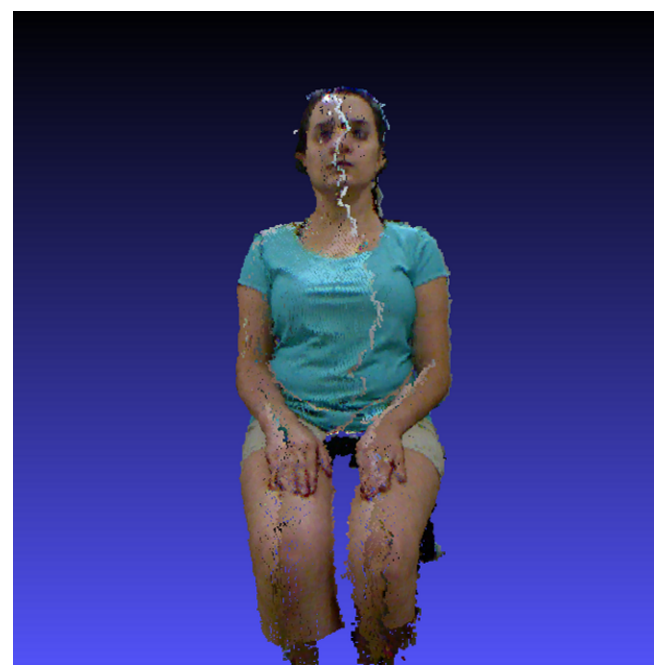

(a)
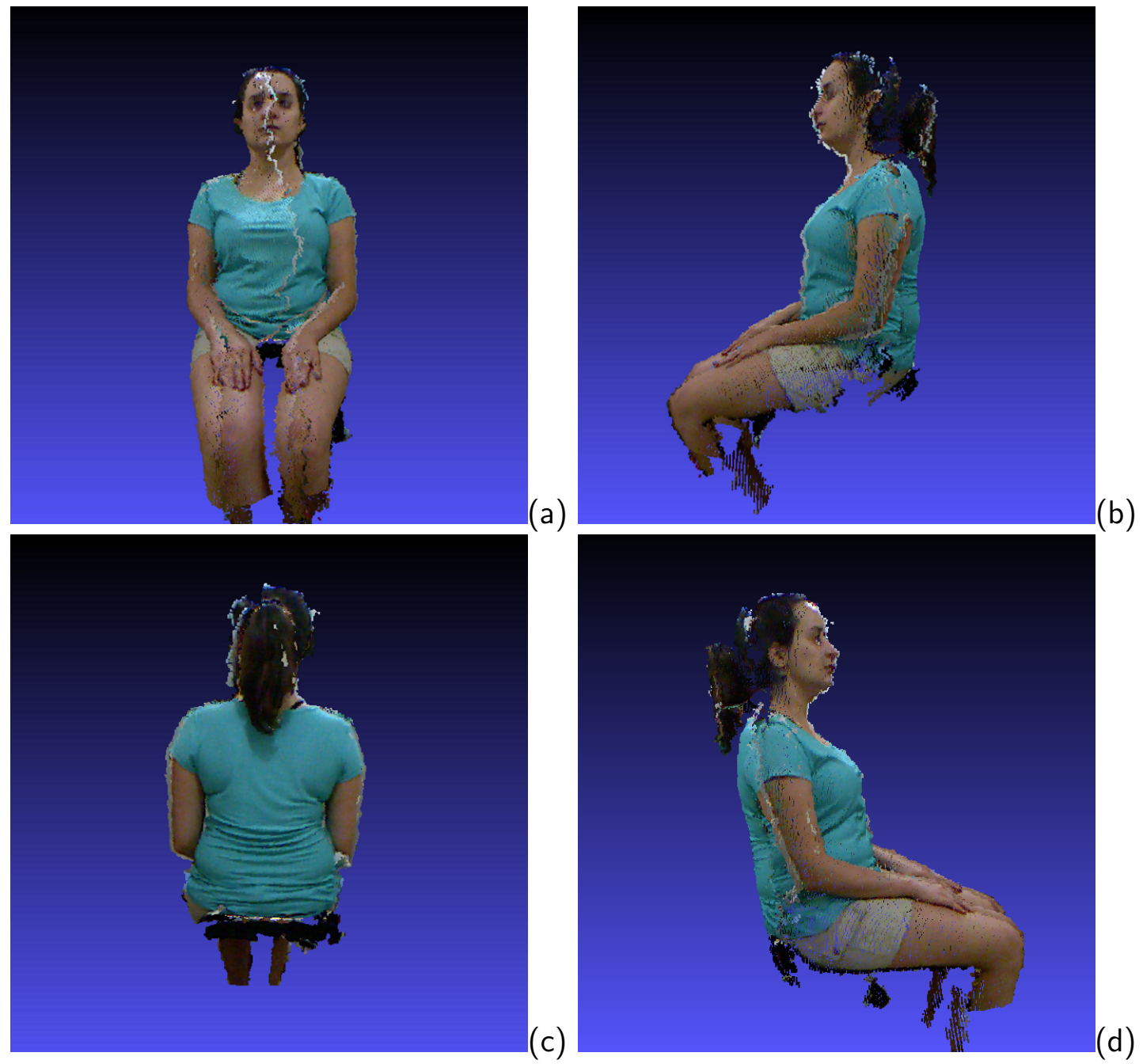

Figura 7.5: Modelo composto por 3 nuvens.

Na imagem (a) da figura 7.5 é possível notar uma zona de oclusão próxima a área referente as pernas. Nas imagens laterais (b) e (d) são constatadas zonas de sombra na região referente ao cabelo (parte anterior da cabeça). 


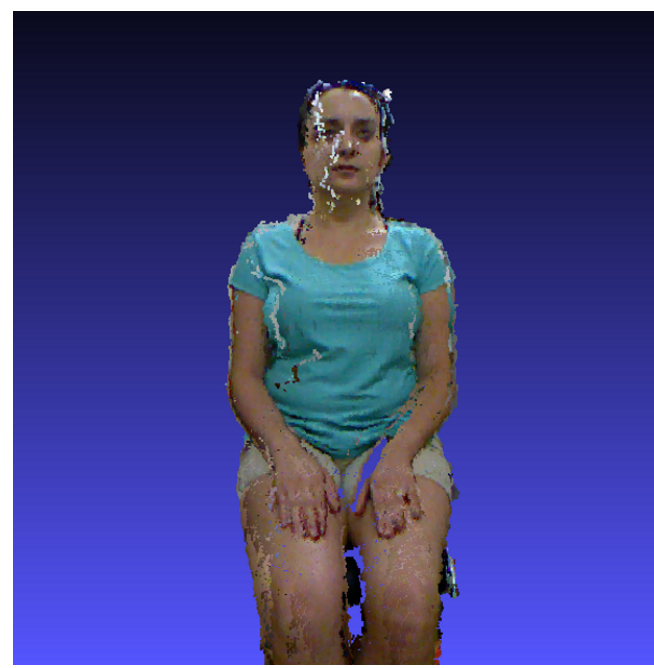

(a)
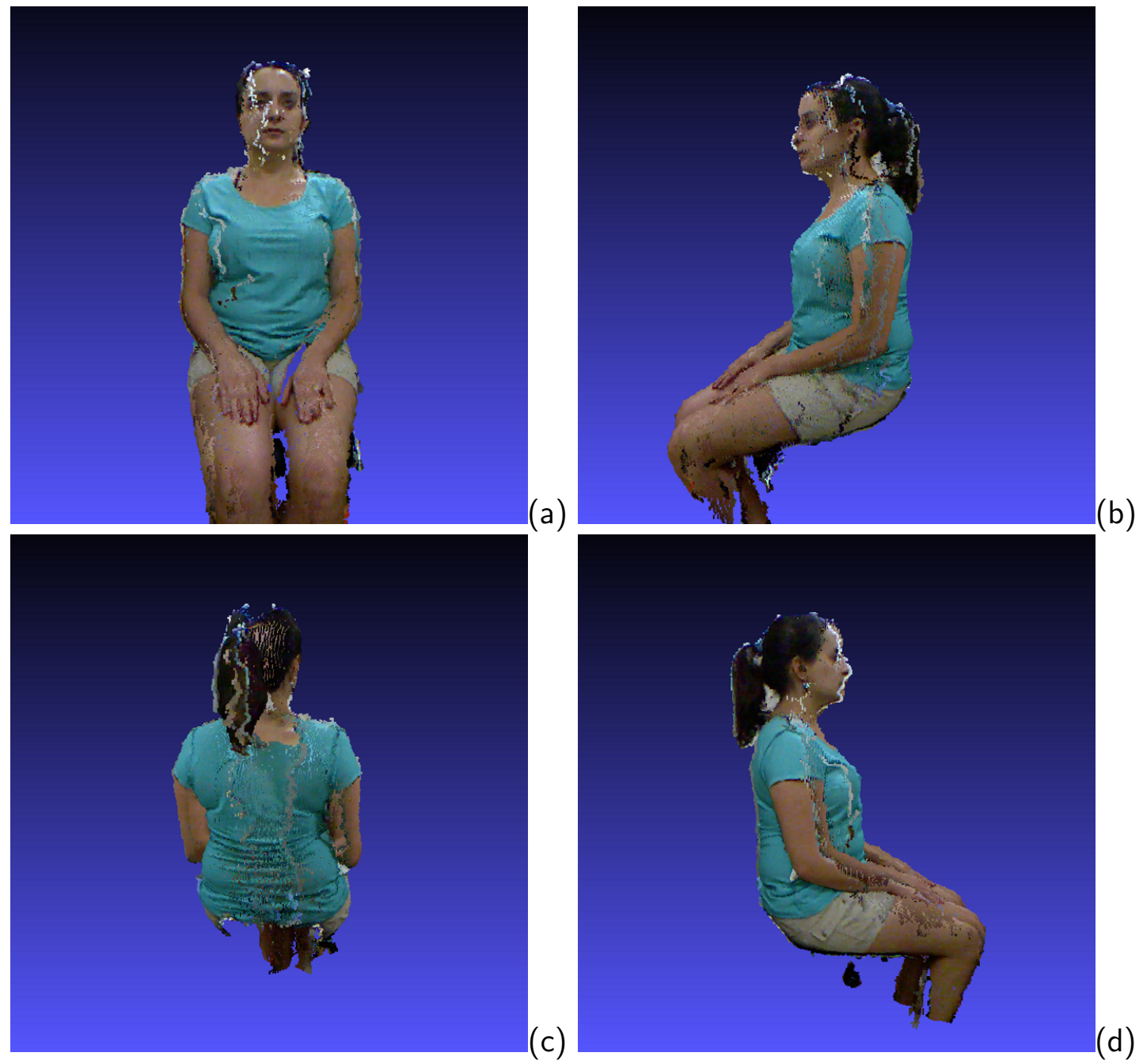

Figura 7.6: Modelo composto por 4 nuvens.

Na imagem (a) da figura 7.6 é possível notar que a zona de oclusão próxima à área referente às pernas e a mão direita diminuiu consideravelmente ao se adicionar a quarta nuvem de pontos. Nas imagens (b) e (d) não são mais constatadas zonas de sombra na região referente ao cabelo. 


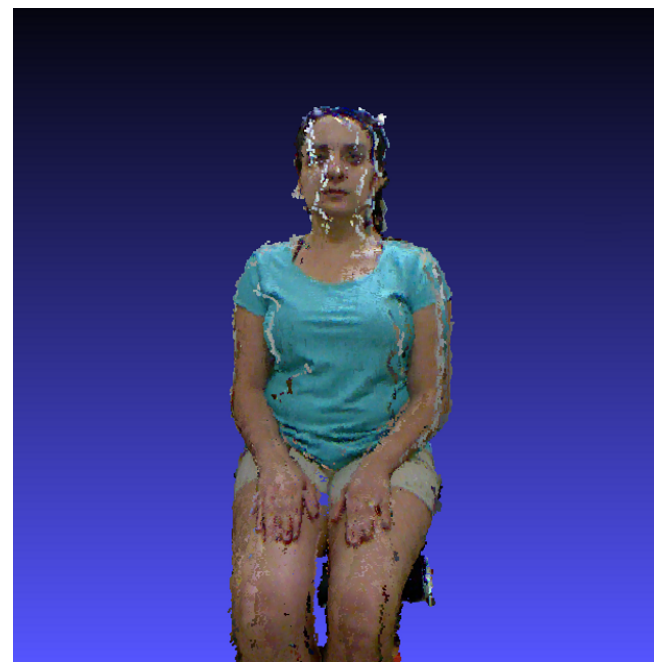

(a)
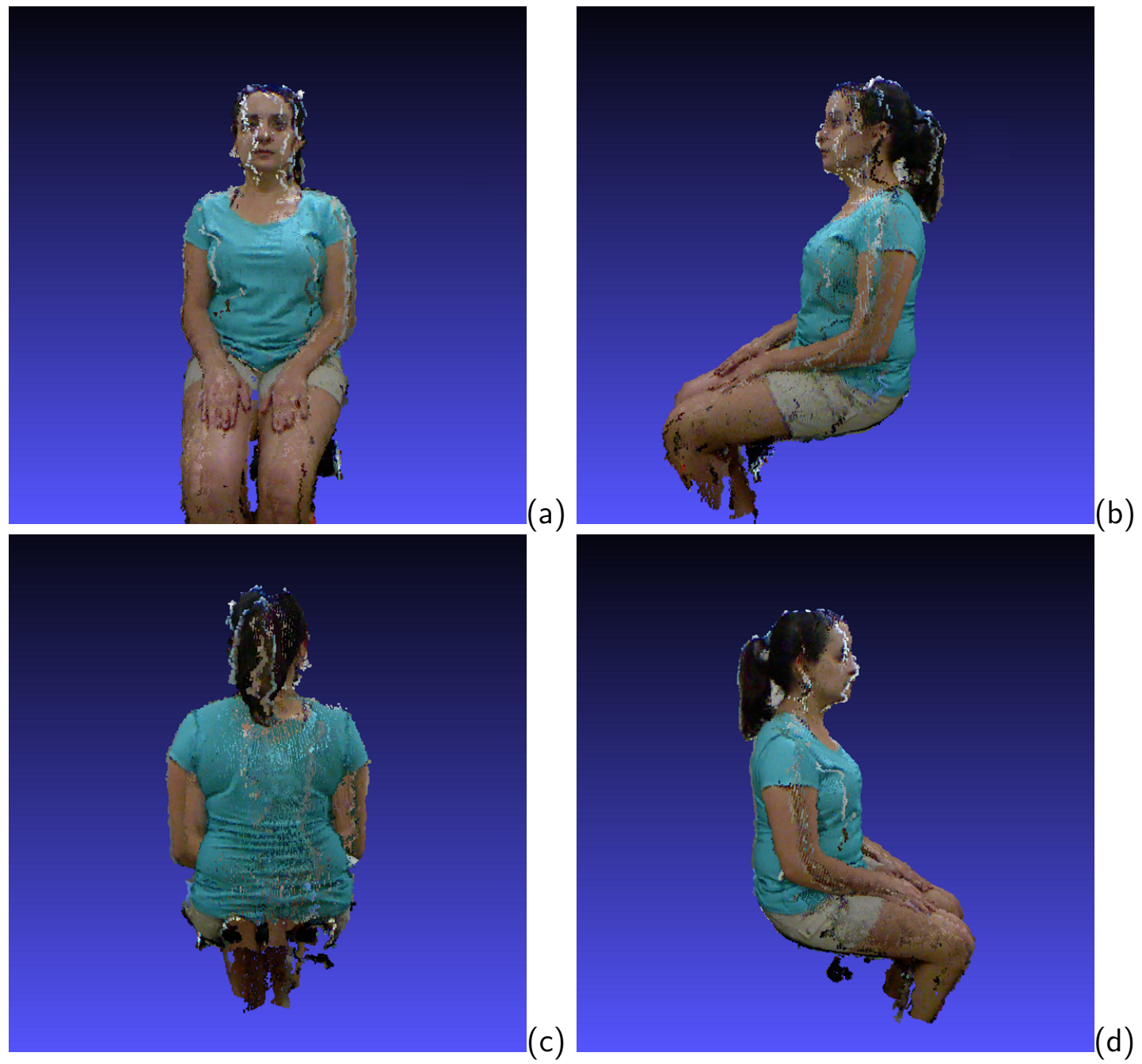

Figura 7.7: Modelo composto por 5 nuvens.

Por último, na figura 7.7 a zona de oclusão encontrada na região das pernas e mãos reduziu significativamente na imagem (a) em relação ao modelo composto por quatro nuvens.

Na figura 7.8 é notado um orifício na região do modelo referente ao topo da cabeça, que ocorre devido à posição do sensor em relação ao usuário. Mesmo com dezessete nuvens essa zona de sombra permanece. 


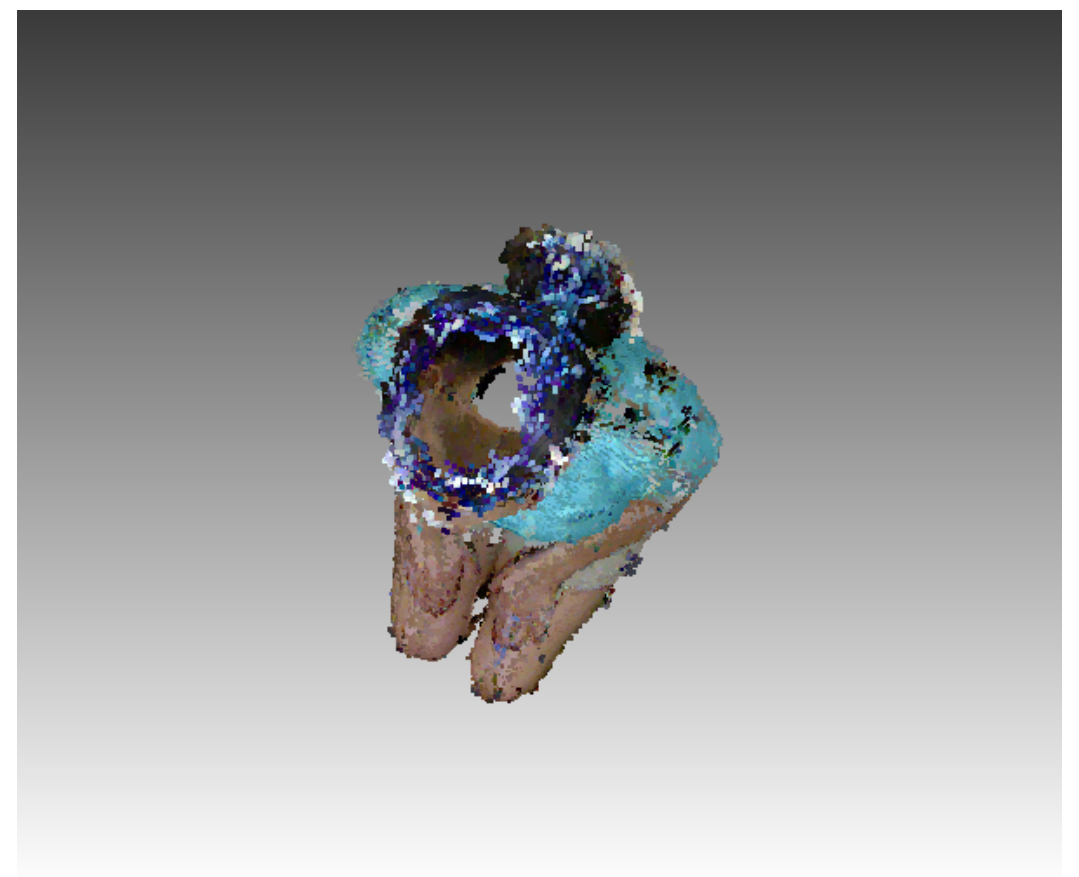

Figura 7.8: Ponto de vista superior do modelo com 17 nuvens.

\subsection{Análise dos Resultados}

No modelo composto por duas nuvens (figura 7.4) a zona de sombra na região frontal e dorsal é notável. Por outro lado, na figura 7.5 o modelo foi gerado unindo três nuvens, a maioria da superfície do usuário foi reconstruída e pequenas áreas de oclusão são notadas na região das pernas e cabelo.

Ao adicionar mais uma nuvem (modelo da figura 7.6 ) as zonas de sombras reduzem consideravelmente e enfim, o modelo composto por cinco nuvens (modelo da figura 7.7) praticamente não possui pontos de oclusão. No entanto, ao analisar a figura 7.8 observa-se uma zona de sombra na região referente ao topo da cabeça. Tendo em vista que neste trabalho a aplicação dessa técnica é em um sistema de teleconferência imersiva, esse ponto de vista superior pode ser evitado sem grandes prejuízos aos usuários. Ou ainda, uma nova nuvem poderia ser capturada por um sensor colocado no teto do estúdio. 
Tabela 7.1: Erro médio em metros entre a nuvem capturada na posição angular $x$ e as três nuvens subsequentes capturadas nas posições $x+22,5^{\circ}, x+45^{\circ}$ e $x+67,5^{\circ}$. Nas células vazias não foi alcançado o número mínimo de correspondências para ocorrer o alinhamento.

\begin{tabular}{cccc}
\hline \hline Nuvem A & Erro entre A e & Erro entre A e & Erro entre A e \\
$($ posição $x)$ & $B_{\left(x+22,5^{\circ}\right)}$ & $C_{\left(x+45^{\circ}\right)}$ & $D_{\left(x+67,5^{\circ}\right)}$ \\
\hline $0^{\circ}$ & 0,00288 & & \\
$22,5^{\circ}$ & 0,00243 & 0,00266 & \\
$45^{\circ}$ & 0,00193 & 0,00313 & \\
$67,5^{\circ}$ & 0,00283 & & \\
$90^{\circ}$ & 0,00335 & & \\
$112,5^{\circ}$ & 0,00274 & 0,00299 & \\
$135^{\circ}$ & 0,00232 & 0,00278 & \\
$157,5^{\circ}$ & 0,00219 & 0,00434 & \\
$180^{\circ}$ & 0,00303 & & \\
$202,5^{\circ}$ & 0,00262 & & \\
$225^{\circ}$ & 0,00281 & 0,00334 & \\
$247,5^{\circ}$ & 0,00219 & 0,00301 & \\
$270^{\circ}$ & 0,00243 & & \\
$292,5^{\circ}$ & 0,00368 & & \\
$315^{\circ}$ & 0,00252 & 0,00306 & \\
$337,5^{\circ}$ & 0,00223 & 0,00327 & \\
$360^{\circ}$ & 0,00288 & & \\
& & & \\
\hline
\end{tabular}

A tabela 7.1 demonstra como se comportou o algoritmo de ICP para o refinamento do registro realizado após a aplicação do método manual de alinhamento de nuvens point based glueing. Ao comparar os dados dessa tabela com os resultados apresentados no experimento anterior (capítulo 6) é possível de se constatar que a precisão do ICP depende principalmente da distância entre a nuvem de entrada e a nuvem global, e da forma do modelo alvo. Quando foi utilizada a cadeira vazia (capítulo 6) atingiu-se um alinhamento satisfatório em ângulos de $64^{\circ}$, em contrapartida, com o alvo humano ocorreu alinhamento entre nuvens separadas por $45^{\circ}$ em média. 


\section{CONCLUSÕES}

A pesquisa realizada neste trabalho comparou as principais técnicas de reconstrução geométrica aplicadas em teleconferência imersiva e encontrou limitações a serem superadas. Dando continuidade à pesquisa desenvolvida no Interlab (técnicas 3.1 e 3.2) sobre vídeo-avatar, foi constatado o interesse em se ampliar a superfície reconstruída do avatar que anteriormente era gerada por uma técnica de mapeamento de profundidade através de visão estéreo. Outro desafio identificado foi a redução da complexidade na etapa de calibração das câmeras.

Esses dois pontos motivaram a elaboração do VMD (capítulo 4). Essa proposta consiste em uma arquitetura de sistema de aquisição e visualização da superfície externa do ser humano alvo. Em vista disso, a captura de dados é realizada por múltiplos sensores de profundidade e a união das nuvens de pontos, obtidas por cada sensor, é realizada de forma automática por meio do algoritmo de ICP. Quando comparado o setup do VMD com as demais técnicas que geram o modelo 3D, observa-se o ganho na agilidade de montagem dos equipamentos graças à técnica de luz estruturada utilizada e ao algoritmo de registro automático.

Os experimentos apresentados nas seções 5, 6 e 7 demonstraram a viabilidade da proposta de VMD e os limites de sua aplicação. A principal vantagem dessa solução em relação ao AVMix é a ampliação da superfície do avatar realístico que na proposta anterior era reduzida. Além disso, a proposta deste trabalho suporta a introdução de novos sensores ao setup ampliando a superfície coberta até que se alcance o modelo 3D completo. Isso é possível graças às características do ICP que tem como entradas uma nuvem desalinhada e uma nuvem global, essa última pode ser composta por diversas nuvens pré-alinhadas.

Quando comparado com o sistema 3D Video Capture, o VMD tem a vantagem de não necessitar de um processo de calibração manual através de marcadores de calibração (como por exemplo, tabuleiro de xadrez). Em relação ao Kinect RGB Demo, o VMD é mais simples pois dispensa o alinhamento manual prévio devido ao uso de filtro de remoção de fundo fazendo com que o alinhamento realizado pelo ICP funcione para nuvens desalinhadas por ângulos de até $64^{\circ}$ conforme visto no experimento 6 . 
No experimento de medição de ruído (capítulo 5) foi constatado que ao utilizar um segundo sensor Kinect simultaneamente com o primeiro, são gerados ruídos no mapa de profundidade gerado pelo primeiro sensor. No entanto, esse valor de ruído medido foi inferior a 3,6\%. Esses ruídos tendem a reduzir ao registrar um conjunto de nuvens de pontos graças às áreas de sobreposição das nuvens vizinhas.

No segundo experimento (sobre registro de pares de nuvens) o comportamento do algoritmo ICP foi estudado de acordo com a distância e posição de dois sensores. Através de análise numérica e qualitativa pôde se concluir que a configuração onde os dois sensores são posicionados com pontos de vista convergentes gerou um registro com melhor alinhamento quando comparado com a posição paralela. Além disso, na configuração convergente o alinhamento foi alcançado em todas as distâncias com valor máximo de $160 \mathrm{~cm}$ o que representa um ângulo de $64^{\circ}$ entre sensores.

Tendo em vista a análise dos resultados do último experimento com a base rotatória é possível de se estimar a quantidade mínima de sensores para gerar um modelo 3D completo do usuário.

Considerando os resultados dos experimentos do capítulo 6 e 7 pode se constatar que o fator limitante no módulo de registro da arquitetura VMD é a área mínima de intersecção (entre as duas nuvens em processo de registro) necessária para que o ICP realize o registro corretamente. Tomando como base a configuração com distância máxima no experimento de análise do ICP, onde os dois sensores foram posicionados a um ângulo máximo $\alpha$ de $64^{\circ}$, seria necessário $\frac{360^{\circ}}{\alpha}$ sensores para reconstruir o modelo $3 \mathrm{D}$, resultando em um setup com seis sensores.

\subsection{Trabalhos Futuros}

Durante a execução dos experimentos foram identificadas as possibilidades de trabalhos futuros abaixo relacionados a esse trabalho:

- Avaliação de desempenho e da qualidade da visualização utilizando os algoritmos de reconstrução de superfície baseados em malhas poligonais abordados na seção 2.1.4, com intuito de gerar um modelo de maior qualidade;

- Pesquisa e desenvolvimento de algoritmos de correção de espaço de cor para corrigir as diferenças entre as texturas geradas pela câmera RGB de cada sensor conforme discutido em 4.1.5; 
- Pesquisa e desenvolvimento de modelos de processamento distribuído para processar a informação gerada por múltiplos sensores tendo em vista a aplicação dessa técnica em videoconferência imersiva que requer processamento em tempo real. 


\section{REFERÊNCIAS BIBLIOGRÁFICAS}

BAKER, H. H.; BHATTI, N.; TANGUAY, D.; SOBEL, I.; GELB, D.; GOSS, M. E.; CULBERTSON, W. B.; MALZBENDER, T. Understanding performance in coliseum, an immersive videoconferencing system. ACM Trans. Multimedia Comput. Commun. Appl., v. 1, n. 2, p. 190-210, maio 2005. ISSN 1551-6857.

BERNARDINI, F.; MITTLEMAN, J.; RUSHMEIER, H.; SILVA, C.; TAUBIN, G. The ball-pivoting algorithm for surface reconstruction. Visualization and Computer Graphics, IEEE Transactions on, v. 5, n. 4, p. $349-359$, oct-dec 1999. ISSN 1077-2626.

BESL, P.; McKay, N. A method for registration of 3-D shapes. IEEE Transactions on pattern analysis and machine intelligence, v. 14, n. 2, p. 239-256, 1992.

BURRUS, N. Nicolas Burrus Homepage - Kinect RGBDemo v0.6.1. 2011. http://nicolas.burrus.name/index.php/Research/KinectRgbDemoV6. Acessado em: 20 de novembro de 2011.

FOLLMER, S.; JOHNSON, M.; ADELSON, E.; ISHII, H. deform: an interactive malleable surface for capturing 2.5d arbitrary objects, tools and touch. Proceedings of the 24th annual ACM symposium on User interface software and technology. New York, NY, USA: ACM, 2011. (UIST '11), p. 527-536. ISBN 978-1-4503-0716-1. Disponível em: $<$ http://doi.acm.org/10.1145/2047196.2047265>.

GONZALEZ, R.; WOODS, R. Processamento de imagens digitais. [S.I.]: Editora Edgard BI cher, 2000.

GROSS, M.; WüRMLIN, S.; NAEF, M.; LAMBORAY, E.; SPAGNO, C.; KUNZ, A.; Koller-Meier, E.; SVOBODA, T.; GOOL, L. V.; LANG, S.; STREHLKE, K.; MOERE, A. V.; STAADT, O. blue-c: a spatially immersive display and 3D video portal for telepresence. ACM SIGGRAPH 2003 Papers. New York, NY, USA: ACM, 2003. (SIGGRAPH '03), p. 819-827. ISBN 1-58113-709-5. Disponível em: <http://doi.acm.org/10.1145/1201775.882350>.

HORN, B. K. P. Closed-form solution of absolute orientation using unit quaternions. JOSA $A$, v. 4, n. 4, p. 629-642, 1987. Disponível em: $<$ http://www.opticsinfobase.org/abstract.cfm?\&id=2711>.

INSLEY, J.; SANDIN, D.; DEFANTI, T. Using video to create avatars in virtual reality. Visual Proceedings of the 1997 SIGGRAPH Conference, Los Angeles, CA, pp. 128. Los Angeles, CA, USA: [s.n.], 1997. (SIGGRAPH Conference '97), p. 128. Disponível em: $<$ http://www.evl.uic.edu/core.php? $\bmod =4 \&$ type $=3 \&$ indi $=94>$.

IZADI, S.; KIM, D.; HILLIGES, O.; MOLYNEAUX, D.; NEWCOMBE, R.; KOHLI, P.; SHOTTON, J.; HODGES, S.; FREEMAN, D.; DAVISON, A.; FITZGIBBON, A. KinectFusion: real-time 3D reconstruction and interaction using a moving depth camera. Proceedings of the 24th annual ACM symposium on User interface software and technology. New 
York, NY, USA: ACM, 2011. (UIST '11), p. 559-568. ISBN 978-1-4503-0716-1. Disponível em: <http://doi.acm.org/10.1145/2047196.2047270>.

JANG, I. Y.; LEE, K. Depth video based human model reconstruction resolving self-occlusion. IEEE Transactions on Consumer Electronics, v. 56, n. 3, p. 1933 -1941, ago. 2010. ISSN 0098-3063.

KAZHDAN, M.; BOLITHO, M.; HOPPE, H. Poisson surface reconstruction. Proceedings of the fourth Eurographics symposium on Geometry processing. Aire-la-Ville, Switzerland, Switzerland: Eurographics Association, 2006. (SGP '06), p. 61-70. ISBN 3-905673-36-3. Disponível em: <http://dl.acm.org/citation.cfm?id=1281957.1281965>.

KIRNER, T. G.; KIRNER, C.; KAWAMOTO, A. L. S.; CANTãO, J.; PINTO, A.; WAZLAWICK, R. S. Development of a collaborative virtual environment for educational applications. Proceedings of the sixth international conference on 3D Web technology. New York, NY, USA: ACM, 2001. (Web3D '01), p. 61-68. ISBN 1-58113-339-1. Disponível em: <http://doi.acm.org/10.1145/363361.363378>.

KREYLOS, O. Oliver Kreylos' Research and Development Homepage - Kinect Hacking. 2011. http://idav.ucdavis.edu/ okreylos/ResDev/Kinect/index.html. Acessado em: 15 de maio de 2011.

LEE, S.; KIM, I.; AHN, S. C.; LIM, M.; KIM, H. Toward immersive telecommunication: 3D video avatar with physical interaction. ACM Press, 2005. p. 56. ISBN 0473106574. Disponível em: <http://dl.acm.org/citation.cfm?id $=1152411 \& b n c=1>$.

LEMESZENSKI, D.; NAKAMURA, R. Multiple 3d data acquisition system setup based on structured ligth technique for immersive videoconferencing applications. Anais do WRVA'2011 8 Workshop de Realiade Virtual e Aumentada, nov. 2011. ISSN 1982-1657. Disponível em: $<$ http://www.iftm.edu.br/wrva2011/cd/index.html>.

LIN, H.; SUBBARAO, M. A vision system for fast 3D model reconstruction. Proceedings of the 2001 IEEE Computer Society Conference on Computer Vision and Pattern Recognition, 2001. CVPR 2001. [S.I.]: IEEE, 2001. v. 2, p. II-663- II-668 vol.2. ISBN 0-7695-1272-0.

LIU, Y. Automatic 3d free form shape matching using the graduated assignment algorithm. Pattern recognition, v. 38, n. 10, p. 1615-1631, 2005.

LORENSEN, W. E.; CLINE, H. E. Marching cubes: A high resolution 3d surface construction algorithm. SIGGRAPH Comput. Graph., ACM, New York, NY, USA, v. 21, n. 4, p. 163-169, ago. 1987. ISSN 0097-8930. Disponível em: <http://doi.acm.org/10.1145/37402.37422>.

MeshLab. 2012. Http://meshlab.sourceforge.net/. Disponível em: $<$ http://meshlab.sourceforge.net/>.

MICROSOFT. Kinect for Windows SDK Documentation - Microsoft Research. 2011.

Acessado em: 01 de novembro de 2011. Disponível em: <http://research.microsoft.com/enus/um/redmond/projects/kinectsdk/guides.aspx $>$.

MöLLER, T.; HAINES, E.; HOFFMAN, N. Real-time rendering. [S.I.]: AK Peters Limited, 2008. 446 p. ISBN 987-1-56881-424-7. 
NAEF, M.; STAADT, O.; GROSS, M. blue-c api: a multimedia and 3d video enhanced toolkit for collaborative vr and telepresence. Proceedings of the 2004 ACM SIGGRAPH international conference on Virtual Reality continuum and its applications in industry. New York, NY, USA: ACM, 2004. (VRCAI '04), p. 11-18. ISBN 1-58113-884-9. Disponível em: <http://doi.acm.org/10.1145/1044588.1044590>.

NAKAMURA, R. Vídeo-Avatar com detecção de colisão para realidade aumentada e jogos. Tese (Doutorado) — Universidade de São Paulo, 2008.

OpenCV. 2012. Http://opencv.org/. Online accessed 15-January-2012. Disponível em: $<$ http://opencv.org/>.

PETIT, B.; LESAGE, J. D.; MENIER, C.; ALLARD, J.; FRANCO, J. S.; RAFFIN, B.; BOYER, E.; FAURE, F. Multicamera real-time 3d modeling for telepresence and remote collaboration. International journal of digital multimedia broadcasting, v. 2010, 2009. Disponível em: <http://www.hindawi.com/journals/ijdmb/aip/247108/>.

REINHARD, E.; ADHIKHMIN, M.; GOOCH, B.; SHIRLEY, P. Color transfer between images. Computer Graphics and Applications, IEEE, v. 21, n. 5, p. $34-41$, sep/oct 2001. ISSN 0272-1716.

RUSU, R. B.; COUSINS, S. 3D is here: Point Cloud Library (PCL). IEEE International Conference on Robotics and Automation (ICRA). Shanghai, China: [s.n.], 2011.

SALVI, J.; PAGES, J.; BATLLE, J. Pattern codification strategies in structured light systems. Pattern Recognition, v. 37, n. 4, p. 827-849, 2004.

SCHARSTEIN, D.; SZELISKI, R. A taxonomy and evaluation of dense Two-Frame stereo correspondence algorithms. Int. J. Comput. Vision, v. 47, n. 1-3, p. 7-42, abr. 2002. ISSN 0920-5691. Disponível em: <http://dl.acm.org/citation.cfm?id=598429.598475>.

SISCOUTTO, R. Proposta de Arquitetura para Teleconferência Baseada na Integração de Vídeo-Avatar Estereoscópico em Ambiente Virtual Tridimensional. Tese (Doutorado) Universidade de São Paulo, 2003.

SISCOUTTO, R. A.; TORI, R. AVTC-Augmented virtuality tele-conferencing. Proceedings of VII Symposium on Virtual Reality. [s.n.], 2004. p. 124?136. Disponível em: $<$ http://en.scientificcommons.org/6845176>.

TOKUNAGA, D. M.; SANCHES, S. R. R.; TRIAS, L. P.; JUNIOR, J. L. B.; NAKAMURA, R.; TORI, R. Video-based microfacet-billboard avatar for educational immersive teleconference systems. XI Symposium on Virtual and Augmented Reality.(aceito para publica \ccão). [s.n.], 2009. Disponível em: <http://www.lbd.dcc.ufmg.br:8080/colecoes/svr/2009/0018.pdf >.

TORI, R. Educaçao Sem Distancia. [S.I.]: Senac, 2010. ISBN 9788573599213.

TSAI, R. A versatile camera calibration technique for high-accuracy 3d machine vision metrology using offtheshelf tv cameras and lenses. Robotics and Automation, IEEE Journal of, v. 3, n. 4, p. 323-344, 1987. Disponível em: $<$ http://ieeexplore.ieee.org/xpls/abs_all.jsp?arnumber $=1087109>$. 
WANG, Z.; BOVIK, A. C.; SHEIKH, H. R.; SIMONCELLI, E. P. Image quality assessment: from error visibility to structural similarity. IEEE Transactions on Image Processing, v. 13, n. 4, p. 600-612, abr. 2004. ISSN 1057-7149.

WILL, P.; PENNINGTON, K. Grid coding: A preprocessing technique for robot and machine vision. Artificial Intelligence, v. 2, n. 3-4, p. 319-329, 1971.

YAMAZAKI, S.; SAGAWA, R.; KAWASAKI, H.; IKEUCHI, K.; SAKAUCHI, M. Microfacet billboarding. Proceedings of the 13th Eurographics workshop on Rendering. Aire-laVille, Switzerland, Switzerland: Eurographics Association, 2002. (EGRW '02), p. 169-180. ISBN 1-58113-534-3. Disponível em: <http://dl.acm.org/citation.cfm?id=581896.581919>. 